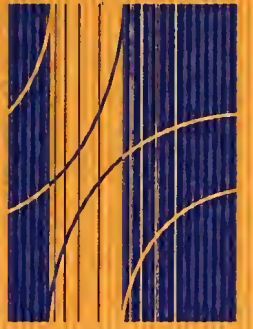

Joint

Transportation

Research

Program

J T R P

FHWA/IN/JTRP-98/4

Final Report

AUTOMATION AND STANDARDIZATION OF MEASURING MOISTURE CONTENT AND DENSITY USING TIME DOMAIN REFLECTOMETRY

W. Feng

C. Lin

V. P. Drnevich

R. J. Deschamps

September 1998

Indiana

Department

of Transportation

Purdue

University 

Final Report

FHWA/IN/JTRP-98/4

\title{
AUTOMATION AND STANDARDIZATION OF MEASURING MOISTURE CONTENT AND DENSITY USING TIME DOMAIN REFLECTOMETRY
}

\author{
W. Feng \\ and \\ C. Lin \\ Research Assistants \\ and \\ V. P. Drnevich \\ and \\ R. J. Deschamps \\ Principal Investigators \\ School of Civil Engineering \\ Purdue University \\ Joint Transportation Research Program \\ Project No: C-36-5S \\ File No: 6-6-19 \\ Prepared in Cooperation with the \\ Indiana Department of Transportation and \\ the U.S. Department of Transportation \\ Federal Highway Administration
}

The contents of this report reflect the views of the authors who are responsible for the facts and the accuracy of the data presented herein. The contents do not necessarily reflect the official views or policies of the Federal Highway Administration and the Indiana Department of Transportation. This report does not constitute a standard, specification or regulation.

Purdue University

West Lafayette, Indiana

September 17, 1998 
Digitized by the Internet Archive in 2011 with funding from

LYRASIS members and Sloan Foundation; Indiana Department of Transportation 


\begin{tabular}{|l|l|}
\hline 1. Report No. & 2. Government Accession No. \\
FHWA/IN/JTRP-98/4 & \\
\hline
\end{tabular}

4. Title and Subtitle

Automation and Standardization of Measuring Moisture Content and Density Using Time Domain Reflectometry

7. Author(s)

W. Feng, C. Lin, V. P. Dmevich, and R. J. Deschamps

9. Performing Organization Name and Addreas

Joint Transportation Research Program

1284 Civil Engineering Building

Purdue University

West Lafayette, Indiana 47907-1284

12. Sponsoring Agency Name and Address

Indiana Department of Transportation

State Office Building

100 North Senate Avenue

Indianapolis, IN 46204
3. Recipient's Catalog No.

5. Report Date

September 1998

6. Performing Organization Code

8. Performing Organization Report No.

FHWA/N/JTRP-98/4

10. Work Unit No.

11. Contract or Grant No

JHRP-018

13. Type or Report and Period Covered

Final Report

14. Sponsoring Agency Code

\section{Supplementary Notes}

Prepared in cooperation with the Indiana Department of Transportation and Federal Highway Administration.

\section{Abstract}

The methodology developed by Siddiqui and Drnevich (1995) for measuring soil water content and density using Time Domain Reflectometry (TDR) was extended for routine use in the quality control testing of compacted soils. The objectives of the study were to develop computer software to automate data interpretation and data reduction, develop prototype equipment for field use, compare the results of the TDR method with the sand cone and nuclear density methods on actual construction sites and develop draft specifications for ASTM and AASHTO.

New prototype equipment was developed for compaction quality control testing. Waveform interpretation and data reduction were automated by incorporating developed algorithms into a Windows ${ }^{\mathrm{TM}}$ based computer program that is used on a palm top computer connected to the TDR apparatus. Over 150 laboratory and field tests were performed to evaluate the TDR equipment and procedure for use in the determination of moisture content and density of compacted soil.Under field conditions it was shown that the TDR method is more accurate than the nuclear density gage in estimating water content when compared to oven drying, with standard errors of $1.1 \%$ and $1.8 \%$, respectively. The ability to assess the accuracy of the TDR method for determining density was limited because the true density of the compacted soil is not known. The sand cone test was used as a basis for comparing the TDR and nuclear density tests on several sites while accepting that the sand cone test is not an exact method.

The time required to perform the TDR test under field conditions is approximately 15 to 20 minutes. The sand cone test can also be performed in approximately 15 minutes, while the nuclear density test can be performed in approximately two minutes. The time required to complete the TDR test relative to the nuclear density test, is viewed as its greatest limitation. In general, the nuclear gage provides estimates of density and water content much more rapidly than the sand cone or TDR tests, is less accurate than the TDR test in estimating water content, and must be calibrated for a specific soil using sand cone tests. Moreover, the nuclear gage uses a hazardous source requiring operators to take safety training and leading to expenses associated with equipment maintenance and disposal. The sand cone test is time consuming, and can not provide estimates of water content. The TDR test is also time consuming, but does provide accurate estimates of water content.

At the present stage of the research, the TDR test has not shown great advantage in the measurement of water content and density relative to the nuclear density test. However, progress is being made in the development of an approach to use other features of the reflected waveform, in addition to the apparent dielectric constant, within the interpretation process. It is anticipated that the additional information that can be obtained from the reflected waveform will allow a more accurate estimate of density to be obtained while eliminating the need to recompact the soil in a mold. This should greatly reduce the test duration.

\section{Key Words}

Soils, water content, density, field compaction control, time domain reflectometry, dielectric constant, coaxial transmission lines, multiple rod probes, data automation.

\section{Distribution Statement}

No restrictions. This document is available to the public through the National Technical Information Service, Springfield, VA 22161
19. Security Classif. (of this report)

Unclassified
20. Security Classif. (of this page)

Unclassified
21. No. of Pages

122 
TABLE OF CONTENT

Page

LIST OF TABLES

iv

LIST OF FIGURES

$\mathrm{v}$

LIST OF SYMBOLS AND ABBREVIATIONS

vii

\section{CHAPTER 1}

INTRODUCTION

1.1 Background

1.2 Problem Statement

1.3 Objectives

1.4 Scope of Work

1.5 Report Format

\section{CHAPTER 2}

BACKGROUND

2.1 TDR Basics

\section{CHAPTER 3}

DESIGN OF TDR PROTOTYPE EQUIPMENT .......................... 3.1

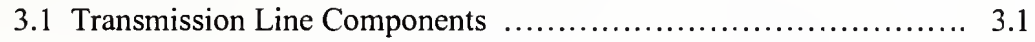

3.2 Factors Influencing Wave Transmission ......................... 3.1

3.2.1 Types of Transmission Line $\quad$.......................... 3.1

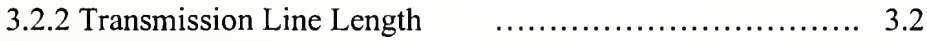

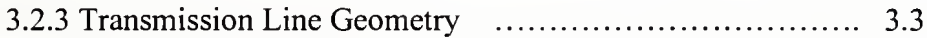

3.2.4 Volume of Soil Tested .................................. 3.3

3.3 Equipment Modifications from Previous Study ................... 3.6

3.4 Design Drawings of the Components of the Transmission Line/Probe 3.6

3.4.1 Coaxial Head .......................................... 3.7

3.4.2 Coaxial Cylinder $\quad$................................ 3.7

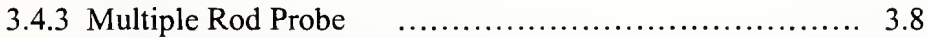

3.5 Characteristics of the Prototype Equipment $\quad \ldots \ldots \ldots \ldots \ldots \ldots \ldots \ldots . \ldots . \ldots . \ldots$

\section{CHAPTER 4}

AUTOMATION OF TDR WAVEFORM INTERPRETATION

4.1 Introduction

4.2 Interpretation of the TDR Waveform

4.3 Algorithm to Read the TDR Waveform

4.4 Remarks on Waveform Interpretation 
CHAPTER 5

AUTOMATION OF DATA REDUCTION AND TESTING PROCEDURE ...5.1

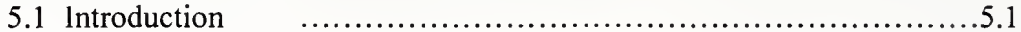

5.2 TDR++ -- A TDR Automation Software ..............................5.1

5.2.1 Data Acquisition and Tester Controlling …............5.4

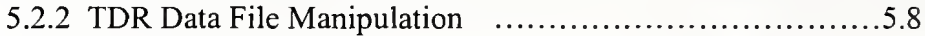

5.2.3 Signal Displaying and Note Editing $\quad \ldots \ldots \ldots \ldots \ldots \ldots \ldots \ldots . . .10$

5.2.4 Data Interpretation and Reduction $\quad$........................ 5.11

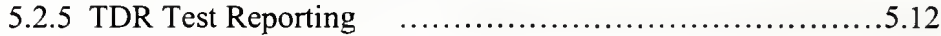

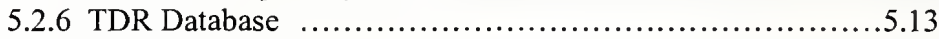

5.2.7 On-line Help ............................................. 5.13

5.3 Remarks on Procedural Automation $\quad$...............................5.14

\section{CHAPTER 6}

LABORATORY AND FIELD EVALUATION OF TDR METHOD _.......6.1

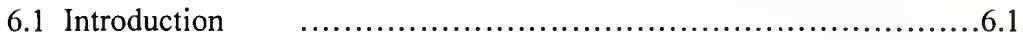

6.2 Reexamination of the Calibration Equations $\quad$....................... 6.1

6.2.1 Experimental Method ......................................6.4

6.2.2 Results and Discussion ................................... 6.4

6.3 Laboratory Evaluation of the Testing Procedure and Prototype

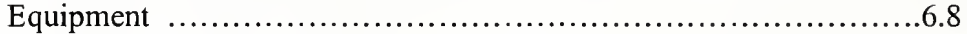

6.3.1 Experimental Method ................................... 6.8

6.3.2 Results and Discussion ................................... 6.9

6.4 Field Evaluation of the Testing Procedure and Prototype Equipment...6.12

6.4.1 Experimental Method .......................................6.13

6.4.2 Results and Discussion ....................................13

6.5 Conclusions $\quad$.................................................... 6.15

\section{CHAPTER 7}

STANDARDIZED PROCEDURE AND ASTM/AASHTO STANDARD DRAFT

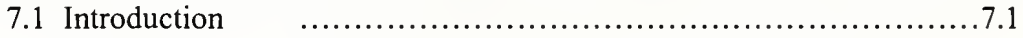

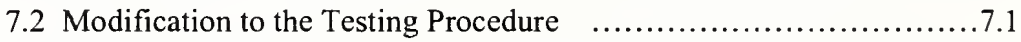

7.3 Draft of Standards $\quad$..............................................

\section{CHAPTER 8}

SUMMARY, CONCLUSION AND RECOMMANDATIONS $\quad \ldots \ldots \ldots \ldots \ldots . . . \ldots .1$

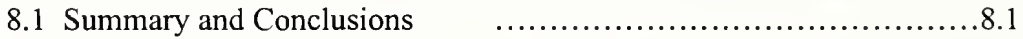

8.2 Recommandations for Additional Research $\quad$........................

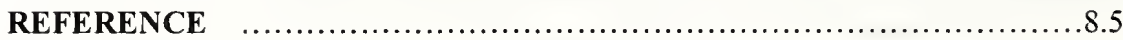
APPENDIX
I. ASTM Standard Draft

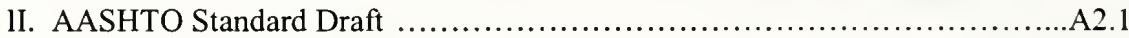

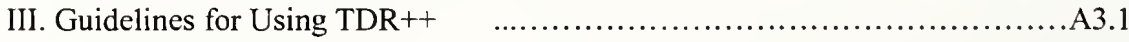




\section{LIST OF TABLES}

Page

Table

3.1 Minimum Test Hole Volume Based on Maximum Size of Included Particle..... 3.5

5.1 Distance-per-division representations .............................................................5. 5.7

5.2 File name extension and corresponding file format....................................... 5.10

6.1 Soil Characteristic for experiments to reexamine the calibration equations....... 6.5

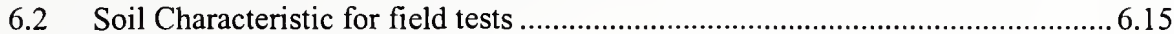

6.3 The result of measurements of soil water content and density in field tests.......6.17

6.4 The errors of measurements of soil water content and density in field tests....... 6.18 


\section{LIST OF FIGURES}

Figure

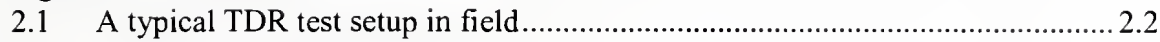

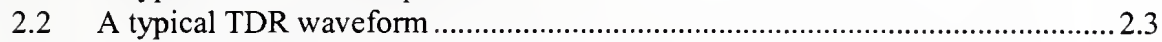

3.1 Configuration of Coaxial Head ............................................................................ 3.4

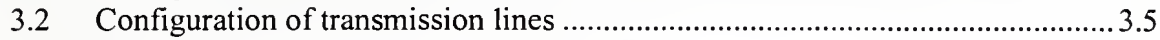

3.3 Assembly drawing of coaxial head.........................................................................

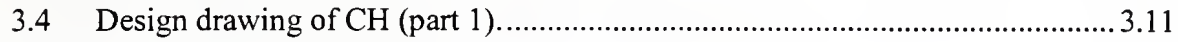

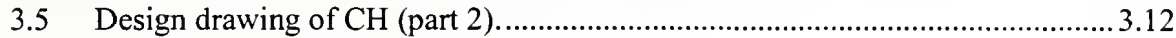

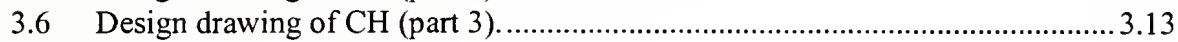

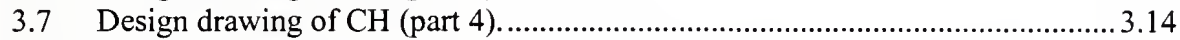

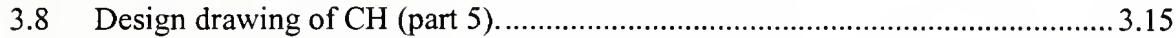

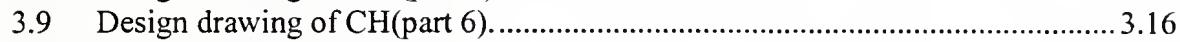

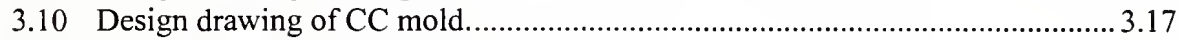

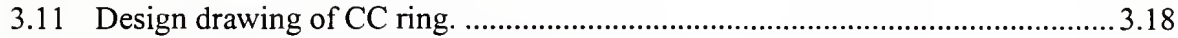

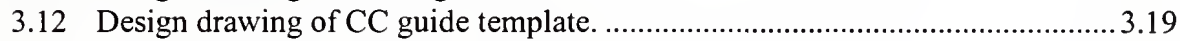

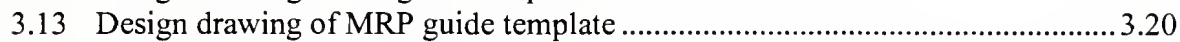

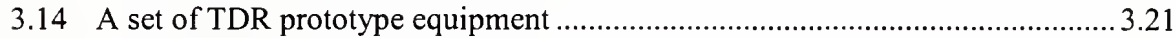

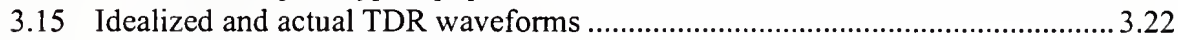

3.16 TDR waveforms of soil in CC filled up to different level.....................................2.23

3.17 Interpretation of TDR waveform by tangent lines. ................................................ 3.23

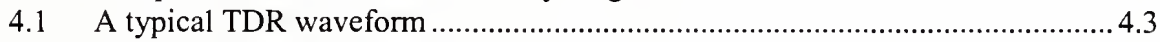

4.2 Two methods to determine the first and second reflection point. ....................... 4.4

4.3 TDR traces with different shapes. ................................................................. 4.6

4.4 a) An original waveform b) the smoothed waveform; c) The first derivative of the original waveform and d) The second derivative of the original waveform.4.7

4.5 Illustration of Symbols in the Algorithm .......................................................10

4.6 TDR readings for different traces using the algorithm in chapter $4 \ldots \ldots \ldots \ldots \ldots \ldots . . .14 .12$

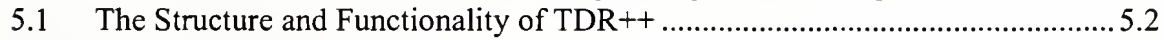

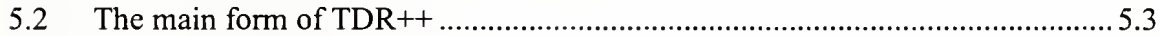

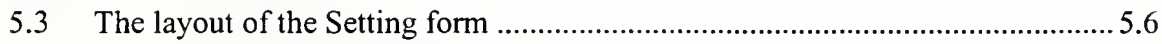

5.4 The layout of the picture box. .................................................................... 5.11

6.1 Comparison of the oven-dry water content and the TDR measured water content for different types of soils (listed in Table 6.1) using Topp's empirical

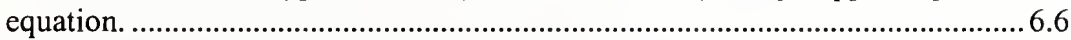

6.2 $\sqrt{ } K$ vs. $\theta$ relationship for different types of soils (listed in Table 6.1).pes of soils (listed in Table 6.1) using Topp's empirical equation.

6.3 Density-compensating water content relationship for different types of soils (listed in Table 6.1).

6.4 Density-compensating water content relationship for Crosby Till......................... 6.10

6.5 Comparison of the oven-dry water content and the TDR measured water content for Crosby Till using Topp's empirical equation. 
6.6 Comparison of the oven-dry water content and the TDR measured water content for Crosby Till using Density-compensating water content equation. ...6.11

6.7 Variation of error in density measurement with the difference of density in two CC mold.

6.8 Density-compensating water content relationship for all soil types in field tests.

6.9 Comparison of the oven-dry water content with the TDR measured water 6.16 content and Nuclear gauge measured water content in field tests. 


\section{LIST OF SYMBOLS AND ABBREVIATIONS}

The list is not complete, however, symbols are usually identifies where used if use is different than given below.

$\begin{array}{ll}\theta & \text { volumetric moisture content } \\ \rho_{\mathrm{d}} & \text { dry density of soil } \\ \rho_{\mathrm{w}} & \text { density of water } \\ \text { AASHTO } & \text { American Association of State Highway and Transportation Officials } \\ \text { ASTM } & \text { American Society of Testing and Materials } \\ \mathrm{c} & \text { velocity of light in vacuum }=10^{8} \mathrm{~m} / \mathrm{s} \\ \mathrm{CA} & \text { Coaxial Apparatus } \\ \mathrm{CC} & \text { Coaxial Cylinder } \\ \mathrm{CH} & \text { Coaxial Head } \\ \mathrm{cm} & \text { centi-meter } \\ \mathrm{dB} & \text { decibels } \\ \mathrm{DEC} & \text { Data Communication Equipment } \\ d V_{s} & \text { derivative of the smoothed voltage } \\ \mathrm{ft} & \text { foot } \\ \mathrm{G} & \text { giga }=10^{9} \text { (prefix) } \\ \mathrm{g} & \text { gram } \\ \mathrm{Hz} & \text { hertz=1 cycle per second } \\ \text { in } & \text { inch } \\ \mathrm{INDOT} & \text { Indiana Department of Transportation } \\ \mathrm{k} & \text { kilo }=10^{3} \text { (prefix) } \\ \mathrm{K}_{\mathrm{a}} & \text { apparent dielectric constant } \\ \mathrm{L} & \text { length of probe inserted into the soil } \\ \mathrm{l}_{\mathrm{a}} & \text { apparent length } \\ \mathrm{m} & \text { meter } \\ \mathrm{m} & \text { milli=10 } \\ \mathrm{mm} & \text { milli-meter } \\ \mathrm{mrho} & \text { millirho } \\ \mathrm{MRP} & \text { multiple rod probe } \\ \mathrm{r}_{\mathrm{i}} & \text { radius of inner conductor } \\ \mathrm{OLE} & \text { Object Linking and Embedding } \\ \mathrm{P} 4 & \text { percentage of soil passing No.4 sieve } \\ \mathrm{P} 10 & \text { percentage of soil passing No.10 sieve } \\ \mathrm{P} 40 & \text { percentage of soil passing No.40 sieve } \\ \mathrm{P} 200 & \text { percentage of soil passing No.200 sieve } \\ \mathrm{SE} & \text { Standard Error } \\ \mathrm{r}_{\mathrm{o}} & \text { radius of outer conductor } \\ \mathrm{TDR} & \text { time domain reflectometry } \\ \mathrm{USCS} & \text { Unified Soil Classification System } \\ \mathrm{V}_{\mathrm{p}} & \text { velocity of propagation } \\ V_{R} & \text { reflected voltage } \\ & \end{array}$




$\begin{array}{ll}V_{S} & \text { smoothed voltage } \\ V_{T} & \text { transmitted voltage } \\ \text { W } & \text { gravimetric water content } \\ \text { WOD }_{\text {OD }} & \text { oven dry water content } \\ \text { W }_{\text {TDR }} & \text { TDR water content }\end{array}$




\section{IMPLEMENTATION REPORT}

A new method to measure in-place density and moisture content of soil using Time Domain Reflectometry (TDR) was developed and evaluated. The method is applicable for use in density and water content control of compacted earthworks. This project extends the study completed by Siddiqui and Drnevich (1995). They identified four tasks that would require completion to implement their findings: development of prototype equipment, automation of data interpretation and reduction, comparison with conventional quality control tests on actual construction sites, and development of draft specifications. These tasks became the objectives of this study.

The TDR method uses an electronic TDR apparatus that generates and measures waveforms that are used to measure the electromagnetic properties of soil. A test involves: taking a reading from the waveform on the display and using the reading along with measurement of soil mass with an electronic balance to obtain moisture content and density using appropriate calculations. Software was developed for use with a "palm top" computer to interpret the waveform. Previously this task required a skilled technician to obtain consistent results. In addition, the developed software performs all data reduction and provides the operator with direct estimates of water content and density.

The development of prototype equipment included reducing the number of required components and modifying the original equipment to increase signal quality. The new equipment was used on nine different construction sites in Indiana to compare results with the sand cone and nuclear density tests. In general, the TDR method provided better estimates of water content than the nuclear density gage, while the nuclear density gage provided estimates of density closer to the sand cone test, which it is calibrated against. It was shown that the spatial variability in density was not negligible at these sites.

The TDR method has advantages over the nuclear density test in that it does not use radioactive materials and does not generate expenses associated with safety training, equipment maintenance, and equipment disposal. However, the time required to complete a TDR test is comparable to the sand cone test, approximately 15 minutes, while the nuclear test can be completed in about two minutes. The present duration of the TDR test is viewed as the primary disadvantage of the approach and it is desirable to improve the accuracy of the density measurements.

Draft specifications were prepared to describe this equipment and the testing procedure in the format of both ASTM and AASHTO. The results of this study and preliminary findings from a subsequent study were presented to the ASTM D18.08 committee on field compaction in June, 1998. This committee was very receptive to the use of TDR for quality control, but felt that the new study could substantially alter, the procedures, accuracy, and equipment used to perform a test. Accordingly, it was recommended that the current study be completed before standard specifications were carried through the approval system. Therefore, the recommended implementation plan would be to modify the developed draft ASTM and AASHTO standards, according to the results of the new study, and guide these standards through the approval process at that time. 


\section{CHAPTER 1}

\section{INTRODUCTION}

\subsection{Background}

Siddiqui and Drnevich (1995) developed a new method of measuring soil water content and density using Time Domain Reflectometry. This method can measure the water content of soil both in the laboratory, and in the field. This study is the implementation phase of the previous work.

The determination of soil water content and density are the most common geotechnical tests performed and among the most common quality control tests used in civil engineering. Water content is typically measured by oven drying or with a nuclear density gauge. Calcium carbide gas pressure tester method also can be used for obtaining moisture content at field. However, determination of water content by oven drying is very time consuming and delays interpretation of both laboratory and field tests. The nuclear density gauge requires extensive calibration, has an uncertain zone of influence, and uses hazardous materials, which leads to the necessity for safety training and expensive maintenance. Calcium carbide gas pressure tester method uses calcium carbide as a reagent, which is irritating to human body, and the acetylene gas produced in the test is highly flammable or explosive. Moreover, the precision of this test is uncertain. This research has demonstrated that the use of Time Domain Reflectometry (TDR) has the potential to overcome these limitations and provide estimates of water content and density of soil in the laboratory and in the field.

The basis of TDR is to send an electromagnetic wave along a coaxial line to a probe, which is inserted into the ground. A portion of the wave is reflected at the soil surface and again at the end of the probe. An oscilloscope in the TDR apparatus reads the reflected 
waveform. The points of reflection are visible on the waveform and the distance between these two reflection points represents the velocity of wave propagation along the probe. The wave velocity is related to the dielectric constant of the soil that surrounds the probe. The measured dielectric constant can then be used to estimate the volumetric water content of the soil because there is a strong correlation between dielectric constant and volumetric water content.

\subsection{Problem Statement}

During the previous study TDR was shown to be capable of measuring both soil water content and density in the laboratory and in the field. Implementation of the research requires that the subjectivity of data interpretation and data reduction is eliminated, prototype equipment is developed and standardized, and the testing procedure is standardized.

\subsection{Objectives}

The primary objectives of this project were to: 1) develop prototype test equipment; 2) automate TDR waveform interpretation and data reduction; 3) generate additional data with the new equipment under field conditions to assess the accuracy of the method; and 4) generate ASTM and AASHTO draft standards for the equipment and procedure.

\subsection{Scope of Work}

The scope of work is closely aligned with meeting the outlined objectives. The following sections present specific efforts to meet these goals. 


\section{Equipment Development}

During the initial study, several pieces of equipment were developed for measuring the water content and density of soils. Equipment was designed for tests in the laboratory, in the field for construction control, and in situ for use within soil borings (Drnevich and Siddiqui, 1995). An objective for this study was to develop prototype equipment for compaction quality control to improve reflected waveform quality and simplify the test procedure.

\section{Data Interpretation and Procedural Automation}

Accurate interpretation of the reflected wavelength is critical for accurate predictions of water content and density. However, this interpretation can be somewhat subjective and results are apt to be operator dependent. To eliminate the subjectivity in the readings and to simplify the data reduction process, an algorithm was developed and incorporated into a computer program such that data readings and data processing are fully automated and independent of the operator. Readings of water content and density are displayed directly on the computer screen.

\section{Laboratory and Field Tests}

Approximately 150 water content and density tests have been performed in the laboratory and the field to assess the adequacy of the prototype equipment, and to improve the testing procedure. Tests measurements under field conditions were compared with tests using the nuclear density gauge and the sand cone test, and with oven dried water content. 


\section{Development of ASTM and AASHTO Standards}

ASTM and AASHTO draft standards have been developed to standardize the equipment and testing procedure. It is anticipated that these standards will be improved as feedback is generated from operators of the equipment.

\subsection{Report Format}

Chapter 2 of this report provides a brief review of the development and use of TDR, basic concepts, and related research. Chapter 3 describes the design of the prototype equipment including factors considered during development, and design drawings. The algorithm used to automate waveform interpretation is developed in Chapter 4. Chapter 5 describes the software that was developed for data interpretation, data reduction, and output presentation. The results of laboratory and field tests and comparison to conventional test methods are presented in Chapter 6. Chapter 7 introduces the proposed testing procedures, including ASTM and AASHTO draft standards. A summary of the study, conclusions and recommendations are provided in Chapter 8 . 


\section{CHAPTER 2}

\section{BACKGROUND}

\subsection{TDR Basics}

Fellner-Feldegg (1969) introduced time domain reflectometry (TDR) as a means of measuring the complex dielectric permittivity of liquids. Since that time, TDR has been applied to the measurement of dielectric properties of many materials including soils. In recent years, intensive studies have been undertaken on the application of TDR to the measurement of soil water content, bulk soil electric conductivity, and soil density.

A comprehensive review of the literature on TDR, including theoretical background and equipment was presented in the JHRP final report "A New Method of Measuring Density and Water Content of Soil Using the Technique of Time Domain Reflectometry" by Siddiqui and Drnevich (1995) and will not be repeated here. In this section, a brief summary of the application on TDR to obtain water content and density is provided.

\section{TDR Equipment}

TDR equipment includes a TDR apparatus, a coaxial cable, a probe, and a head to connect the coaxial cable and the probe. A typical test setup for field conditions is shown in Figure 2.1.

The Tektronix 1502B Metallic TDR Cable Tester was used in this study. It is the same equipment used by many other TDR researchers. The apparatus transmits a step pulse, electromagnetic wave along a standard coaxial cable. A built-in oscilloscope receives the transmitted wave superimposed with the reflected wave. The apparatus is a wide band device, 
with a frequency range of 0 to $10 \mathrm{GHz}$. The signal is recorded and displayed in the time domain.

\section{Tektronix Cable Tester}

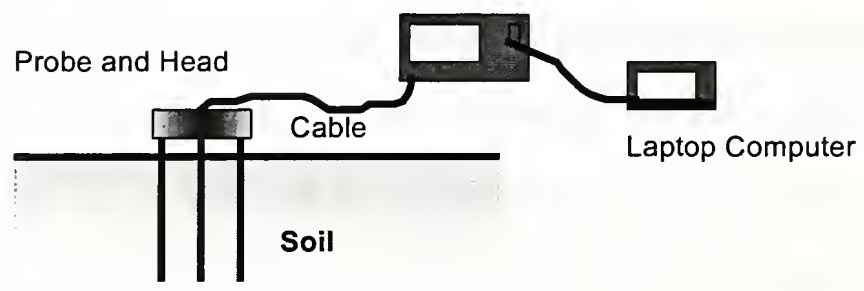

Figure 2.1 A typical TDR test setup in field

For application with soil, the coaxial cable typically leads to a head and a number of steel rods, or probes, that penetrate the soil. The head connects the coaxial cable and the rods. The rods are embedded in soil and act as an extension to the coaxial line such that the soil serves as the insulating material between the rods. At each point along the coaxial system where there is a discontinuity of impedance, a reflected wave is produced. Discontinuities of impedance occur where: the coaxial cable is attached to the head, the head is attached to the rods, the rods enter the soil, and at the ends of the rods. The TDR waveform received by the oscilloscope is a superposition of these multiple reflections along with the initially transmitted wave. Thus, differences in the geometry of the head or rods lead to different shapes in the reflected waveform. 


\section{TDR Waveform Interpretation}

The overall shape of the reflected TDR trace is influenced by the impedance and length of the various components in the transmission line and therefore varies with the equipment used. Two specific points on the reflected waveform are needed for data interpretation, namely the reflection that occurs at the top of the soil surface and the reflection that occurs at the end of the rods. These points are used to interpret the dielectric constant of the soil surrounding the rods. A typical TDR waveform is shown in Figure 2.2.

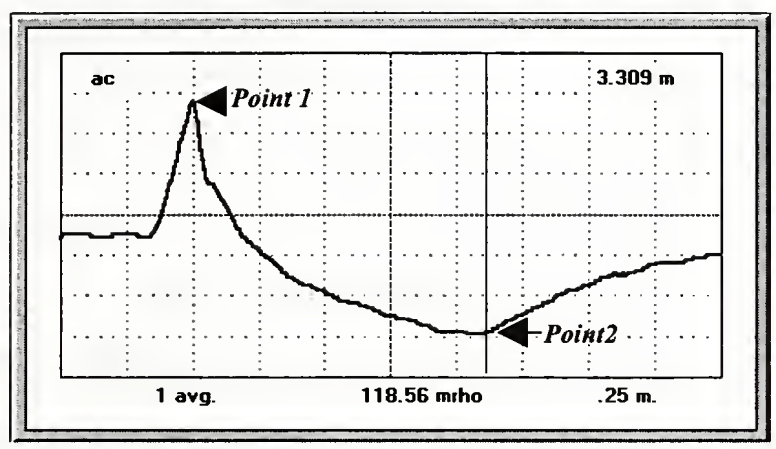

Figure 2.2 A typical TDR waveform

In Figure 2.2, the peak is marked as "Point 1" which represents the reflection at the soil surface, while the valley is marked as "Point 2" which corresponds to the reflection at the end of the TDR probe. The TDR device uses a parameter defined as the nominal velocity of propagation, $V_{p}$. This velocity is multiplied by the travel time of the reflected wave so that the reading at each horizontal position on the oscilloscope is expressed as a unit of distance. The distance between Points 1 and 2 on the waveform is defined as the apparent length $\left(l_{a}\right)$. 
Since the actual length of the rods are known in advance, the true travel velocity can be determined by multiplying the nominal propagation velocity by the ratio of rod length to apparent length. The apparent dielectric constant of the soil $\left(\mathrm{K}_{\lrcorner}\right)$is defined as follows:

$$
\mathrm{K}_{\mathrm{a}}=\frac{\mathrm{c}^{2}}{\mathrm{v}^{2}}
$$

where

$$
\begin{aligned}
& c=\text { the speed of light, } \\
& v=\text { true travel velocity }
\end{aligned}
$$

An alternative, and more convenient, representation for $\mathrm{K}_{\mathrm{a}}$ is:

$$
\mathrm{K}_{\mathrm{a}}=\frac{\left(\mathrm{l}_{\mathrm{a}} / \mathrm{V}_{\mathrm{P}}\right)^{2}}{\mathrm{~L}^{2}}
$$

where $\quad l_{\mathrm{a}}=$ the apparent length,

$\mathrm{L}=$ length of the rods inserted into the soil, and

$\mathrm{V}_{\mathrm{p}}=$ the ratio of the nominal velocity of the apparatus to the velocity of light

$\mathrm{V}_{\mathrm{p}}$ typically ranges between 0.30 to 0.99 , depending on the set of the instrument.

\section{Correlations Between Apparent Dielectric Constant, Water Content, and Density of Soil}

The apparent dielectric constant of the soil $\left(\mathrm{K}_{\mathrm{a}}\right)$ that is obtained from the TDR waveform is used to estimate the water content and density of the soil. Several relationships have been proposed that relate $\mathrm{K}_{\mathrm{a}}$ to volumetric water content. Dmevich and Siddiqui (1995), and Siddiqui (1995) critically evaluated these relationships and they proposed a methodology for obtaining water content and density of soils using two relationships. The first of these relationships was proposed by Topp et al in 1980 and consists of a polynomial regression equation that can be used to estimate volumetric water, $\theta$, as a function of $\mathrm{K}_{\mathrm{a}}$ : 


$$
\theta=-0.053+2.92 \times 10^{-2} K_{a^{-5}} .5 \times 10^{-4} K_{a^{2}+4.3 \times 10^{-6}} K_{a}^{3}
$$

The second equation, proposed by Siddiqui (1995), relates the ratio of dielectric constant and soil density to gravimetric water content.

$$
\frac{\sqrt{K_{a}} \rho_{w}}{\rho_{d}}=a+b w
$$

where:

$$
\begin{aligned}
& \rho_{d}=\text { dry density of soil } \\
& \rho_{w}=\text { density of water } \\
& w=\text { gravimetric water content } \\
& a, b=\text { soil dependent coefficients }
\end{aligned}
$$

In the previous JHRP study, Siddiqui and Drnevich introduced a procedure to obtain both the gravimetric water content and soil density using Eqns. 2.3 and 2.4. Briefly, the procedure entails: 1) making a measurement of the dielectric constant in situ where the density and water content are unknown; 2) excavating the tested soil and compacting it in a mold of known volume and remeasuring the dielectric constant; 3 ) measuring the wet density of the soil in the mold using a balance; 4) using Topp's equation to estimate the volumetric water content from which the gravimetric water content can be calculated for the soil in the mold; and 5) use Eqn. 2.4 to obtain in situ density by assuming the gravimetric water content is the same in the mold and in situ.

During the present study it was noted that the use of Topp's equation yielded too much scatter in the measurements of volumetric water content. Although this equation is broadly used by many investigators, test results performed in this study show that both soil density and soil type have a significant influence on the $\theta-\mathrm{K}_{\mathrm{a}}$ relationship. Accordingly, an alternative procedure was developed during this study and will be introduced in Chapter 6 . 


\section{CHAPTER 3}

\section{DESIGN OF TDR PROTOTYPE EQUIPMENT}

\subsection{Transmission Line Components}

The wave transmission line consists of a coaxial cable, a coaxial head $(\mathrm{CH})$, and either a coaxial cylinder (CC) or a multiple rod probe (MRP). Each of these coaxial components contains an inner conductor and an outer conductor. A typical coaxial cable consists of an inner conducting wire surrounded by a cylindrical casing that acts as the outer conductor. Each of the other coaxial components is a variation of this system.

The coaxial head $(\mathrm{CH})$ actually consists of three components, as shown in Figure 3.1 : 1) a coaxial line similar to the coaxial cable; 2) a solid cylindrical head with Delrin ${ }^{\circledR}$ as the insulating material; and 3) multiple rod section consisting of a center rod and three perimeter conducting rods with air as the insulating material.

The coaxial cylinder (CC) consists of a central conducting rod and a steel outer conducting cylinder. The cylinder is filled with soil and serves as the insulating material as shown in Figure 3.2. The multiple rod probe (MRP) consists of a central rod and three perimeter rods of the same spacing as the $\mathrm{CH}$. The rods penetrate the soil so that the soil acts as the insulating material as shown in Figure 3.2.

\subsection{Factors Influencing Wave Transmission}

The factors that influence wave transmission include the type, length, and geometry of the transmission line, and the characteristics and volume of soil tested. 


\subsubsection{Type of Transmission Line}

The types of transmission lines used in this study can be divided into two groups: 1) those with a bounded outer cylindrical conductor; and 2) those with an unbounded outer conductor. The coaxial cable and CC are in the first group while the MRP is in the second. The head actually has components in both groups. Zegelin et. al. (1989) showed that an MRP with three outer rods provided signals that were essentially the same as those with cylindrical outer conductors.

\subsubsection{Transmission Line Length}

The length of the $\mathrm{CH}$ transmission line is chosen to be small so that the transient effect of the head dies out fast. The maximum length that can be used for the CC and MRP with soil as the insulating medium is controlled by the following factors.

(1) Loss of signal strength along the length of the line.

(2) Spatial resolution of the TDR apparatus.

(3) Ease of installation of rods in soil.

(4) Desired sampling depth.

Based on these factors, an optimum length can be selected.

The signal strength decays as it travels through a conductive medium. The length of the probe must be short enough that a detectable reflection from the end of the probe is received. To get a detectable return signal, the ratio of reflected voltage, $V_{R}$, to transmitted voltage, $V_{T}$, must be greater than zero. This ratio increases as $L$ decreases. On the other hand, the variability of the interpreted value of $\mathrm{K}_{\mathrm{a}}$ from the TDR measurement increases with decreasing rod length. Siddiqui (1995) performed a detailed analysis of the controlling 
factors and it was found that the maximum rod length ranged approximately between $0.2 \mathrm{~m}$ for saturated bentonite to 1 meter for clean sands. Accordingly, rod lengths of 0.1 to $0.2 \mathrm{~m}$ were considered applicable for a wide range in soil types. This is consistent with the desired test depths of compacted soils, which typically consist of less than $0.3 \mathrm{~m}$.

\subsubsection{Transmission Line Geometry}

The ratio of the radii of the outer $\left(r_{0}\right)$ and inner $\left(r_{i}\right)$ conductor is the most important geometric parameter when considering a cross section through the coaxial system. The ratio $r_{0} / r_{i}$, and the dielectric constant of the insulating medium determine the impedance of a transmission line. The magnitude of $r_{0}$ or $r_{i}$ does not influence the results, only the ratio. Measurements are better (less spatial sensitivity) with equipment that has lower values of $r_{0} / r_{i}$. However, practical limits exist due to the need to have equipment robust enough to penetrate compacted soils and to minimize the disturbance of soil during penetration.

\subsubsection{Volume of Soil Tested}

The sampling volumes should be as large as practical to minimize the measurement errors. With the sand cone method, the appropriate test hole volume depends on soil gradation and should not be smaller than the volumes indicated in Table 3.1 according to ASTM D1556. 

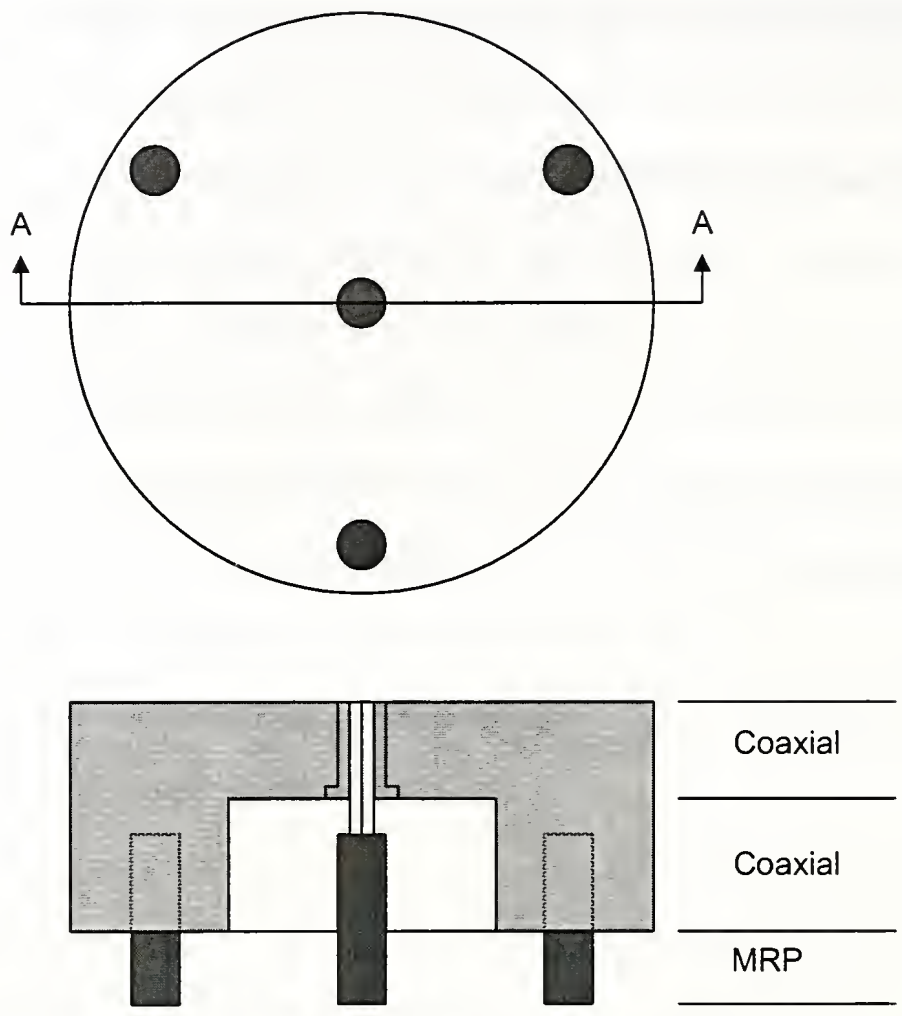

Section A-A

Figure 3.1 Configuration of Coaxial Head 


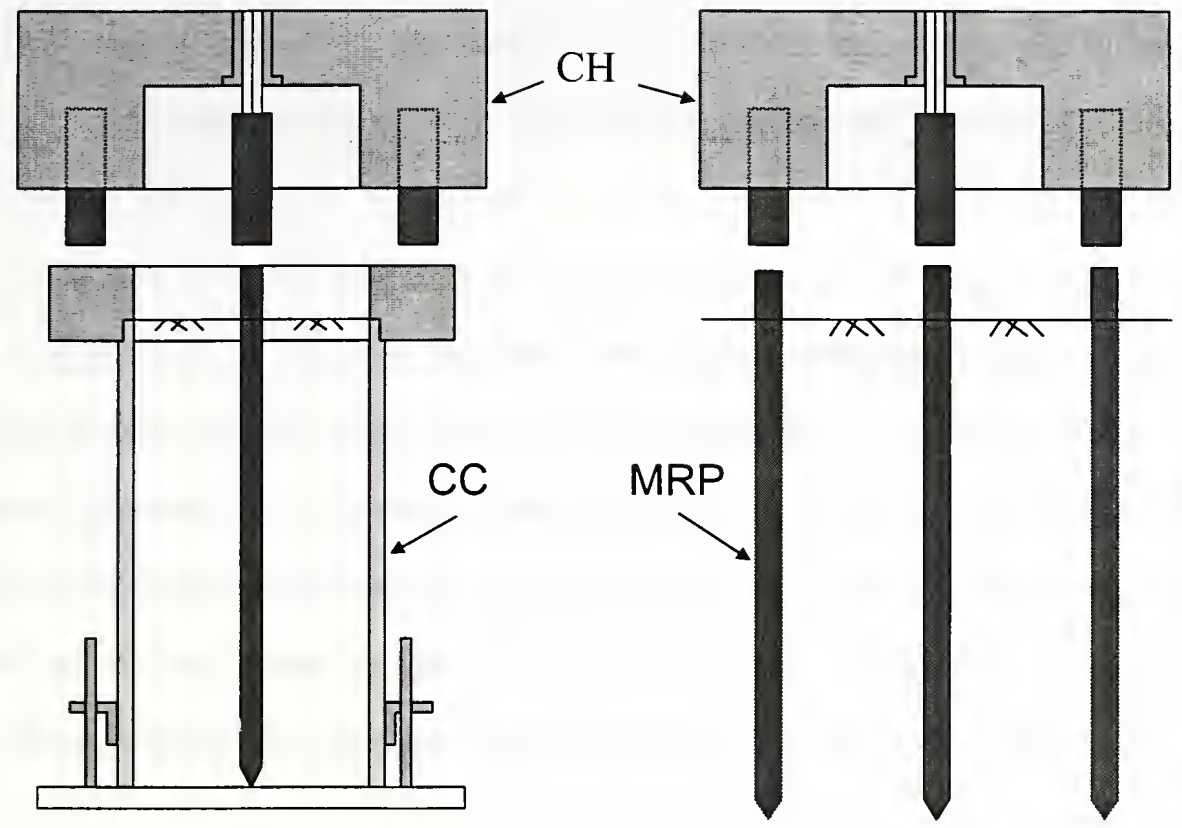

Figure 3.2 Configuration of transmission lines

Table 3.1 Minimum Test Hole Volume Based on Maximum Size of Included Particle

\begin{tabular}{|c|c|c|c|}
\hline \multicolumn{2}{|c|}{ Maximum Particle Size } & \multicolumn{2}{c|}{ Minimum Test Hole Volumes } \\
\hline in & Mm & $\mathrm{cm}^{3}$ & $\mathrm{ft}^{3}$ \\
\hline $1 / 2$ & 12.5 & 1420 & 0.05 \\
\hline 1 & 25 & 2120 & 0.075 \\
\hline 2 & 50 & 2830 & 0.1 \\
\hline
\end{tabular}


The sampling volume of the TDR field test is designed to meet the highest value in the above table. The spacing between the inner conductor and outer conductor is $66 \mathrm{~mm} \mathrm{(2.6")}$ and the length of the rods inside the soil is $223.5 \mathrm{~mm}\left(8.8^{\prime \prime}\right)$. This configuration will give sampling volume of $3060 \mathrm{~cm}^{3}\left(0.113 \mathrm{ft}^{3}\right)$ which is larger than the maximum value in Table $3.1,2830 \mathrm{~cm}^{3}\left(0.1 \mathrm{ft}^{3}\right)$.

\subsection{Equipment Modifications from Previous Study}

Siddiqui and Drnevich (1995) developed equipment and a procedure for estimating water content and density of soils in a compaction mold and in situ. As part of the present study, which is an implementation of the previous work, this equipment has been modified and improved. Modifications were made so that the equipment would be more robust, easier to use, and provide superior wave transmission. The following modifications to the equipment were made during this phase of the study.

1) A single head was used for both the CC and the MRP. This reduced the needed equipment and lowered overall cost of the apparatus.

2) The ratio $r_{0} / r_{i}$ is now 12.8 .

3) The volume of the $\mathrm{CC}$ is $1650 \mathrm{~cm}^{3}\left(1 / 17 \mathrm{ft}^{3}\right)$.

4) Lengths of the CC and MRP transmission line are $234 \mathrm{~mm}$ (9.2 in) and $254 \mathrm{~mm}$ (10 in), respectively.

\subsection{Design Drawings of the Components of the Transmission Line/Probe}

Based on all the considerations discussed in the previous section, a coaxial apparatus transmission line was developed and included: a coaxial cable, a coaxial cylinder (CC), a 
coaxial head $(\mathrm{CH})$, and a multiple rod probe (MRP) transmission line. The detailed design drawings of each component are shown in Figures 3.2 through Figure 3.14 using a conventional machine design approach.

\subsubsection{Coaxial Head}

The most important change to the coaxial apparatus is in the $\mathrm{CH}$, which can now be used for both the MRP and the CC. This simplifies the testing process, reduces the possibility of errors, and makes the system more economical. The head was redesigned by modifying the Delrin ${ }^{\circledast}$ insert to improve signal quality. The $\mathrm{CH}$ has four metal studs threaded into the metal head. The lengths of the central stud and two of the outer studs are the same 21 $\mathrm{mm}(0.825 \mathrm{in})$. The fourth stud is threaded to provide adjustable length. The assembly drawing of the $\mathrm{CH}$ is shown in Figure 3.3 and the drawings of each part are shown in Figures 3.4 to 3.9 .

\subsubsection{Coaxial Cylinder}

The coaxial cylinder transmission line consists of a CC mold, a ring and a central rod. A template is used to guide the insertion of a central rod into the CC mold. The design drawings for the $\mathrm{CC}$ mold, $\mathrm{CC}$ ring, and $\mathrm{CC}$ template are shown in Figure 3.10, 3.11 and 3.12, respectively. The central rod is made of stainless steel, $8 \mathrm{~mm}(5 / 16 \mathrm{in}$.) in diameter, and $234 \mathrm{~mm}$ (9.2 in.) long. It is driven through the $\mathrm{CC}$ template while it rests on top of the $\mathrm{CC}$ mold. After the central rod is driven into the soil in the $\mathrm{CC}$ mold, the template is removed and 
the $\mathrm{CC}$ ring is placed on top of the $\mathrm{CC}$ mold. The $\mathrm{CH}$ is then placed on top of the $\mathrm{CC}$ ring and the threaded stud is adjusted until contact is made as shown in Figure 3.2.

\subsubsection{Multiple Rod Probe}

The MRP consists of four rods which are steel spikes, $9.5 \mathrm{~mm}(3 / 8 \mathrm{in}$.$) in diameter and$ $254 \mathrm{~mm}$ (10in.) long. A template is used to guide insertion of the spikes into the ground so that the configuration is the same as the $\mathrm{CH}$. The design drawing of the guide template is shown in Figure 3.13. The conducting spikes are driven through the template and the template is removed. The $\mathrm{CH}$ is placed on the heads of the spikes so that the central stud sits on top of the central spike and the two equal outer studs sit on top of the two outer spikes. The threaded stud is adjusted until contact is made with the other spike as shown in Figure 3.2 .

\subsection{Characteristics of the Prototype Equipment}

Based on the above design, two sets of prototype equipment were manufactured at Purdue University Machine Shop. Figure 3.14 shows a complete set of TDR prototype equipment. Figure 3.15 is a qualitative representation of the waveform produced by the prototype equipment and the corresponding idealized waveform. For an ideal material, the dielectric properties of the material do not generate energy losses during wave transmission (non-lossy), and all the propagation parameters are independent of frequency (non-dispersive). However, soil is not an ideal material. Significant energy losses do occur during wave transmission and the transmission velocity is frequency dependent. Therefore, soil is both lossy and dispersive. A lossy material is one in which the wave amplitude attenuates and the 
phase changes during transmission. A dispersive material is one where the wave velocity, reflection coefficient, and transmission coefficient are functions of frequency.

Discontinuities in impedance occur: at the connection of the coaxial cable and the $\mathrm{CH}$, inside the $\mathrm{CH}$, at the top of the soil surface, and at the end of the CC or MRP. The goal of waveform analysis is to find the reflection points that occur at the top of the soil surface (Point 1), and at the end of the CC or MRP (Point 2). The analysis requires a procedure that approximates an ideal TDR waveform from a measured waveform with dispersion. Different transmission line systems produce different waveforms and may require different interpretation. For the proposed TDR system, a set of tests has been conducted to verify the first and second reflection points. Soil samples were compacted in the CC mold up to different levels. The results are shown in Figure 3.16. The measured waveforms are rounded by dispersion, but it can be concluded from the figures that the first reflection point is at the peak of the waveform right before it starts to drop. The second reflection point will be around the portion of the waveform where it starts to rise to the steady state. Since what we measure in the TDR system is a result of dispersion, the first and second points are apparent reflection points. Topp et. al. (1982) define these points by the intersection of tangent lines, as shown in Figure 3.17 The waveform interpretation will be discussion in more detail in the next chapter. 


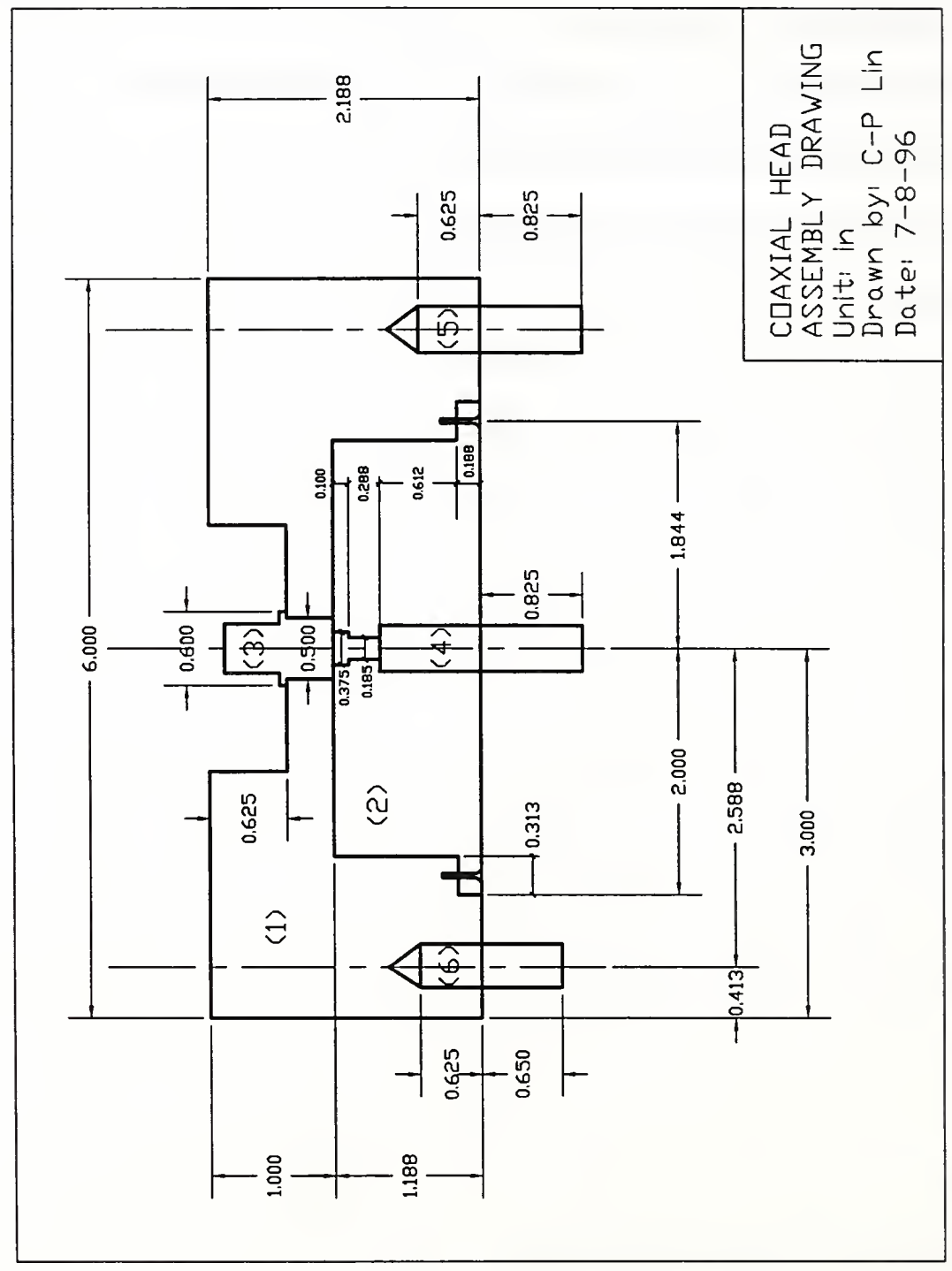

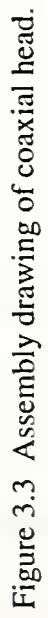




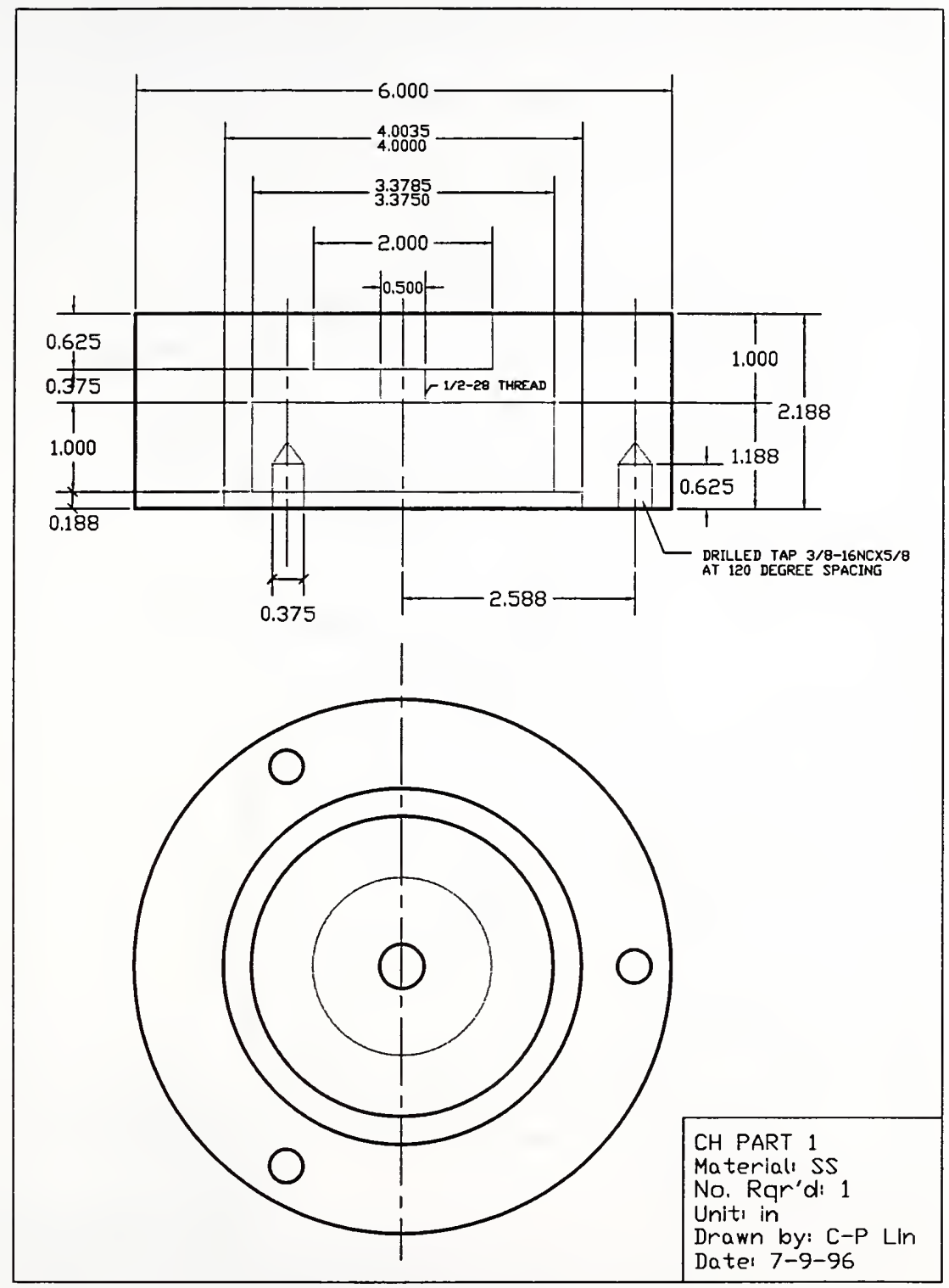

Figure 3.4 Design drawing of $\mathrm{CH}$ (part 1). 

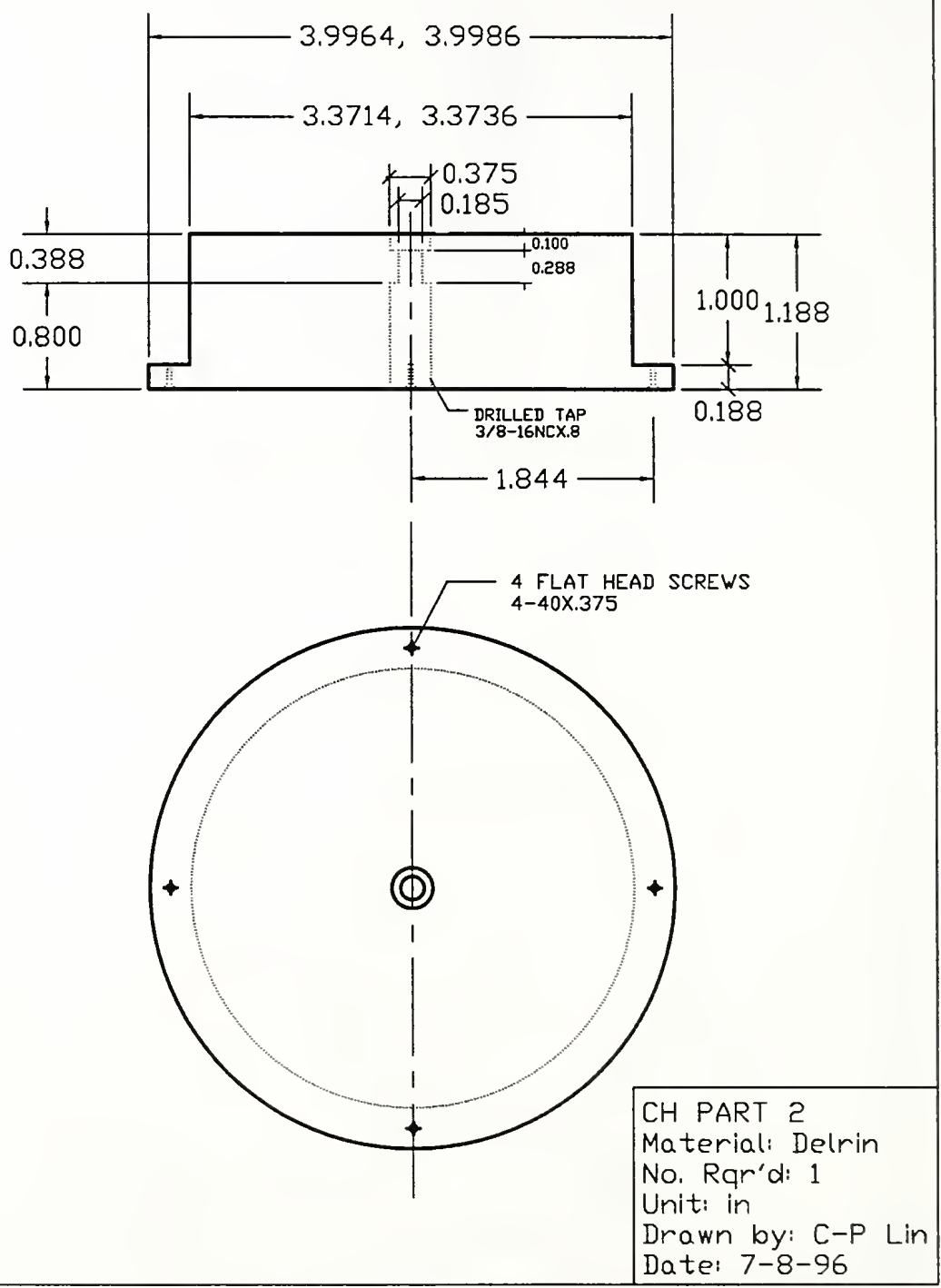

Figure 3.5 Design drawing of $\mathrm{CH}$ (part 2). 


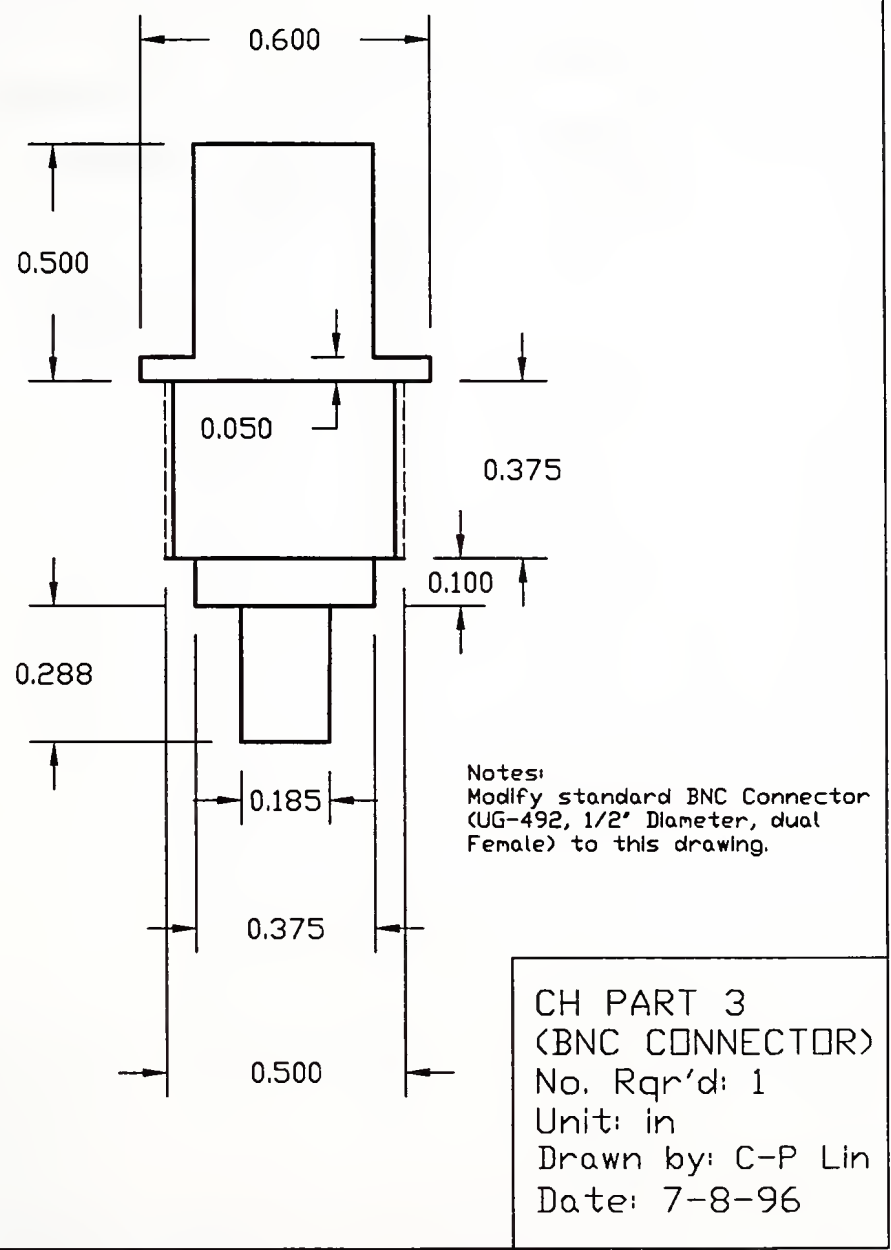

Figure 3.6 Design drawing of $\mathrm{CH}$ (part 3). 


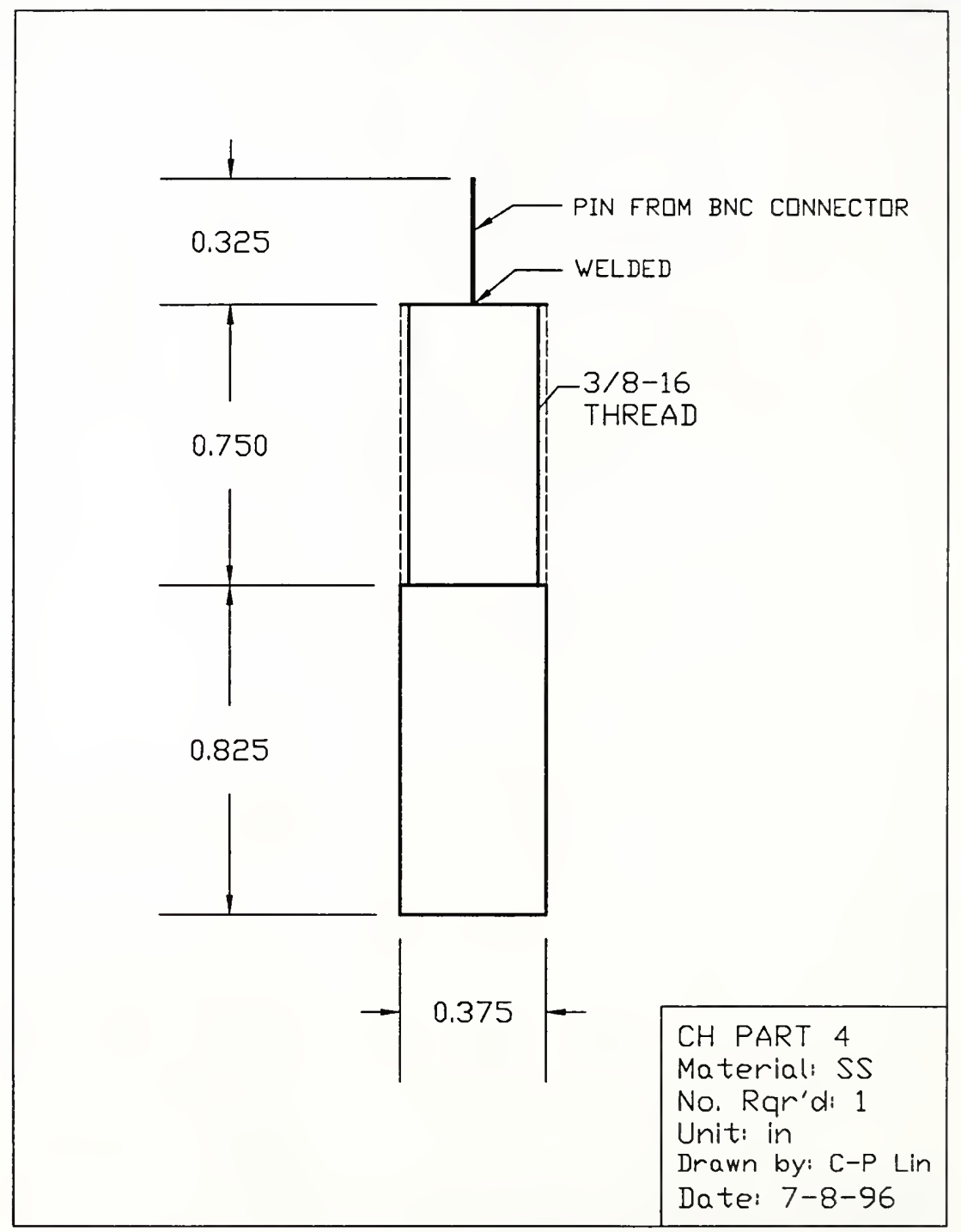

Figure 3.7 Design drawing of $\mathrm{CH}$ (part 4). 


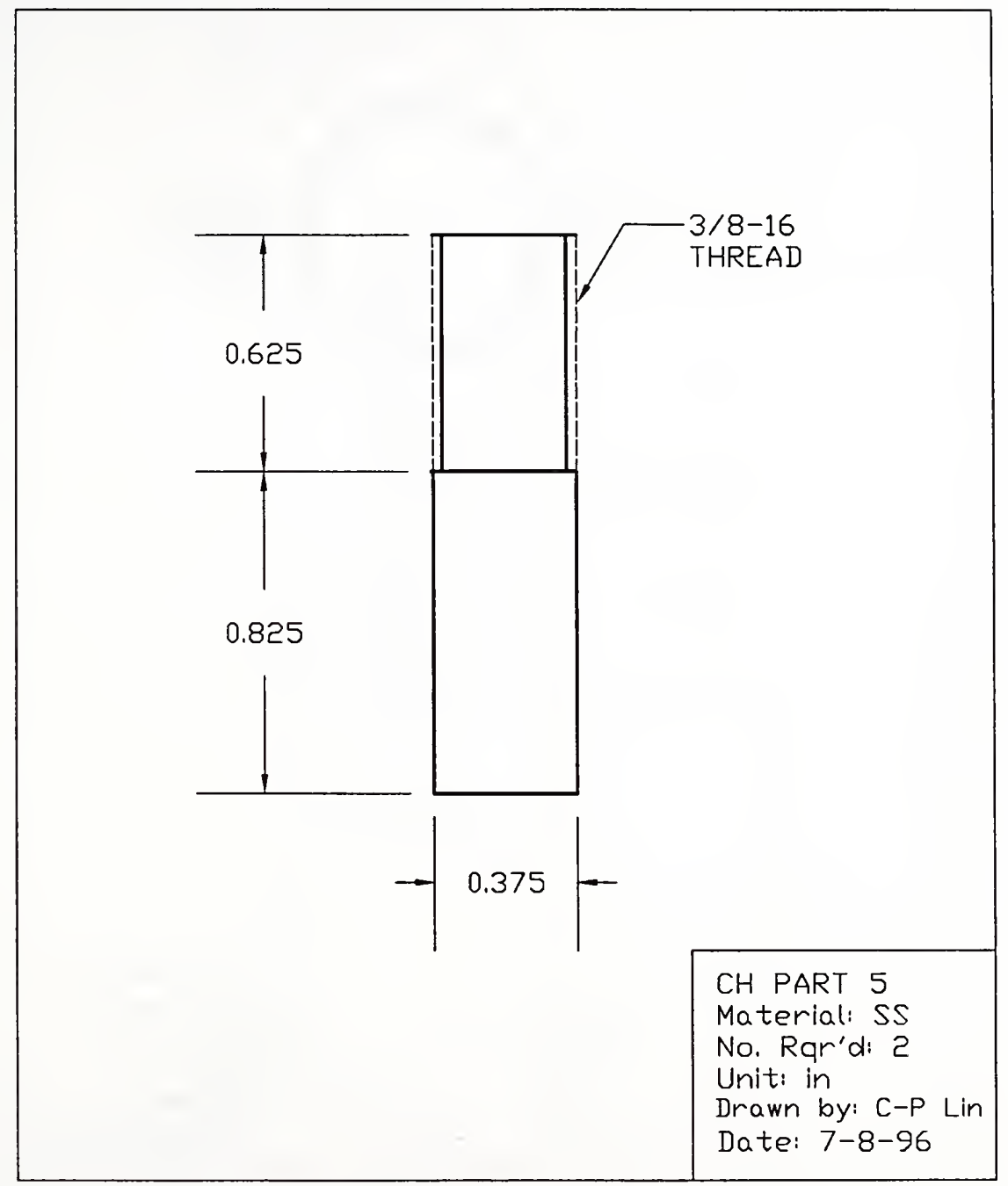

Figure 3.8 Design drawing of $\mathrm{CH}$ (part 5). 


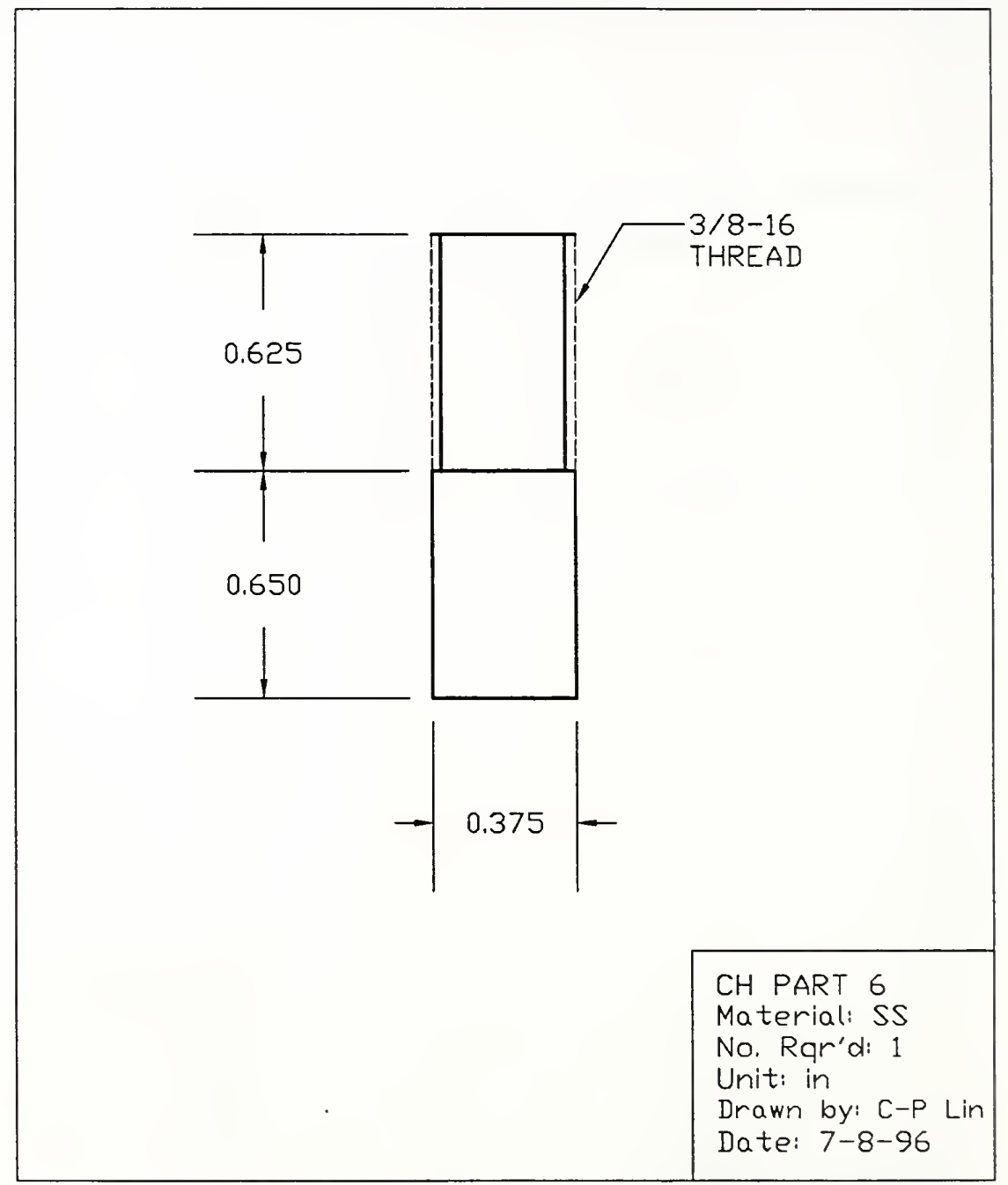

Figure 3.9 Design drawing of $\mathrm{CH}$ (part 6). 


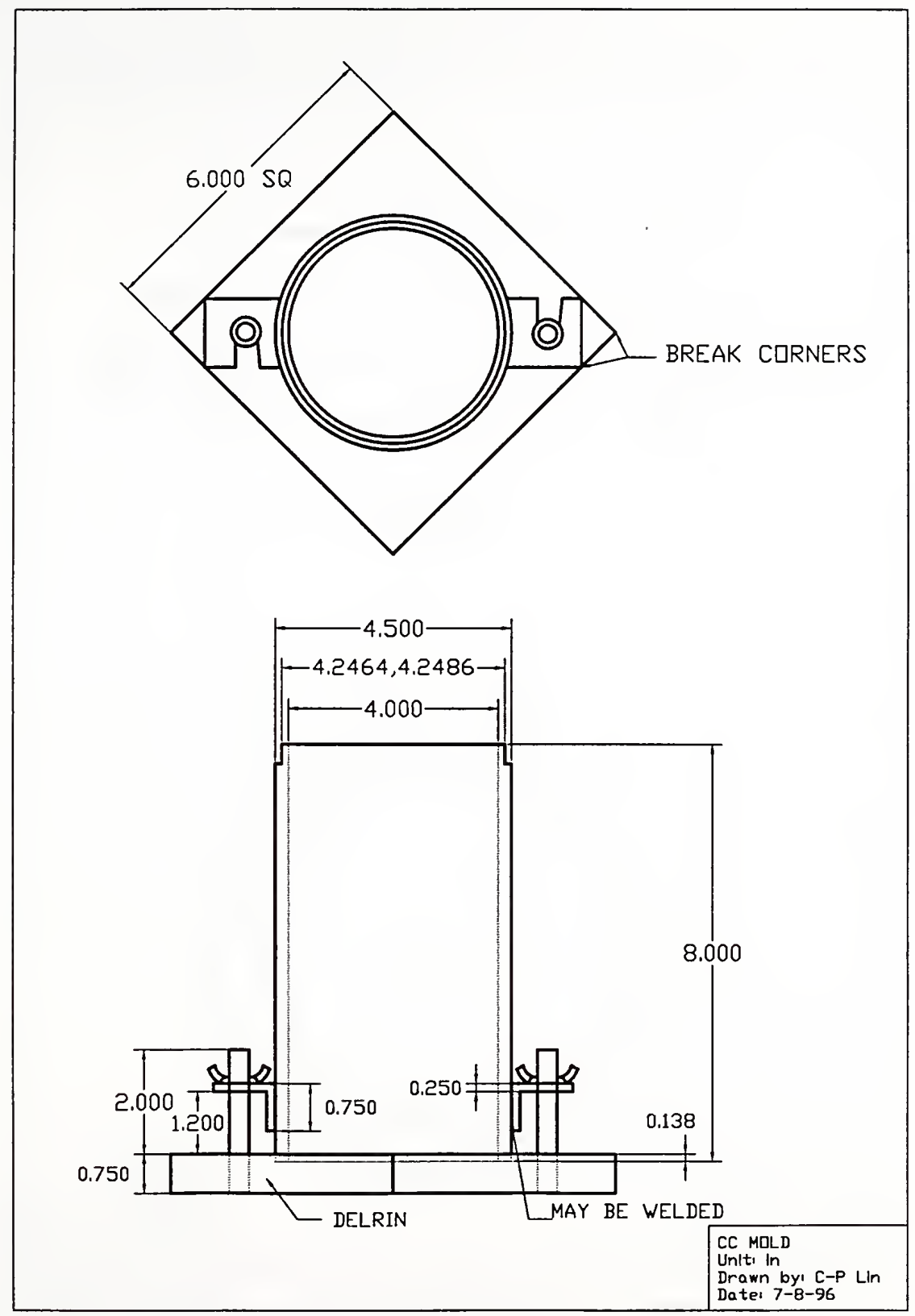

Figure 3.10 Design drawing of CC mold. 

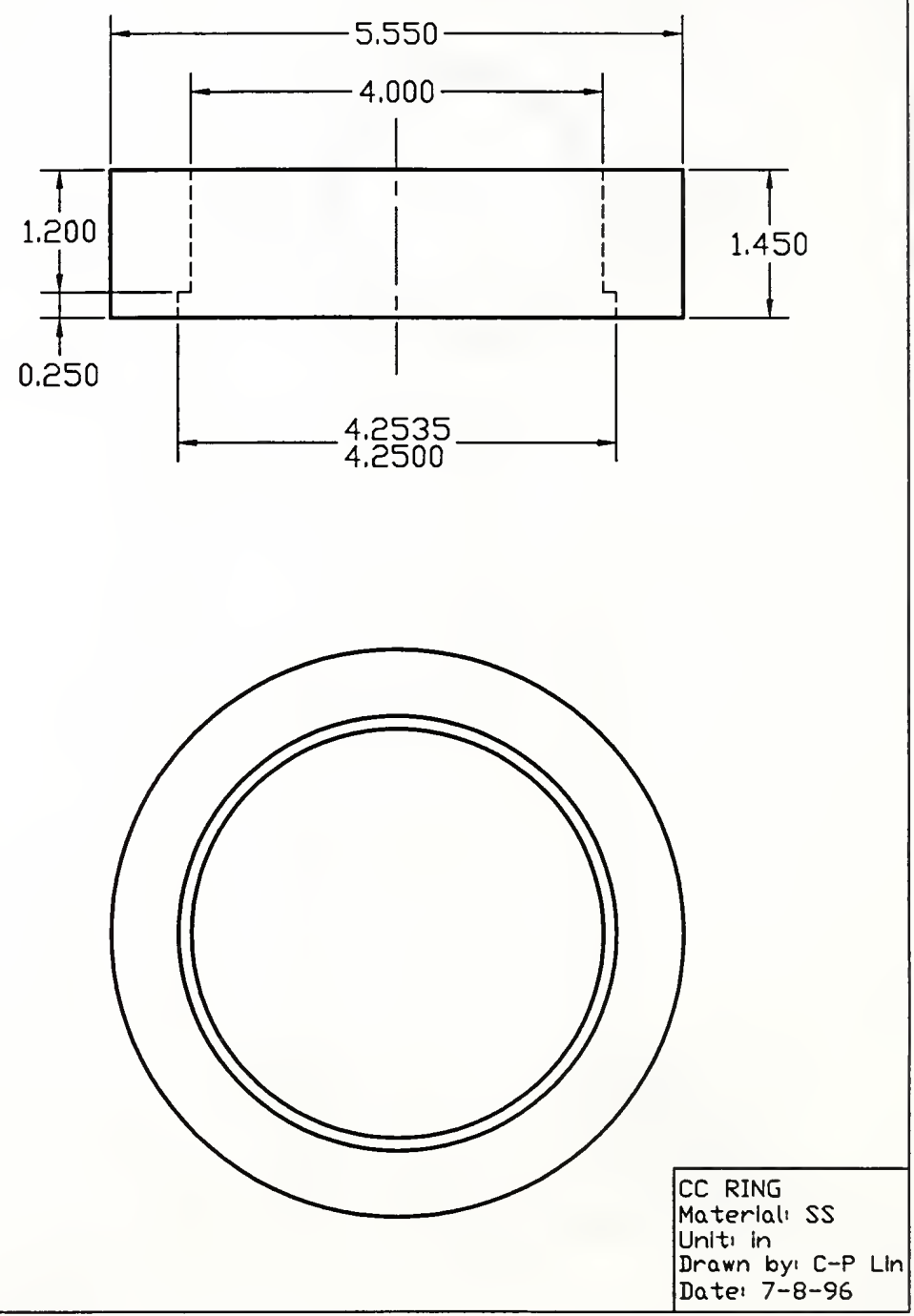

Figure 3.11 Design drawing of CC ring. 

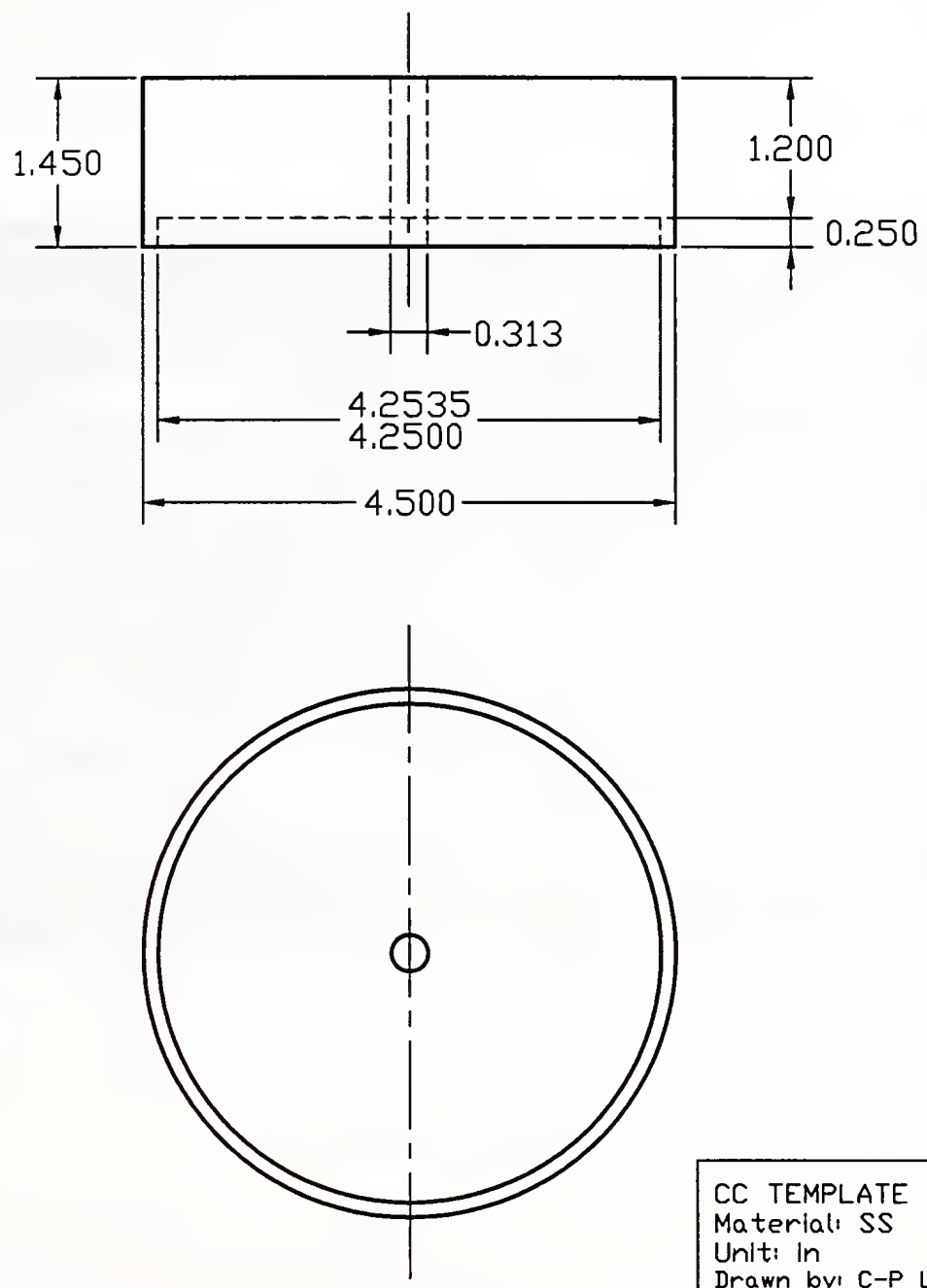

CC TEMPLATE Materiali SS Unit: In Drawn byi C-P Lin Datel 7-8-96

Figure 3.12 Design drawing of CC guide template. 


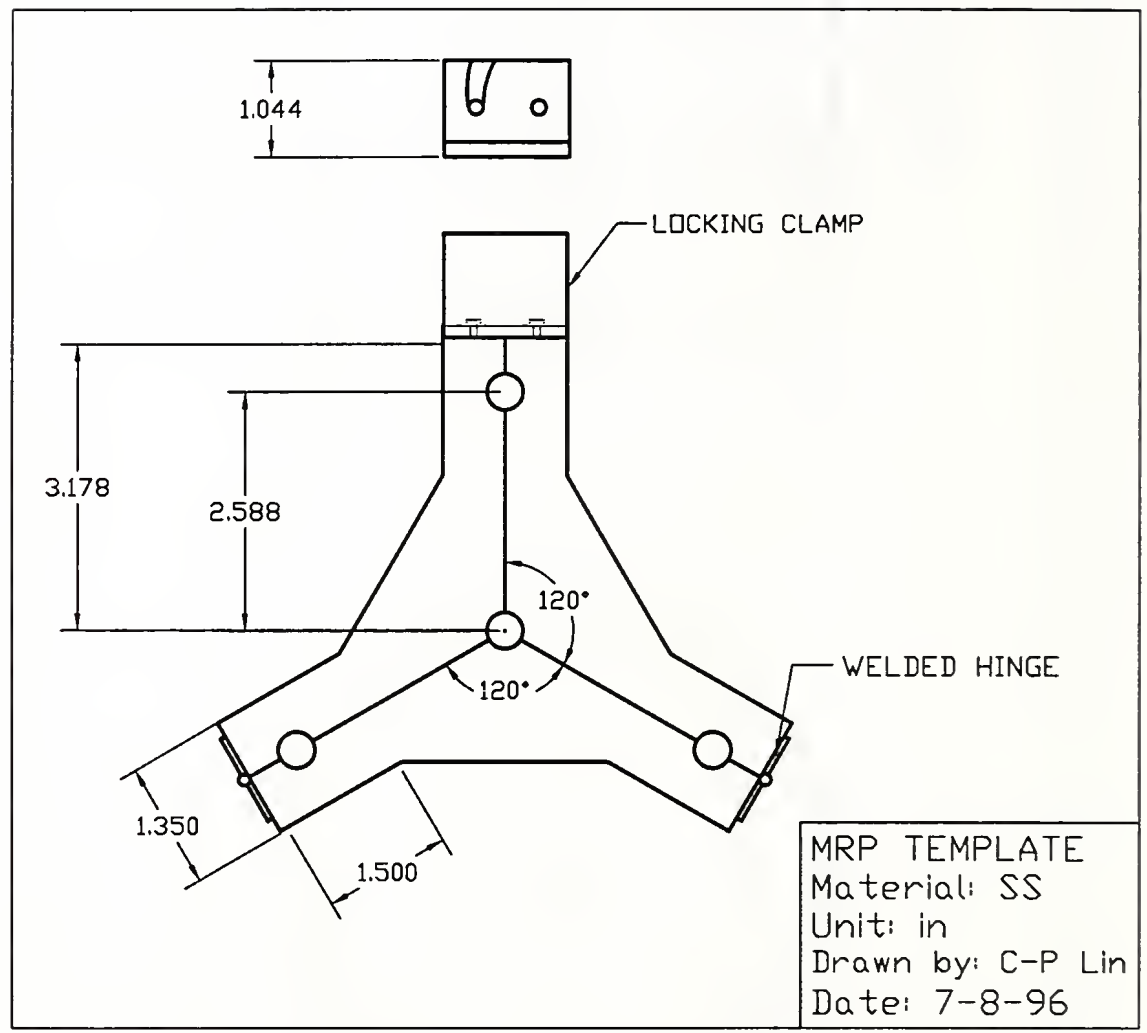

Figure 3.13 Design drawing of MRP guide template 


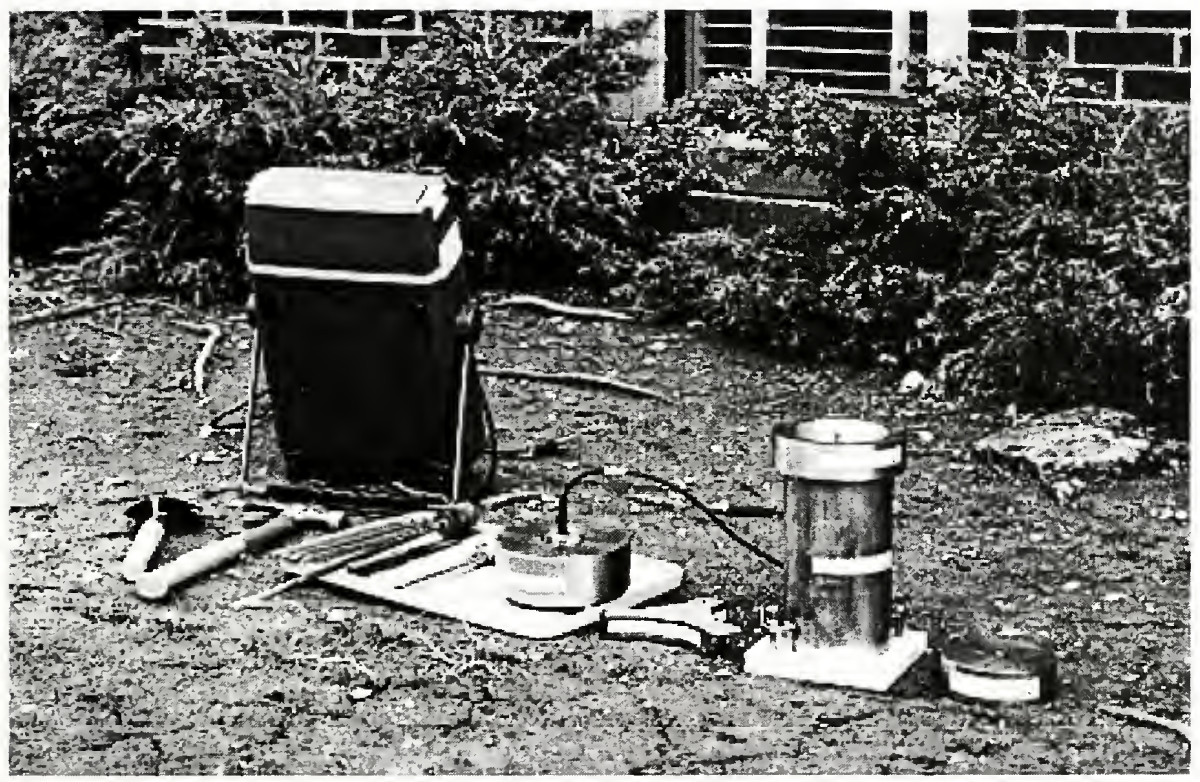

Figure 3.14 A set of TDR prototype equipment 

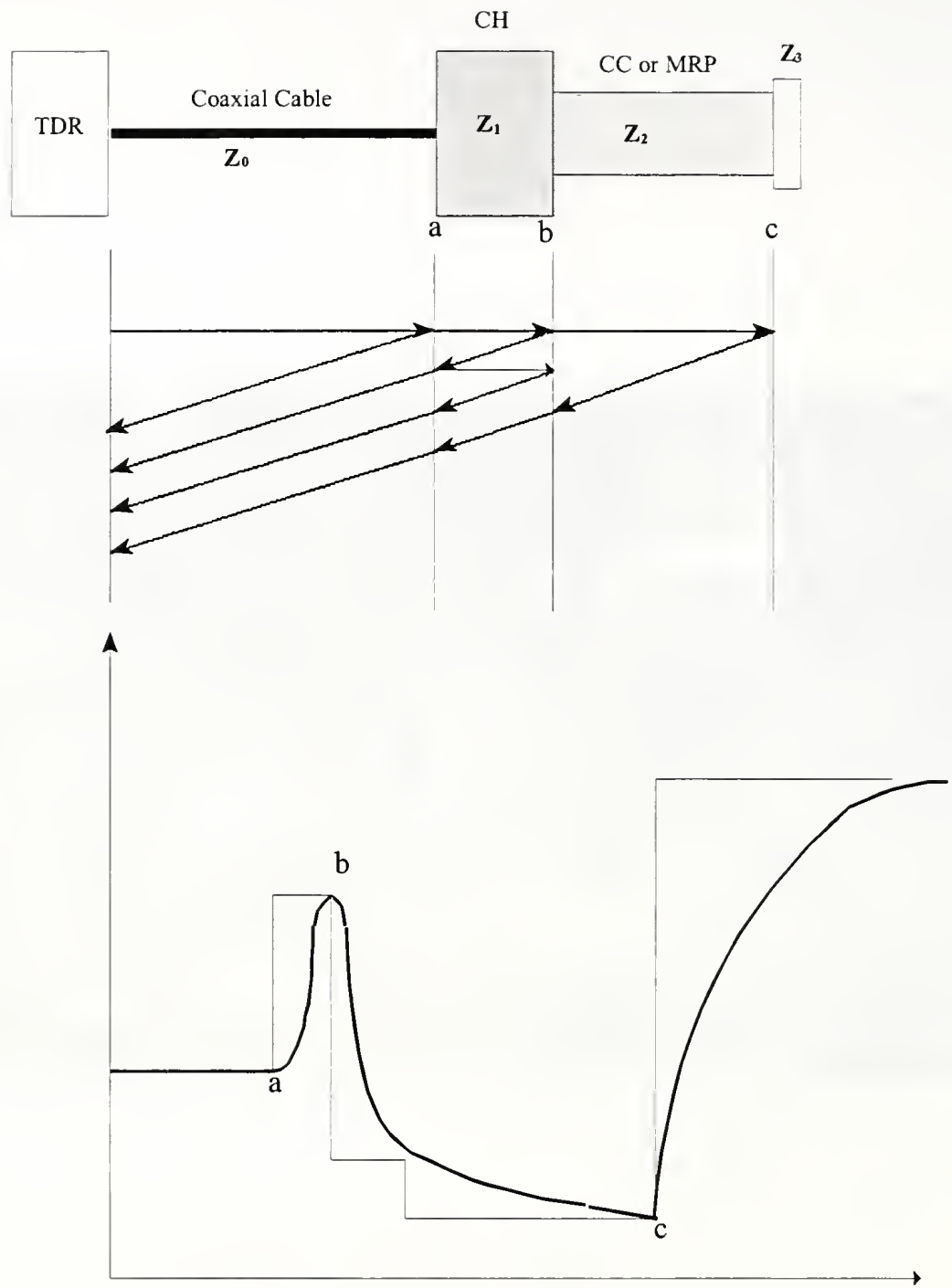

Figure 3.15 Idealized and actual TDR waveforms 


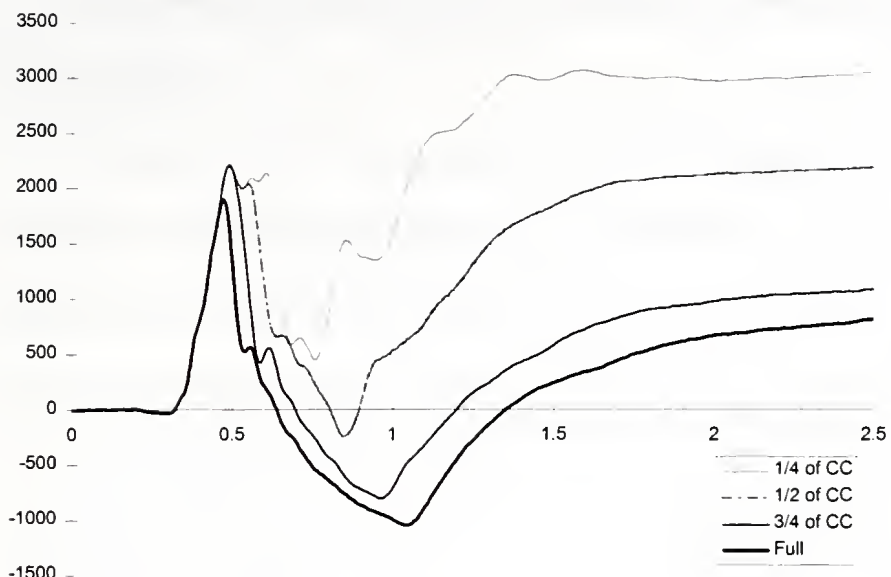

$-1500$

Figure 3.16 TDR waveforms of soil in CC filled up to different level.

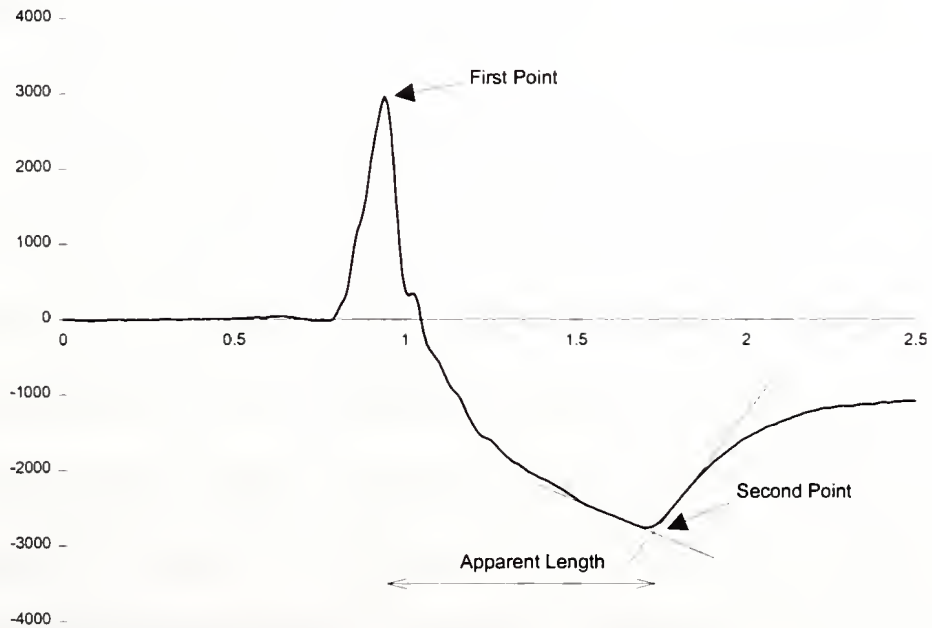

Figure 3.17 Interpretation of TDR waveform by tangent lines. 


\section{CHAPTER 4}

\section{AUTOMATING THE INTERPRETATION OF THE TDR WAVEFORM}

\subsection{Introduction}

The apparent dielectric constant $\left(\mathrm{K}_{\mathfrak{\jmath}}\right)$ is the key parameter used in this study for the interpretation of water content and density of compacted soils. As discussed in Chapter 2, $\mathrm{K}_{\mathrm{a}}$ is obtained from the square of the ratio of apparent length $\left(l_{a}\right)$ to probe length $(L)$. The probe length can be measured directly while the apparent length is interpreted from the distance between two specific points on the reflected waveform. It was noted that a major source of error in the data interpretation is associated with the determination of $l_{2}$.

The apparent length $\left(l_{\mathrm{a}}\right)$ is determined from a TDR trace. Variation in soil type, water content and density will lead to different waveforms. Due to the dispersion of electromagnetic waves along the TDR probe, the desired reflection points are not always distinct and are often somewhat rounded. Interpretation of the apparent length manually can therefore be operator dependent.

A primary objective of the present study was to automate the data interpretation process so that results would be independent of the operator. To accomplish this, an algorithm was developed and coded in a computer program to obtain the apparent length directly from the data. The required algorithm must produce consistent readings and have the capacity to handle variations in waveform shapes. In addition, the algorithm should be able to recognize poor data and warn the operator that the test should be repeated. Development of an algorithm with these features proved to be very challenging. Several algorithms were tried but abandoned when one or more of the desired characteristics could not be met. The 
proposed algorithm has been evaluated on over 100 different TDR waveforms and more than 10 soil types and has performed satisfactorily on all cases tested.

\subsection{Interpretation of the TDR Waveform}

TDR waveforms are traces of reflected signals recorded by an oscilloscope that is incorporated into the TDR apparatus. A typical TDR waveform is shown in Figure 4.1. On the oscilloscope display, the vertical direction represents voltage and the horizontal direction represents time. The horizontal axis can be transformed from time to distance by multiplying the time readings by a user-defined velocity of propagation $\left(\mathrm{V}_{\mathrm{p}}\right)$. Accordingly, the cursor can be moved along the TDR waveform to obtain distance readings.

An understanding of the nature of the TDR waveform aids in the interpretation of the apparent length. The source of a TDR signal is a step pulse, which consists of a wide range of frequency components. All frequency components travel at the same initial velocity in the coaxial line but at different velocities in the soil because soil is a dispersive material. Moreover, the wave amplitudes are diminished in the soil because it is a lossy material. When the traveling waves reach a change in impedance a portion of the wave is reflected. The relative energy of the reflected to transmitted wave is frequency dependent. Changes in impedance occur at the head, at the upper soil surface and at the end of the MRP or CC as discussed in Chapter 3.

The first important reflection point is generated at the upper soil interface (Point 1 , Figure 4.1). This point is distinct and easy to read because the waves that travel to, and are reflected by, this interface travel at the same velocity, i.e. very little dispersion occurs. The second important reflection point is associated with the end of the MRP or CC. This point is 
less distinct (Point 2, Figure 4.1) because the soil is dispersive so that waves of different frequency travel at different velocity, and therefore, have different arrival times back at the oscilloscope. Identification of the second reference point can be made visually by an experienced operator or by using a specific procedure.

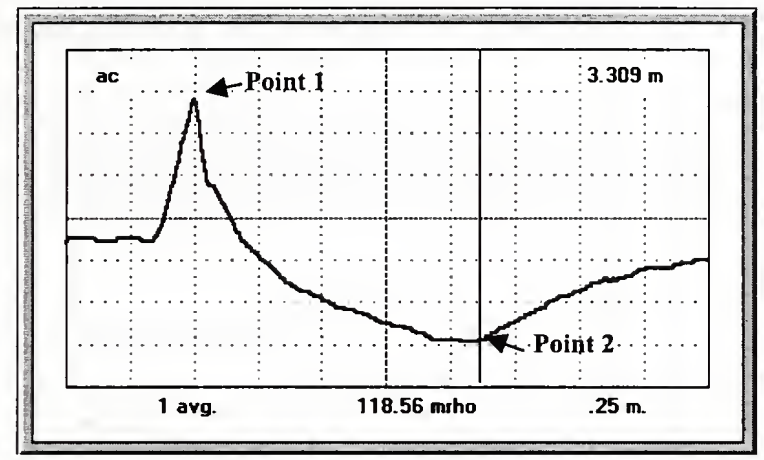

Figure 4.1 A typical TDR waveform

Two methods to identify the second point are shown in Figure 4.2a and 4.2b. They are both "tangent line" methods, but with different schemes. The first method (Topp et al.,1982) is shown in Figure 4.2a. The second reflection point (A2) is located at the intersection of the two lines drawn tangent to the curve at the positions shown. The second scheme was proposed by Baker and Allmaras (1990). A line parallel to the horizontal axis is drawn tangent to the smoothed trace at a local minimum. A second tangent is placed at the point of the maximum first derivative following the local minimum. The intersection of this line with the horizontal line is Point A2.

Both of these published methods are based on the assumption that the reflected signal has a linear rising shape. This is true for most cases, but it is often difficult to determine the 
slope of the tangent line. The second method appears less arbitrary because the horizontal line passing through the local minimum, but there still is difficulty in the interpretation of the second tangent line. Moreover, with the variety of reflected waveforms encountered these methods are not always applicable. The desired method must be able to interpret the extreme cases consistently.

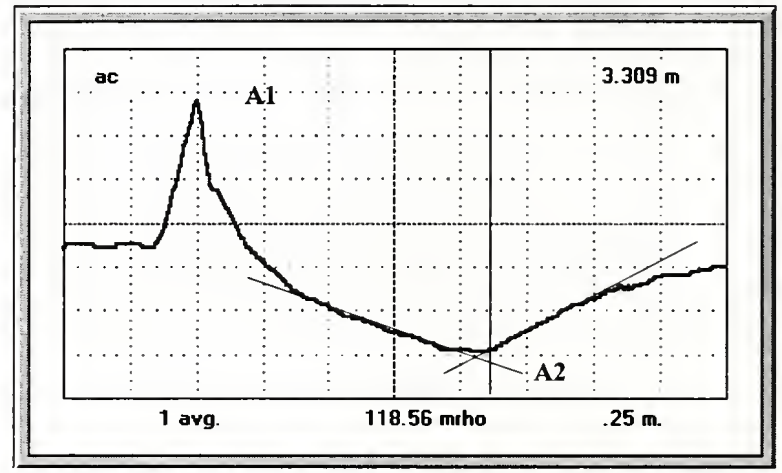

(a)

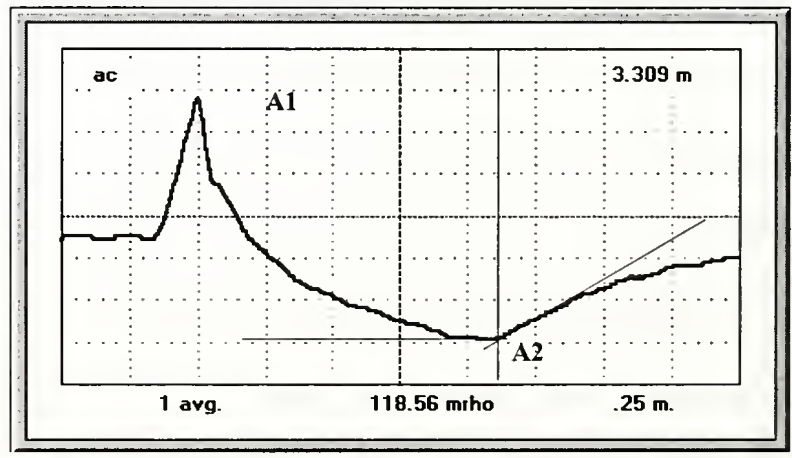

(b)

Figure 4.2 Two methods to determine the first and second reflection point. 
Figure 4.3 shows six traces with different shapes: a) from a field test of clayey soil, b) and c) from field tests on two different sandy soils, d) from a lab test of saturated sand, e) from concrete, and $f$ ) from tap water. The potential varieties of waveforms that may be encountered are evident from these six cases. The desired algorithm for use in TDR data interpretation needs to work for wide range of possible cases and be consistent with interpretations made by an experienced operator. In addition, it is desirable for the algorithm to be able to identify abnormal or spurious results to alert the operator.

\subsection{Algorithm to Read the TDR Waveform}

The proposed algorithm uses the following information: the original waveform data; a "smoothed" waveform; and the first and second derivatives of the smoothed waveform. Figure 4.4a shows an original waveform. Figure $4.4 \mathrm{~b}, 4.4 \mathrm{c}$ and $4.4 \mathrm{~d}$ illustrate the smoothed waveform, and the first and second derivative of the smoothed waveform, respectively. The smoothed line is obtained using a seven point sliding average scheme, while the derivatives are obtained using a three point center difference method, as described in Equation 4.1 and 4.2.

$$
V_{s}(i)=\frac{1}{7} \sum_{j=i-3}^{j=i+3} V(j) \text { for } 4 \leq \mathrm{j} \leq \mathrm{N}-3
$$

No Change at ends where $1 \leq \mathrm{j} \leq 3$ or $\mathrm{N}-3 \leq \mathrm{j} \leq \mathrm{N}$

where:

$$
\begin{aligned}
& V(j)=\text { voltage reading at Point } \mathrm{j} \\
& V_{S}(i)=\text { smoothed voltage at Point } \mathrm{i} \\
& \mathrm{N}=\text { number of data points ( } 251 \text { for the Tektronix device) }
\end{aligned}
$$




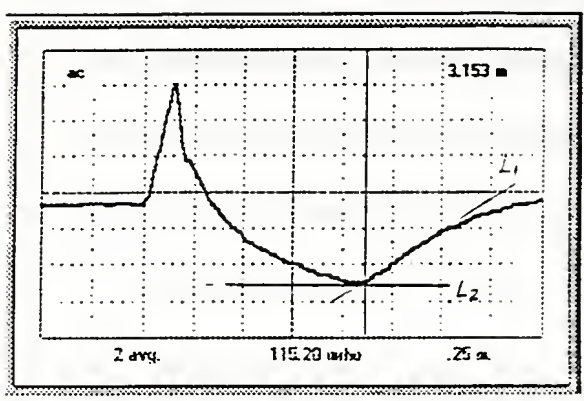

(a)

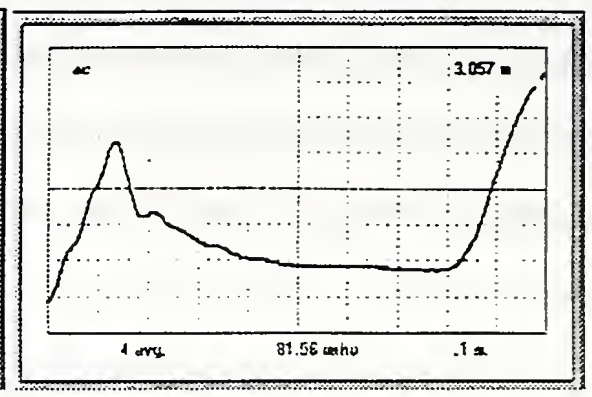

(b)

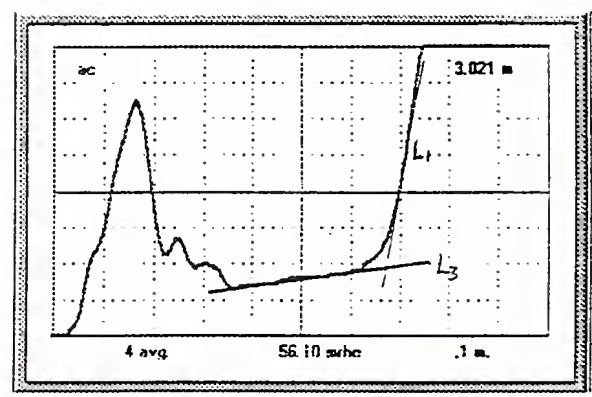

(c)

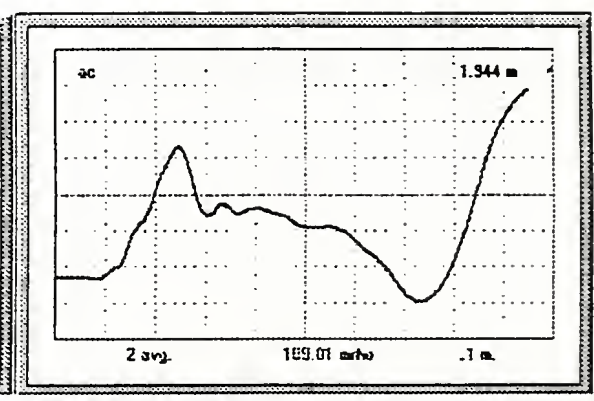

(d)

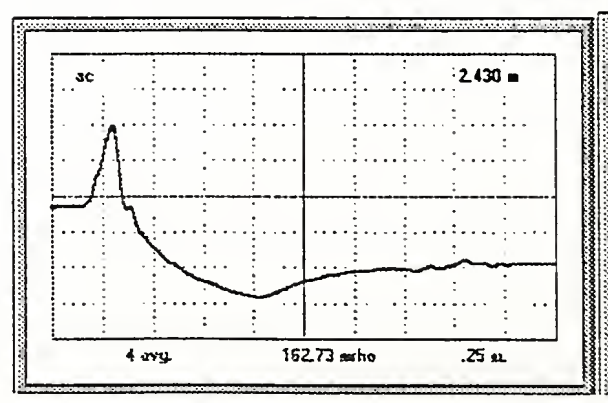

(e)

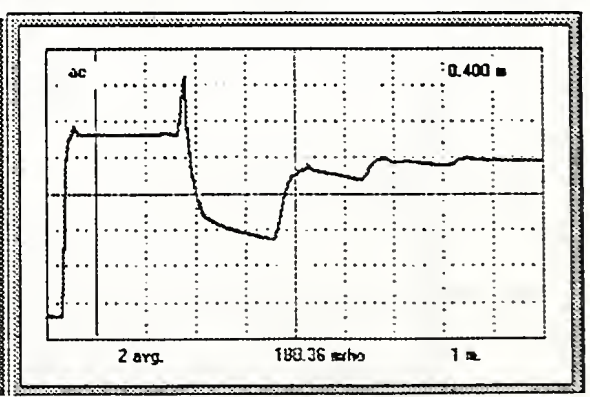

(f)

Figure 4.3 Different TDR waveforms 


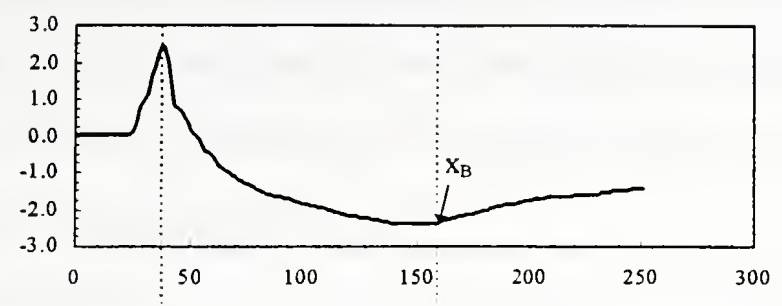

a) The original TDR curve

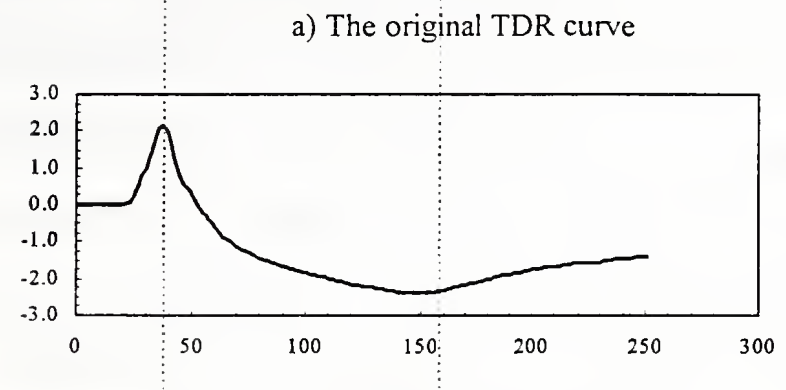

b) The smoothed TDR curve
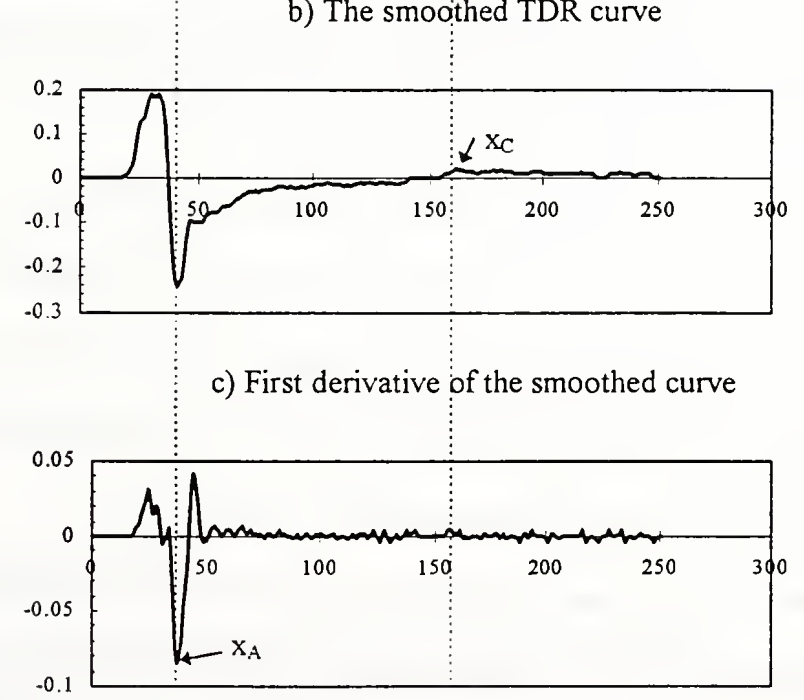

d) Second derivative of the smoothed curve

Figure 4.4 a)An original TDR waveform; b) A smoothed TDR waveform; c) The first derivative of the smoothed waveform; d) The second derivative of the smoothed waveform 


$$
\begin{aligned}
& d V_{s}(i)=\left(V_{s}(i+1)-V_{s}(i-1)\right) / 2 ; 2 \leq \mathrm{i} \leq \mathrm{N}-1 \\
& d V_{s}(1)=V_{s}(2)-V_{s}(1) \\
& d V_{s}(N)=V_{s}(N)-V_{s}(N-1)
\end{aligned}
$$

The objective is to locate the horizontal value (a number between 1 and 251 for this apparatus) of the first and the second reflection points labeled Point 1 and Point 2 in Figure 4.5. A scaling function relates the location number of each horizontal point to a distance measured in meters or feet. The first reflection point is a local maximum so the first derivative is close to zero, and has maximum curvature so the second derivative is a minimum. The search for the first reflection point, $\mathrm{x}_{1}$, was implemented as follows:

1. Locate the point with the minimum second derivative $\left(\mathrm{x}_{\mathrm{A}}, \mathrm{y}^{\prime \prime}{ }_{\min }\right)$ (Fig. 4.4d).

2. Locate the point of minimum voltage beyond $x_{A}\left(x_{B}, y_{\min }\right)$ (Fig. 4.4a), if there are more than one minimum with the same value, pick the rightmost point;

3. Locate the position, $x_{1}$, which has the maximum value of voltage between the origin and $x_{B}$ (Fig. 4.4a). If there are more than one equal maximum values, take the average $x$ value as $x_{1}$. If the distance between equal maximum values is greater than 5 screen points, then the waveform is of poor quality and should not be used because the waveform peak should be very sharp for all cases. The first reflection point, Point 1 , is taken to be $x_{1}$.

The determination of the second reflection point is more difficult because it is less distinct and a significant variation in waveform shape is possible. The procedure for searching for the second point, Point 2 , is as follows:

1. Locate the point with the minimum second derivative $\left(\mathrm{x}_{\mathrm{A}}, \mathrm{y}_{\text {min }}\right)$ (Fig $\left.4.4 \mathrm{~d}\right)$. 
2. Locate the point of minimum voltage beyond $x_{A}\left(x_{B}, y_{\min }\right)$ (Fig. 4.4a), if there are more than one minimum with the same value, pick the rightmost point;

3. Locate the position of the maximum first derivative beyond $x_{B},\left(x_{C}, y^{\prime}{ }_{\max }\right)$. Choose the leftmost point if more than one value exists.

4. Define three lines, one though $x_{C}$ with a slope equal to the first derivative $\left(L_{1}\right)$ (Fig. 4.3a), the second a horizontal line through $\mathrm{x}_{\mathrm{B}}\left(\mathrm{L}_{2}\right)$ (Fig. 4.3a), and the third a best fit line through the approximately linear portion beyond $\mathrm{x}_{\mathrm{B}}\left(\mathrm{L}_{3}\right)$ (Fig. 4.3c)

5. Point $x_{2}$ is located at the intersection of $L_{1}$ and $L_{2}$. For an ideal waveform $x_{B}$ and $x_{2}$ would be the same and would represent Point 2. However, for most real curves, Point 2 is located between $x_{B}$ and $x_{2}$ such that the position of Point 2 must be further interpolated.

6. Three ratios and an algorithm are used to locate Points 2 between $x_{B}$ and $x_{2}$ (see Figure 4.5). This is necessary because of the wide variety of possible waveform shapes.

$$
\begin{aligned}
& r_{0}=\left(x_{2}-x_{B}\right) /\left(x_{B}-x_{1}\right) \\
& r_{1}=\left(x_{2}-x_{B}\right) /\left(x_{2}-x_{1}\right) \\
& r_{2}=\left(x_{B}-x_{1}\right) /\left(x_{2}-x_{1}\right) \\
& \text { IF } r_{0}<0 \text { Then (occurs only due to discretization errors) } \\
& \quad \text { Point } 2=x_{B}
\end{aligned}
$$

Else If $r_{0}<0.1$ then

$$
\text { Point } 2=\operatorname{Int}\left(\mathrm{r}_{1}^{*} \mathrm{x}_{\mathrm{B}}+\mathrm{r}_{2}{ }^{*} \mathrm{x}_{2}\right) \quad(\text { weighted average })
$$

Else

Point 2 is located at the intersection of lines $\mathrm{L}_{1}$ and $\mathrm{L}_{3}$, End If. 
Figure 4.5 shows a schematic of a TDR waveform and the locations of $x_{1}, x_{2}, x_{B}$ and $x_{C}$. The definition of the second reflection point (Point 2) is arbitrary. Two published methods (Topp et al., 1982 and Baker et al., 1990) were previously introduced and a slightly different method is proposed here. An alternative approach is introduced because the other methods could not satisfactorily define Point 2 for the wide variety of waveforms that may be encountered as shown in Figure 4.3. The proposed method produces estimates of Point 2 that are consistent with that of an experienced operator. The logic of the algorithm described previously is explained here.

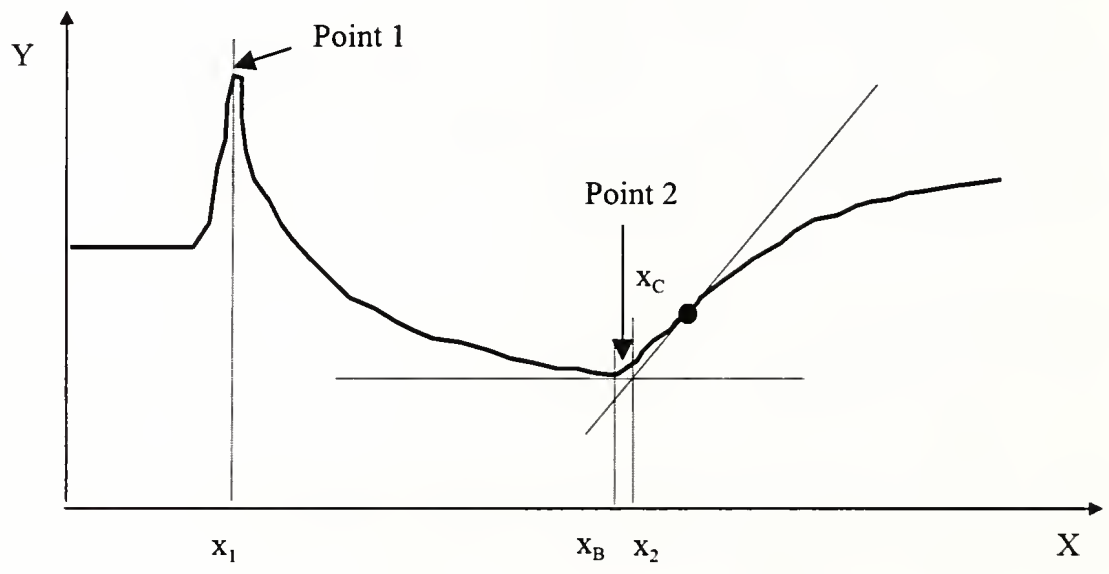

Figure 4.5 Illustration of Symbols in the Algorithm

Point 2 lies between $\mathrm{x}_{\mathrm{B}}$ and $\mathrm{x}_{2}$ (see Fig. 4.5) and the specific location depends on the shape of the trace after $x_{B} . r_{0}$ can only be less than zero when the distance between $x_{B}$ and $x_{2}$ is small and the discretization of the waveform, and the numerical differentiation, leads to $\mathrm{x}_{2}$ being slightly less than $x_{B}$. In this case Point 2 is taken as $x_{B}$. When the distance between $x_{B}$ 
and $x_{2}$ is relative small, $r_{0}$ less than 0.1 , a weighted average is used to determine Point 2 . The larger the value of $r_{0}$, the closer Point 2 will be to $x_{B}$. Finally, if the difference between $x_{B}$ and $\mathrm{x}_{2}$ is large, this indicates a waveform similar to that in Fig. 4.4c, and the intersection of lines $\mathrm{L}_{1}$ and $\mathrm{L}_{3}$ are used to define Point 2 .

The developed algorithm for reading Points 1 and 2 and the TDR waveform was used on the curves show in Figure 4.3 with the results show in Figure 4.6. The locations of Points 1 and 2 are all very close to the values that would be selected from manual readings by an experienced operator.

The criteria used to check if the curve displayed is a valid TDR waveform includes:

1. Horizontal position of Point $2>$ Horizontal position of Point 1;

2. Vertical value at Point $1>$ Vertical value at Point 2;

3. Horizontal position of Point $1>0$; Horizontal position of Point $2>1$ meter;

4. In determining $x_{1}$, the distance between equal maximum values should be less than 5 units.

Notice that these conditions are necessary for a TDR waveform, but not sufficient. Therefore, a non-TDR waveform curve that looks similar and satisfies these criteria will be read as a waveform. But after testing more than 100 waveforms and more than 20 nonwaveforms, no false waveforms were mistakenly interpreted.

\subsection{Comments on Waveform Interpretation}

The accuracy in reading the apparent length of the waveform will directly influence the interpreted dielectric constant and therefore the accuracy of the estimated water content and density. It should be clear from the previous discussion that the determination of the apparent 


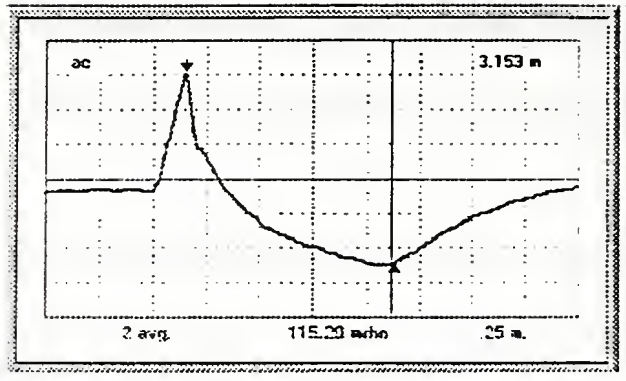

(a)

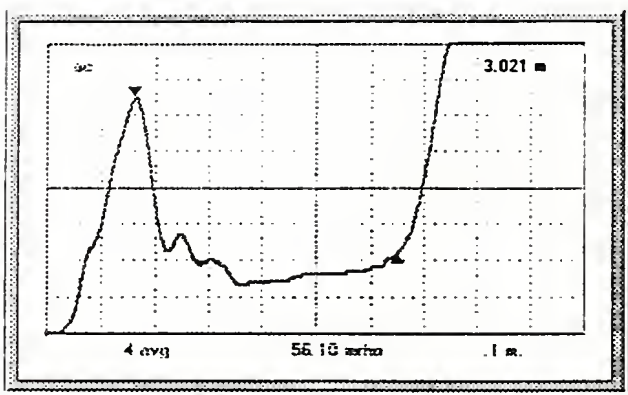

(c)

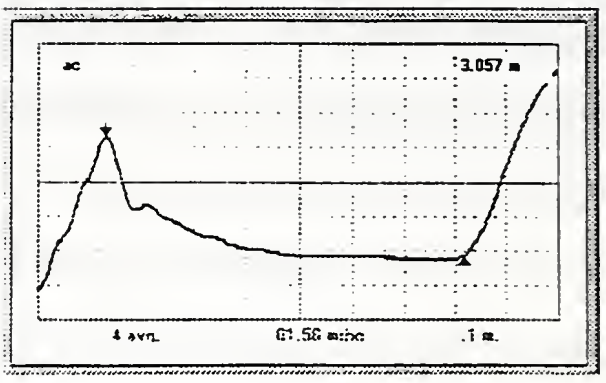

(b)

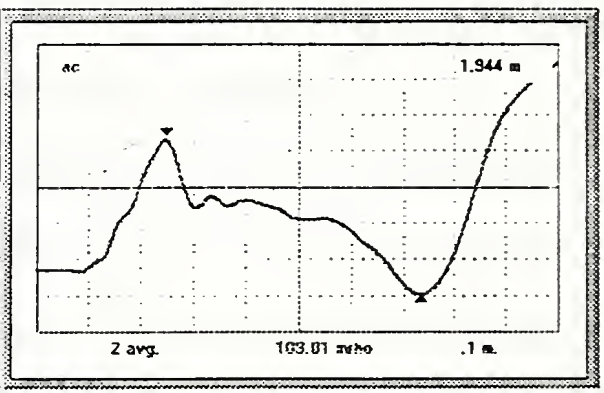

(d)

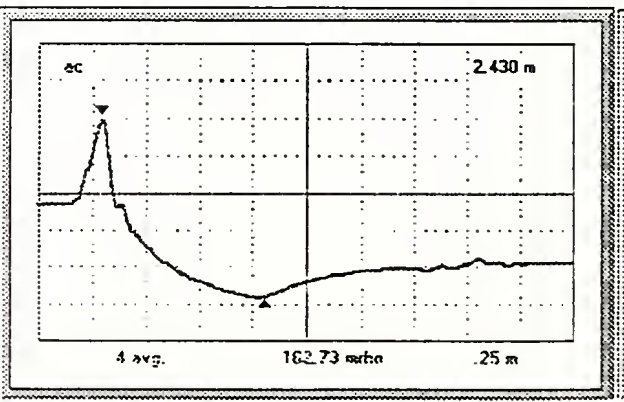

(e)

(f)

Figure 4.6 TDR readings for different traces using the algorithm in this chapter 
length is not exact. The proposed algorithm is believed to be capable of minimizing the errors of interpretation while being flexible enough to handle a wide range of waveform shapes. As additional data is gathered, the algorithm will require further verification to confirm applicability over the broad range in waveform shapes.

The developed algorithm is capable of taking readings for TDR traces with different horizontal scales as shown in Figure 4.6 where the scale is shown in the lower right corner of the traces. If a specific waveform is different using different horizontal scales, a different estimate of the apparent length will be obtained. For example, the apparent length is $0.688 \mathrm{~m}$ using a horizontal scale of $0.1 \mathrm{~m}$, and 0.70 using a horizontal scale of $1 \mathrm{~m}$. This difference occurs because the waveform is made up of only 251 data points. When a large scale is used, many of the data points are being used to describe the waveform outside the zone of interest, that is, outside the range of Point 1 to Point 2. This reduces the resolution of the data in the zone of interest, and therefore, decreases the accuracy of the measured apparent length. An algorithm is used to adjust the scale of the waveform to attempt to maximize resolution in the zone of interest; however, the Tektronix device used in this research can only increment the scale by factors of 2.5. This factor leaves limited flexibility for optimizing the waveform. 


\section{CHAPTER 5}

\section{AUTOMATION OF DATA REDUCTION AND THE TESTING PROCEDURE}

\subsection{Introduction}

The goals of this research program are to measure the water content and density of compacted soils using TDR. There are several steps involved in this procedure, including data acquisition, data interpretation, data reduction, and data reporting. A comprehensive software package was developed to handle these operations. The software has many functional features and was developed in a user-friendly Microsoft Windows ${ }^{\mathrm{TM}}$ environment. Features of the software include, data acquisition and interpretation, report generation, database management, and on-line help. The software was developed using Microsoft's Visual Basic ${ }^{\mathrm{TM}}$ because it is a user-friendly environment and has an object-oriented structure. Different toolboxes are conveniently available and can be customized for specific applications. The software also possesses a straightforward debugging and testing scheme.

The TDR apparatus used in this research (Tektronix 1502B Metallic Cable Test Apparatus) has an extended function module (SP232), which is a plug-in serial interface that acts as a DCE (Data Communications Equipment) device. The SP232 allows the user to control the apparatus by an external computer. This module enables automatic data acquisition and control of tests with the automation software.

\subsection{TDR+t: A Software Package for the Automation and Reduction of TDR Measurements}

TDR++ is the computer program developed for the automation and reduction of measurements of soil water content and density using TDR. The algorithms are based on the 
procedure developed during this and the previous study for measuring soil water content and density using TDR. They were outlined in Chapter 4.

The structure of TDR++ is shown in Figure 5.1. The main functionality of this program includes 1) Data acquisition and apparatus adjustment; 2) Data file manipulation; 3) Signal displaying and note editing; 4) Data interpretation and reduction; 5) Test reporting; 6) Database management; and 7) On-line help.

TDR++ provides a graphic user interface to ease operation. The main form of TDR++ is shown in Figure 5.2. It contains a menu bar, a picture box on the left, a text box on the right, a tool bar, and two miscellaneous bars at the bottom. The user can send commands either by clicking a mouse, or pressing the keyboard.

Tek 1502B

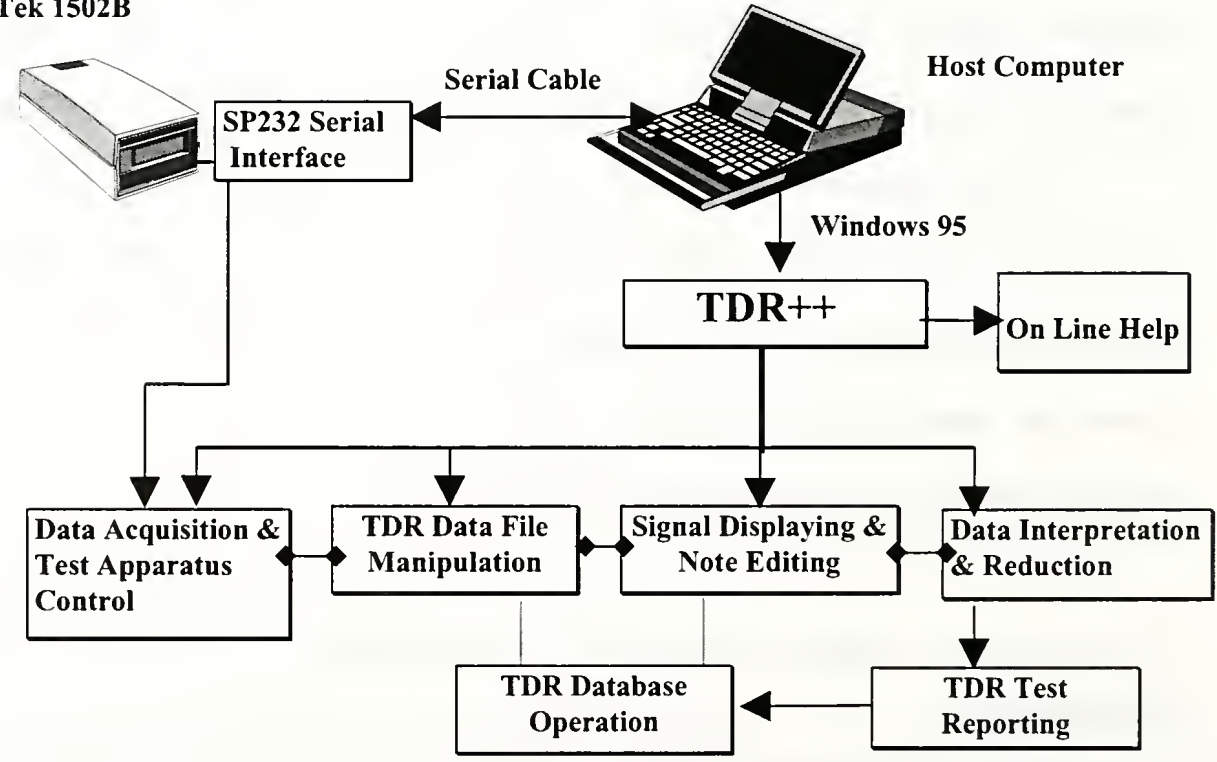

Figure 5.1 The Structure and Functionality of TDR++ 


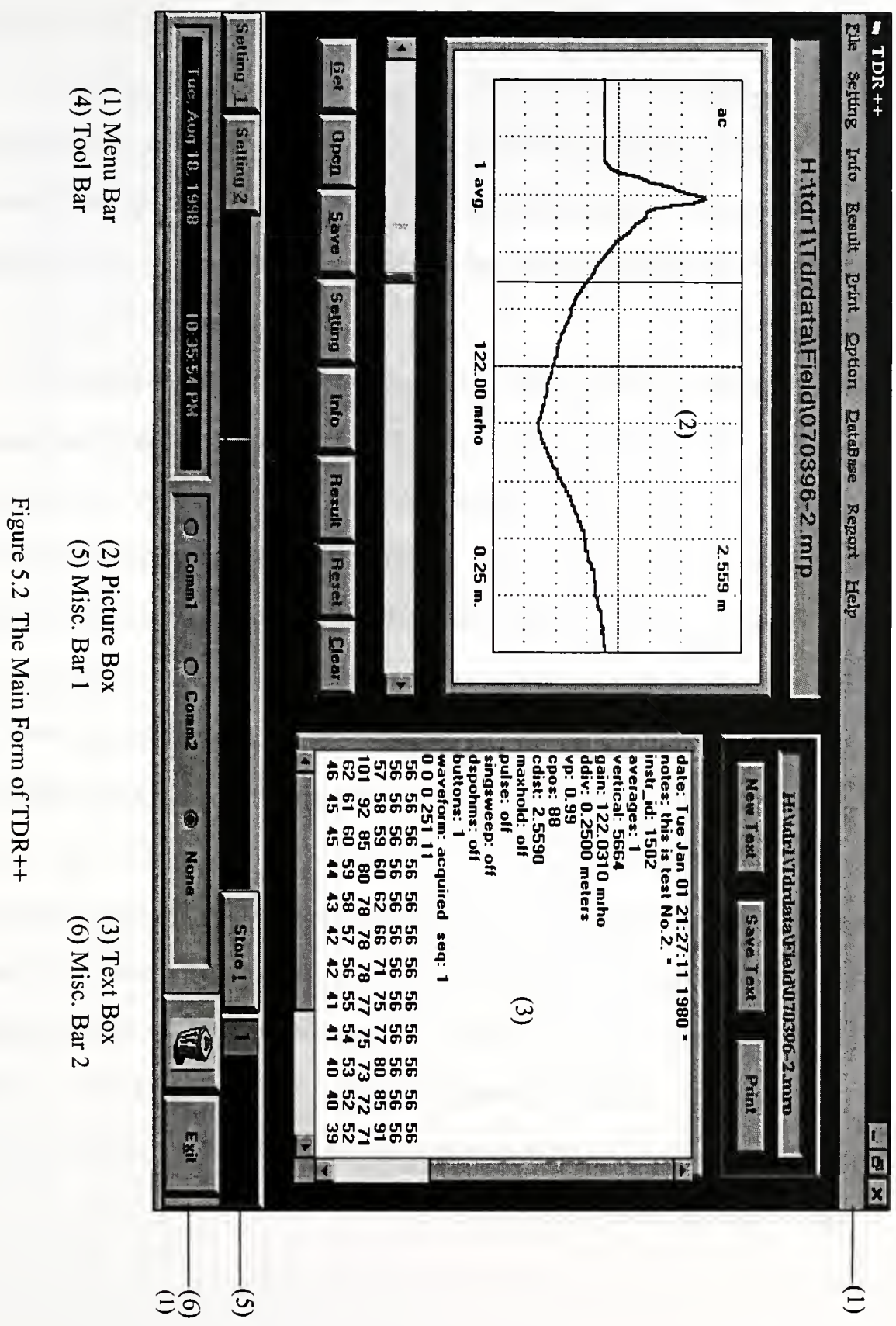




\subsubsection{Data Acquisition and Test Apparatus Adjustment}

\section{Data Acquisition}

TDR++ enables the user to obtain TDR test data from the apparatus (Tektronix 1502B) via an RS232 serial interface (SP232). The user can receive TDR waveform test data by clicking the [Get] button on the tool bar. The time of the acquisition is recorded for test reporting purposes.

A TDR waveform is limited to 251 data points. Although the vertical scale displaying voltage can be divided into either 128 or 8192 increments, 8192 increments are used as default. It takes about 20 seconds to retrieve a TDR waveform. While the data acquisition is underway, TDR++ locks out other processes and displays a message. After the data acquisition is complete, the waveform is displayed in the picture box with the horizontal scale (distance per division), vertical scale (decibels or millirho), filter, and cursor. The file name label displays "New File" to identify that new data is present and has not been saved. If data acquisition is interrupted for any reason an error message is display indicating that the acquisition was unsuccessful.

A connection indicator is included on the bottom tool bar and shows which serial port of the host computer is currently being used. Every ten seconds a connection check is run to examine the serial connection between the host computer and the SP232 module of the Tektronix 1502B. When no connection exists, the indictor shows "None", and all the commands involving serial communication will be disabled. Therefore, the user knows the status of connection every ten seconds. 


\section{Test Apparatus Adjustment}

Apparatus adjustment is necessary in order to obtain a TDR waveform of optimum resolution and position to achieve the best quality readings. Necessary adjustments include resetting the apparatus, selecting appropriate scales for horizontal and vertical axes, and control of the source wave. All the controlling actions are implemented through 1502B/SP232 Instruction Set.

The TDR apparatus periodically requires resetting similar to a computer to reduce communication disorder. TDR++ is designed so that when the device is connected to the computer it will immediately reset, allowing it to clear out memory banks.

The user can adjust the settings to improve the size and position of the waveform by clicking on the [Setting] button on the tool bar. A setting form is displayed that allows control of the instrument, waveform acquisition, software, and cursor distance setup. The layout of the setting form is shown in Figure 5.3.

Instrument setup allows the user to select the units of vertical scale, horizontal scale and the light status. There are two vertical scale units: decibels (dB) and millirho (mrho), in which $\mathrm{dB}$ is a log scale unit and mrho is a linear one. The horizontal scale has units of feet or meters. The display light for the screen of the TDR apparatus can be turned off to conserve batteries. 


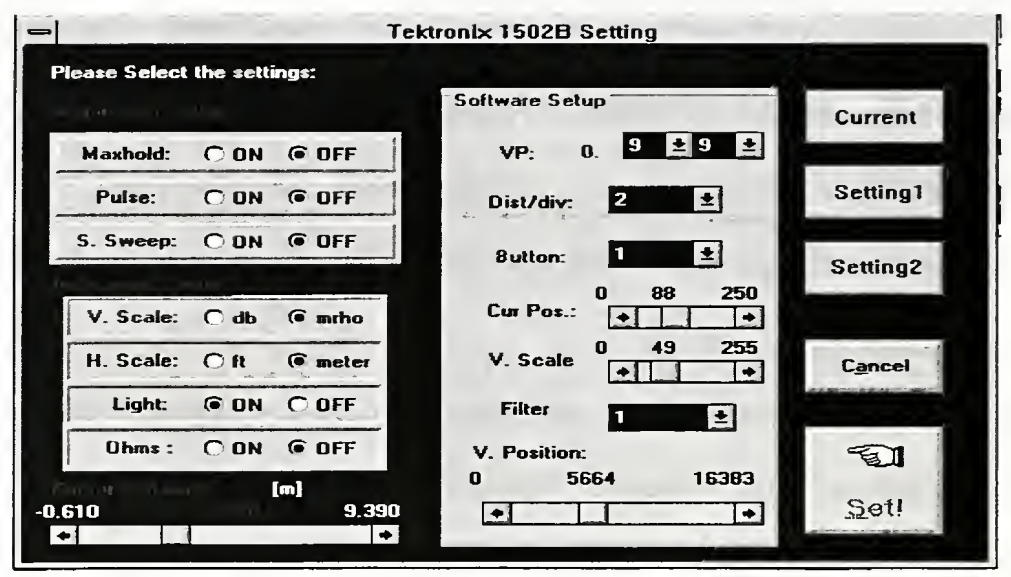

Figure 5.3 The layout of the Setting form

Acquisition setup includes the waveform settings for maximum hold, pulse, and single sweep. These settings are used for different applications of the TDR device. The specific settings for this study are, maximum hold: off; pulse: on; and single sweep: off.

The software setup is used more frequently to adjust the velocity of propagation, distance per division, horizontal position, vertical position, and noise filter. The velocity of propagation ratio is an artificial setting that relates the velocity of propagation of the electromagnetic wave to that of the velocity of light. A value of 0.99 is set as the default in a TDR test. The distance-per-division is actually the horizontal scale. It indicates the distance that a division of the display grid is representing under the pre-set unit (feet or meters). Table 5.1 shows the distance-per-division representations based on instrument setup (horizontal unit). A typical setting for a TDR trace acquisition is either 2 or 3 . 
Horizontal position is the position of cursor on the display, ranging from 0 to 250 , since the number of data points on the display is 251 . The noise filter is the number of averages taken before the waveform is displayed, ranging from 1 average to 128 waveform averages. Four averages were used in this study. Finally, vertical position represents vertical position of the waveform ranging from $0-16383$ with 8192 being approximately the center.

\begin{tabular}{||l|l|l||}
\hline Dist/Div Argument & English (feet) & Metric (meters) \\
\hline 00 & 0.1 & 0.025 \\
\hline 01 & 0.2 & 0.05 \\
\hline 02 & 0.5 & 0.1 \\
\hline 03 & 1 & 0.25 \\
\hline 04 & 2 & 0.5 \\
\hline 05 & 5 & 1 \\
\hline 06 & 10 & 2.5 \\
\hline 07 & 20 & 5 \\
\hline 08 & 50 & 10 \\
\hline 09 & 100 & 25 \\
\hline 10 & 200 & 50 \\
\hline
\end{tabular}

Table 5.1 Distance-per-division representations

The cursor distance is the length from the origin to a specific position on the waveform. The cursor position is the specific location on the viewing window and is measured as a data point from 0 to 251 . The horizontal scale establishes the length between data points. Together, the cursor distance, cursor position, and horizontal scale are used to establish the location and size of the viewing window along the wave trace. For example, if the cursor distance is set to be at 2.00 meters and the cursor position is 0 , it means the cursor is at the first point of the display, and its distance is 2.00 meters. Under a horizontal scale of 
0.1 meter/div, the display will show a window from 2.00 meter to 3.00 meter, because there are 10 divisions on the display and 25 subdivisions/div.

When the cursor distance, cursor position, and scale have been selected, the user clicks the [Set] button in the Setting form to activate the remote control. The change is made on the next acquisition. More than one iteration may be needed to get a satisfactory waveform; however, this adjustment is typically necessary only once for a specific soil being tested. Since TDR waveforms of many soil types have similar horizontal and vertical ranges, it is possible to determine a setting that is applicable for most conventional TDR tests. TDR++ allows the user to pre-set two settings and save them as Setting 1 and Setting 2. The user can then simply select buttons [Setting 1] or [Setting 2] on the setting menu. These two settings can be modified whenever necessary by making adjustments as desired and then clicking the [Set] button for Setting 1 or 2 .

As stated in Chapter 4, the accuracy of the TDR readings relates to the number of available data points within the zone of interest between Points 1 and 2. The Tektronix device has limited flexibility in the scale adjustment because of the degree of magnification associated with a scale increase. Under the most unfavorable conditions as few as 100 points may define the curve between Points 1 and 2. For this case, measurement errors as large as $2 \%$ are possible for each of the two points. It is anticipated the errors associated with a discretization of only 251 data points will be reduced as new equipment is developed.

\subsubsection{TDR Data File Manipulation}

TDR++ is able to manipulate different types of files including those with the predefined extensions, *.mrp, *.cc, *.cdt, *.set and *.wfm, which are explained in Table 5.2. The 
file operations possible using TDR++ include 1) Open a file; 2) Get attributes of the current file; 3) Get included file information; 4) Save a file; 5) Temporarily store a waveform in a file register. The stored waveforms can be retrieved to Picture Box for viewing or a Text Box to examine specific data.

The TDR data is saved as a file. In saving a TDR file, the user needs to select the format first. Five formats with different file name extensions are available for saving a file. The purpose of each format is shown in Table 5.2. Different file formats are used for data manipulation and calculation purposes.

There is a file register designed in TDR++, in which the user can temporally store up to five files, keeping those files accessible for the Picture Box and the Text Box. The purpose of this is for waveform comparison, which will be explained in detail in the next section.

By clicking the [Open] button on the toolbar, the user can open a file with the name he or she selects in the dialog box. Upon opening a file, TDR++ can identify if it is a TDR waveform or not. The program will display the waveform if there is one; otherwise it will open the file as a plain text file. The name of the file will be displayed as a particular label. The waveform displayed in the Picture Box will automatically be set to the current file. All file operations will be with respect to the current file.

Attributes of the current file, such as filename, path, file length, last modified time, etc., can be viewed via the [Properties] button in the File menu.

Information that is saved can be grouped into Test Info, Soil Info, and Input Info, each of which can be viewed by clicking the sub menus under the Info menu. Test Info contains information such as Test $\mathrm{D}$, Test Type, Test Site, Test Time, etc., and is used in the reduction of test data and for record keeping. Soil Info relates to the characteristics of the tested soil, 
including Soil Name, Soil ID, USCS and ASSHTO Classifications, Liquid Limit, Plastic Limit and Clay Fraction. Input Info includes data related to the MRP and CC and is used in data reduction.

\begin{tabular}{|c|c|}
\hline File Name Extension & File Format \\
\hline$* . \mathrm{mrp}$ & MRP data file \\
\hline$*$.cc & CC data file \\
\hline$*$.cdt & Conductivity file \\
\hline$* . \mathrm{set}$ & Setting file \\
\hline$* . \mathrm{wfm}$ & TDR curve file \\
\hline
\end{tabular}

Table 5.2 File name extension and corresponding file format.

\subsubsection{Signal Displaying and Note Editing}

A TDR waveform can be displayed in the Picture Box on the Main Form and the cursor can indicate the position of each data point. A horizontal scroll bar is assigned to move the cursor to the left or the right. The position readout is visible in the upper right-hand corner of the screen. The picture box contains several labels showing the vertical and horizontal scales of the waveform, the noise filter, and the power setting. The layout of the Picture Box is shown in Figure 5.4.

The Picture Box can display up to 6 different waveforms at the same time to provide a visual comparison. Using the [Store] button on the Misc. toolbar, the user can temporarily store up to five waveforms. A colored rectangular icon is created for each waveform stored to 
allow quick retrieval. By simply dragging and dropping these icons into the Picture Box, the waveforms will be displayed in their assigned colors.

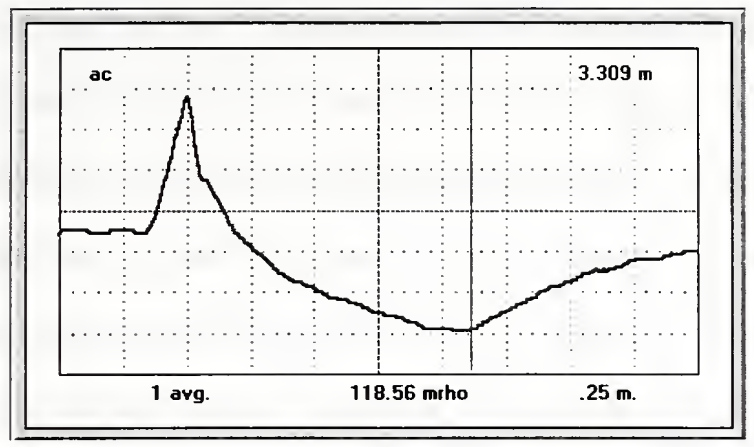

Figure 5.4 The layout of the picture box.

All text files can be opened with the text box. The text box has some editing capability as well as Save, Clear and Print. Dragging the icons in the file register and dropping them in the text box will display the waveform files in text mode. This is useful to check the original data file. Text box has a note pad that can be used by the TDR operator to record notes and comments related to weather, site conditions, equipment, communications, etc. Contents of the Picture Box and Text Box can be printed by using the associated [Print] button

\subsubsection{Data Interpretation and Reduction}

The TDR data interpretation algorithm was introduced in Chapter 4. Data reduction is the process of making necessary calculations required to estimate water content and density from the TDR test. The data reduction procedure was developed in the initial phase of this 
study and modified somewhat during the present work. The details of this procedure along with results of field verification tests are presented in Chapter 6. The implementation of this procedure into the TDR++ software is discussed here.

Data reduction is straightforward for tests in the coaxial cylinder (CC). Calculation of the apparent dielectric constant requires the probe length as input and the apparent length of the reflected waveform interpreted from the algorithm. The wet density of the soil is obtained from the volume of the $\mathrm{CC}$ mold and the mass measured with a balance. The water content is obtained using the developed correlation between apparent dielectric constant, soil density, and water content.

The procedure for reduction of multiple rod probe (MRP) test data is linked to the corresponding results of the test in the CC mold. When reducing the MRP test data, TDR++ will open the linked CC data file in the background and obtain the quantities needed, namely; water content, dry density, and apparent dielectric constant. The link is established in the Test Info form of the MRP data. If there is a modification in either the MRP Input or the CC Input, TDR++ will check the change and recalculate the results. Results are saved in the TDR data file where they remain easily accessible.

\subsubsection{TDR Test Reporting}

TDR++ can generate test reports in either a long form or a short form. When the results of a TDR test are complete, the user can select the desired format from the Report menu. The reports are generated in Microsoft Excel using a technique called OLE Automation. A full description of OLE automation is beyond the scope of this report, but briefly, it allows integration of software tools for a specific functionality. Excel was chosen 
because it is a common spread sheet tool installed on most personal computers. Macros were written in the Excel modules, including Print Preview, Print and Exit. The user can modify the macros easily using the Excel ${ }^{\mathrm{TM}}$ macro recorder or Visual Basic ${ }^{\mathrm{TM}}$.

\subsubsection{TDR Database}

Development of a database of all TDR measurements will allow assessing and improving the test procedure and equipment. The TDR procedure for measuring soil water content and density is based on both theoretical and statistical correlations. The statistical relationships can be enhanced with the accumulation of additional data. The database is being generated in Excel and multiple sheets were designed to contain different input data. The structure of this database is quite flexible and the user can perform various operations on original or secondary data.

Ten different sheets were designed to hold different information, including Test Info, Soil Info, waveforms, Settings, MRP Input, CC Input, Curve Readings, MRP Results, CC Results, and, Reference Info. The Reference sheet is designed to hold measurements from other methods, including oven dry and nuclear gage moisture content, and sand cone and nuclear gauge density.

The stored information in this database is expected to improve the calibration coefficients for different soil types. The accumulation of actual field data, including TDR curves, and soil indices, can be used to improve correlations between TDR measurements and soil properties, which is future goal of this research. 


\subsubsection{On-line Help}

On-line Help is provided in the standard Windows $95^{\mathrm{TM}}$ operating system format. It provides functions for searching, establishing bookmarks, and indexes to assist the user.

\subsection{Comments on Procedural Automation}

The description of the TDR++ automation software presented here does not fully elaborate on all the features of the program. Although the software has been developed in a user- friendly environment, it is anticipated that proficiency in using the software can be accelerated by holding training sessions for operators of the equipment.

Every effort has been made to validate and debug the software package. At this time the software package is working as intended and no known bugs exist. However, it is possible that some difficulties may arise during routine use of the software in a wide variety of field situations by different technicians. Moreover, operators may have valuable feedback that will assist us in improving the system. For this reason we view software development and the testing procedure as an ongoing activity that can be continually improved. Accordingly, the members of the TDR research group welcome comments on this software and procedure from users. 


\section{CHAPTER 6}

\section{LABORATORY AND FIELD EVALUATION OF TDR METHOD}

\subsection{Introduction}

Hundreds of tests were performed in the previous study to establish the calibration equations and evaluate the test procedure. These results were encouraging and showed the potential for using TDR to measure water content and density of soil in situ. Most of the initial tests were done under laboratory conditions, on a limited number of soil types, and over a small range of soil densities. During the present work, additional tests were conducted using the new prototype equipment and included: field tests on actual construction sites, tests on a broader group of soils, and tests over a wider range of soil densities. Based on these results, the procedure that used both Topp's equation and the density-compensating gravimetric water content equation (see Eqn [2.4] which is repeated below as Eqn [6.3]) developed in the previous study was reexamined to further assess the influence of density on the accuracy of measurements. It was found that Topp's equation is of insufficient accuracy to be useful over a wide range in soil densities.

\subsection{Reexamination of the Calibration Equations}

In the previous study, several calibration equations were reviewed. These include

1. Topp's (1980) "universal” empirical equation

$$
\theta=-0.053+2.92 \times 10^{-2} \boldsymbol{K}-5.5 \times 10^{-4} K^{2}+4.3 \times 10^{-6} K^{3}
$$

2. A semi-empirical linear calibration equation 


$$
\sqrt{K}=\boldsymbol{a}+\boldsymbol{b} \theta
$$

3. Theoretical mixing models, such as Maxwell-de Loor's dispersion model (de Loor, 1964) and volumetric mixing model, Birchak et al. (1974).

The theoretical models, in particular Maxwell-de Loor's dispersion model, were found to produce the best results according to conclusions drawn from several studies (Dirksen and Dasberg, 1993, Bohl and Roth, 1994). However, the theoretical mixing models are typically complex and involve several parameters not known a priori. Eqn [6.2] is shown to be an improvement over Topp's equation and provides a good approximation of the theoretical models over limited ranges of soil density due to the added flexibility of the constants $a$ and $b$. Topp's equation and Eqn [6.2] were evaluated using experimental data and a new calibration relationship was proposed by Siddiqui (1995) to partially account for the influence of density on measured results.

$$
\frac{\sqrt{\boldsymbol{K}} \rho_{w}}{\rho_{\boldsymbol{d}}}=\boldsymbol{a}+\boldsymbol{b} \boldsymbol{w}
$$

Linear regression is used in this study to develop correlations between dielectric constant, water content, and density using relationships such as Eqn. [6.3]. Standard error and maximum error are used to compare the relative accuracy of these correlations. The standard error is analogous to the standard deviation. The standard deviation is a measure of the dispersion of a variable about the mean value, and is based on a normal distribution. The standard error is a measure of dispersion from a value predicted by a functional relationship, instead of the mean value. The standard error (SE) has the form of: 


$$
\begin{aligned}
& \mathrm{SE}=\sqrt{\frac{\sum_{i=1}^{n}\left[\left(w_{O D}\right)_{i}-\left(w_{T D R}\right)_{i}\right]^{2}}{n-2}} \\
& \text { where } \quad w_{\mathrm{OD}}=\text { oven dry water content } \\
& w_{\mathrm{TDR}}=\text { predicted water content using TDR correlation } \\
& \mathrm{n}=\text { number of test samples }
\end{aligned}
$$

The maximum error is the largest error between the measured data and that predicted by the correlation. It was concluded in the previous study that the standard error and maximum error of water content measurements using calibration equations, such as Topp's equation, Eqn [6.2], or Eqn. [6.3] with average coefficients are all about $\pm 1.0 \%$ and $\pm 2.0 \%$, respectively. The standard and maximum errors of water content measurement could be reduced to $\pm 0.8 \%$ and $\pm 1.0 \%$, respectively, if soil specific coefficients are used in Eqns [6.2] or $[6.3]$.

The laboratory work performed in the previous study to indicate only marginal benefit in using one calibration equation over another. In fact, the final procedure recommended in the previous study made use of both Topp's equation and Eqn [6.3]. However, the experiments from which the above conclusions were drawn in the previous study were limited to a range in density of 1.4 to $1.65 \mathrm{Mg} / \mathrm{m}^{3}$. Additional experiments were conducted in this study on several Indiana soils over a broader range in densities that are consistent with compacted soil densities used in construction. These additional tests exposed a weakness in using Topp's equation and resulted in a modification to the recommended procedure for making measurements. 


\subsubsection{Experimental Method}

The specific purpose of this study is to measure water content and density of soils used in highway construction for quality control purposes. Therefore, it is desirable to test actual Indiana soils over the typical range in compacted densities. Table 6.1 shows the characteristics of the soils used in the laboratory testing program. The tests were conducted during standard and modified compaction tests. The testing device used was similar to the CC transmission line shown in Figure 3.2. The procedure for performing a test is as follows:

1. Prepare the soil at the desired water content and compact the soil in the compaction mold with standard compaction effort or modified compaction effort, following ASTM D698 and ASTM D1557.

2. Determine the wet density of the soil in the compaction mold by measuring the mass of soil in the known volume.

3. Use the $\mathrm{CC}$ template to insert the central rod into the compaction mold.

4. Remove the mold from the base plate and place the mold on a nonmetallic base plate.

5. Make a measurement using the TDR device and compute the dielectric constant.

6. Take a sample for measuring water content by oven drying.

7.

\subsubsection{Results and Discussion}

Topp's equation was used to compute the volumetric water content. The gravimetric water content was then obtained from the volumetric water content and the measured wet density. The results were compared with the oven-dry water content, as shown in Figure 6.1. The standard error is $1.9 \%$ and the maximum error is $4.0 \%$. Figure 6.1 illustrates that Topp's 
equation typically overestimates the water content of the denser soils (e.g. Indianapolis with a dry density of $2.01-2.12 \mathrm{Mg} / \mathrm{m}^{3}$ ).

Table 6.1 Soil Characteristic for experiments to reexamine the calibration equations.

\begin{tabular}{|c|c|c|c|c|c|}
\hline Soil Type & USCS & $\begin{array}{c}\text { Liquid } \\
\text { Limit }\end{array}$ & $\begin{array}{c}\text { Plasticity } \\
\text { Index }\end{array}$ & $\begin{array}{c}\text { Density } \\
\text { Range } \\
\left(\mathrm{Mg} / \mathrm{m}^{3}\right)\end{array}$ & $\begin{array}{c}\text { Water Content } \\
\text { Range } \\
(\%)\end{array}$ \\
\hline Vigo & $\mathrm{CL}$ & 36 & 12 & $1.6-1.77$ & $9-21$ \\
\hline Hendricks I & $\mathrm{CL}$ & 37 & 13 & $1.62-1.75$ & $11-23$ \\
\hline Indianapolis & $\mathrm{ML}$ & 15 & - & $2.01-2.12$ & $4-11$ \\
\hline Hendricks II & $\mathrm{CL}$ & 32 & 11 & $1.62-1.92$ & $7-20$ \\
\hline Bloomington & $\mathrm{CL}-\mathrm{CH}$ & 50 & 24 & $1.52-1.76$ & $16-24$ \\
\hline
\end{tabular}

To obtain the calibration equation in the form of Eqn [6.2], values of $\sqrt{K}$ were plotted with the actual volumetric water content as shown in Figure 6.2. The results of a regression analysis produced $\mathrm{a}=2.13$ and $\mathrm{b}=7.00$ such that:

$\sqrt{K}=2.13+7.00 \theta$

and $\mathrm{R}^{2}=0.92$. Using this equation and the measured wet density, the water contents were backcalculated and compared with the oven-dry water content. The standard error is $1.5 \%$ and the maximum error is $3.3 \%$.

The density-compensating gravimetric water content equation (Eqn [6.3]) is plotted in Figure 6.3. A regression analysis of the data yields: 
$\frac{\sqrt{K} \rho_{w}}{\rho_{d}}=1.03+8.24 w$

and $\mathrm{R}^{2}=0.98$. Eqn. [6.5] is Eqn. [6.3] with $\mathrm{a}=1.03$ and $\mathrm{b}=8.24$. Using this equation and the measured wet density, the water contents were backcalculated and compared with oven-dry water content. For this case the standard error is $1.1 \%$ and the maximum error is $2.3 \%$. The previous study showed modest improvement of using Eqn [6.3] over Topp's equation; however, when the range of soil densities was expanded, Topp's equation is shown to be inferior to Eqn [6.3]. Accordingly, Topp's equation was abandoned and Eqn [6.3] was used to estimate both water content and density.

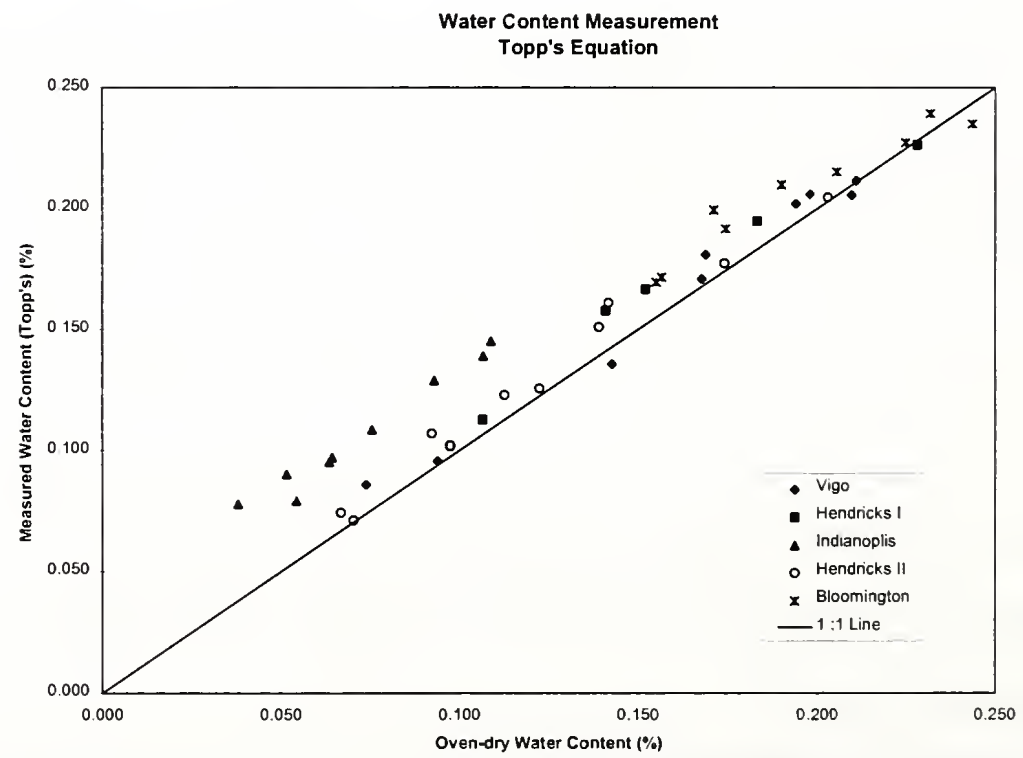

Figure 6.1 Comparison of the oven-dry water content and the TDR measured water content for different types of soils (listed in Table 6.1) using Topp's empirical equation. 


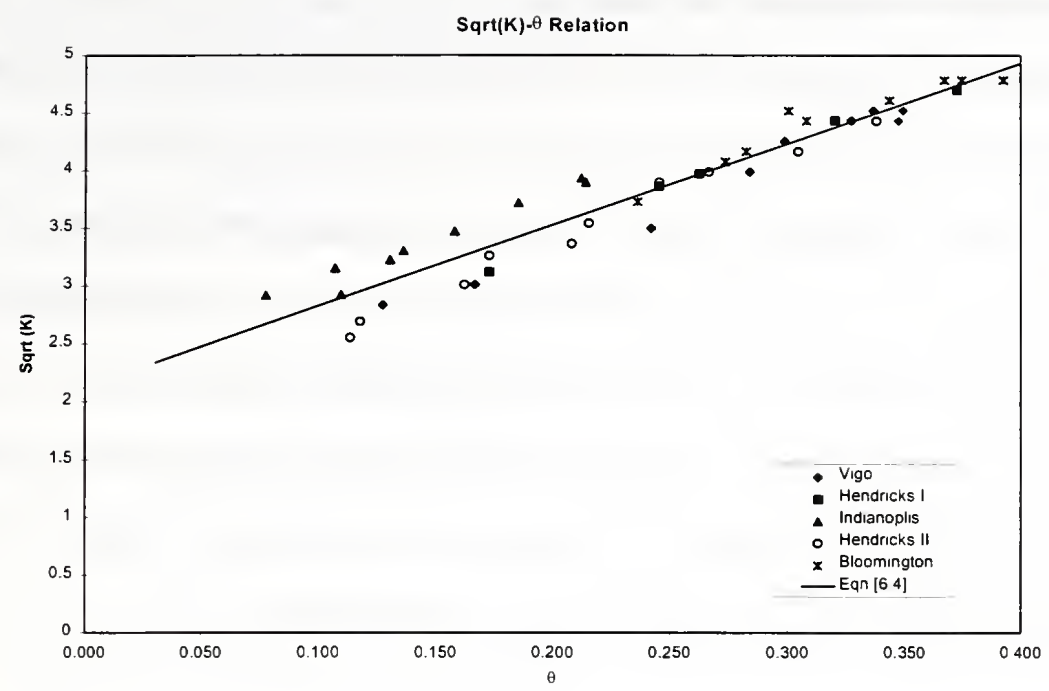

Figure 6.2 $\sqrt{ } K$ vs. $\theta$ relationship for different types of soils (listed in Table 6.1).

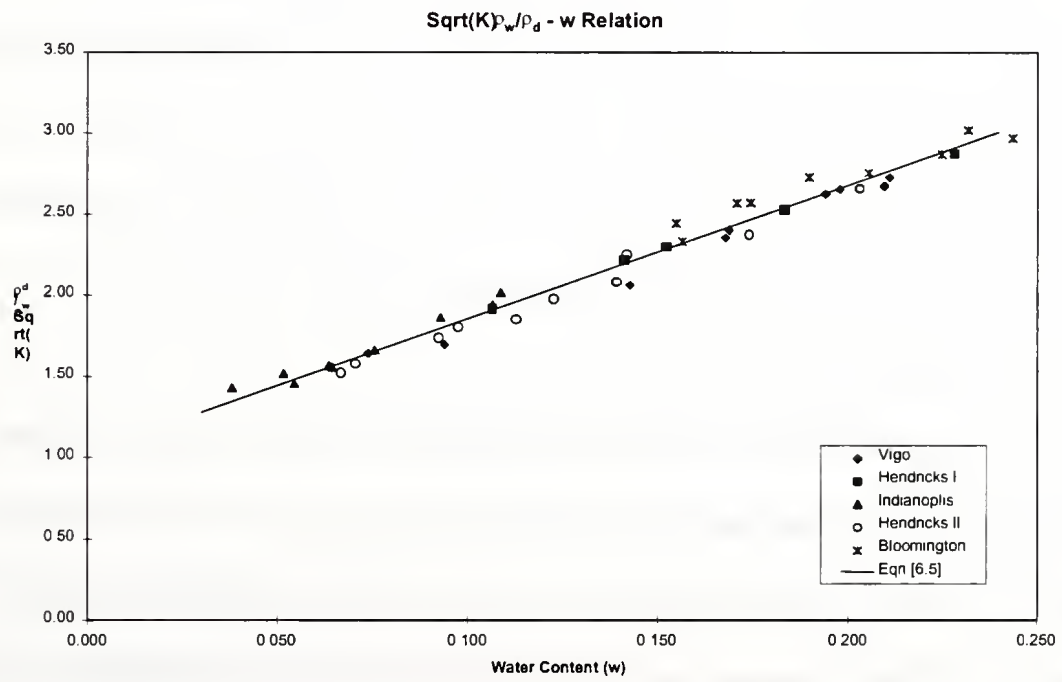

Figure 6.3 Density-compensating water content relationship for different types of soils (listed in Table 6.1). 


\subsection{Evaluation of Laboratory Test Results}

Improved measurements of soil water content and density can be achieved by using Eqn [6.3] as presented by Siddiqui (1995) because the influence of soil density is partially taken into account. Siddiqui (1995), and Drnevich and Siddiqui (1995) reported that better measurements could be obtained if the in situ density and the density of soil in the CC mold differed by less than $10 \%$. Since this requirement affects the expediency of the test, the previous data and new data were evaluated to assess the need for this restriction. Laboratory experiments were conducted using the new prototype equipment to reevaluate the testing procedure and further assess the influence of density on measurements.

\subsubsection{Experimental Method}

A silty clay soil, Crosby Till, was compacted at five different densities for ten different gravimetric water contents ranging from 2 to 18 percent. The compacted energy included: light hand compaction, moderate hand compaction, reduced Proctor compaction, standard Proctor compaction, and modified Proctor compaction. Final densities ranged between 1.3 $\mathrm{kg} / \mathrm{m}^{3}$ and $2.2 \mathrm{Mg} / \mathrm{m}^{3}$. The wet density, apparent dielectric constant and oven-dry water content were measured for each case.

The procedure used to estimate soil density in situ requires a pair of readings: one from the MRP and one from the CC mold. The "known" density in the CC mold is used to estimate the density in situ using the ratio of dielectric constants obtained from the CC mold and in situ. For laboratory data generated in the $\mathrm{CC}$, any two of the measurements can be thought of as a pair of readings from the CC and MRP. For all combinations of data, the water content and density can be estimated using the TDR procedure and the accuracy of the 
measurements can be examined with respect to the difference in density of the two samples used.

\subsubsection{Results and Discussion}

\section{Water Content}

The test data are plotted in Figure 6.4 along with Eqn [6.3] for $a=0.9$ and $b=10.1$. The measured oven-dry water contents were compared with the water contents estimated using TDR and Topp's equation in Figure 6.5, and Eqn [6.3] in Figure 6.6. Figure 6.5 illustrates additional proof that the use of Topp's equation is not satisfactory when the density varies over a large range. There is no consistent influence of density on the accuracy of the estimated water content using Eqn [6.3]. Using Eqn [6.3] with soil specific values of $a$ and $b$, the standard error and maximum error for the water content measured by TDR are $0.7 \%$ and $1.4 \%$, respectively.

\section{Density}

The measurement of the wet density using Eqn [6.3] is independent of the calibration parameters because the two measurements are done for the same soil and at the same gravimetric water content. Although, this equation is a function of soil density, it may not completely capture the influence of soil density on measurements such that differences in density between the two specimens may lead to errors. For this reason Siddiqui (1995) recommended that the soil compacted in the $\mathrm{CC}$ mold should be within ten percent of the density of the soil in situ. The generated laboratory test data is examined to assess the need for this restriction. 
The percent error in density measurement versus percent difference in density between the two samples is plotted in Figure 6.7. The dry density ranged from 1.4 to $2.0 \mathrm{Mg} / \mathrm{m}^{3}$. The scatter in the data indicates that a consistent error in measurements due to differences in density between the samples does not exist. The standard error and maximum error for measurement of wet density using the TDR method for the tests performed is $0.036 \mathrm{Mg} / \mathrm{m}^{3}$ $(2.3 \%)$ and $0.118 \mathrm{Mg} / \mathrm{m}^{3}(7.5 \%)$, respectively.

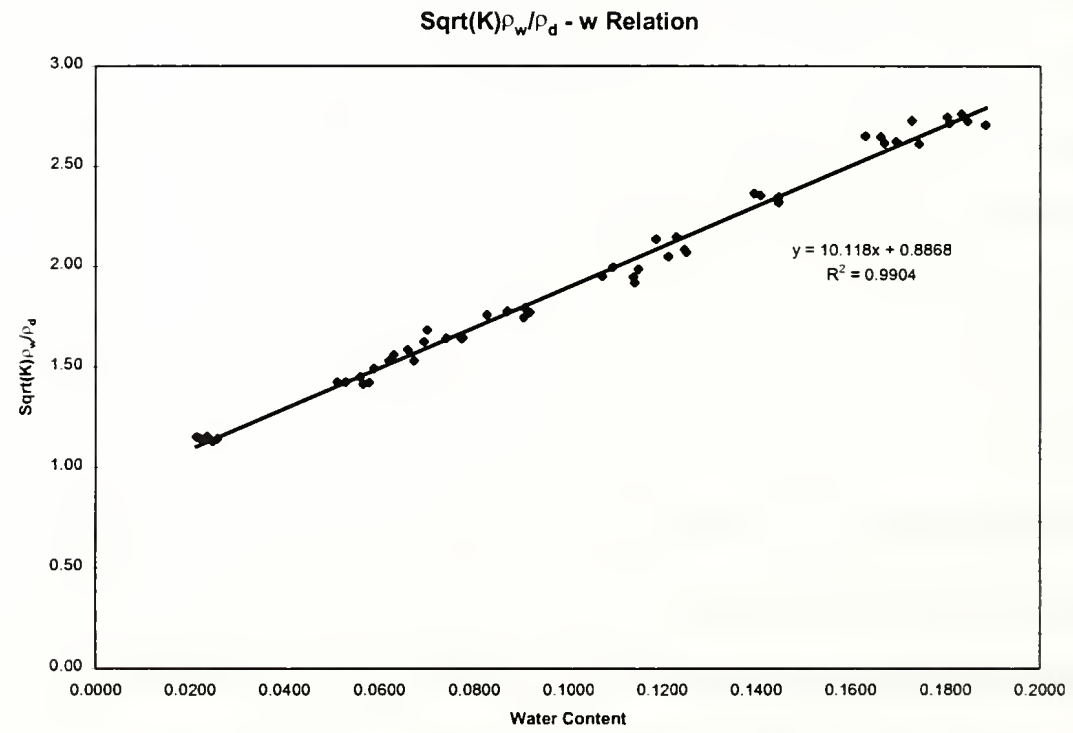

Figure 6.4 Density-compensating water content relationship for Crosby Till. 


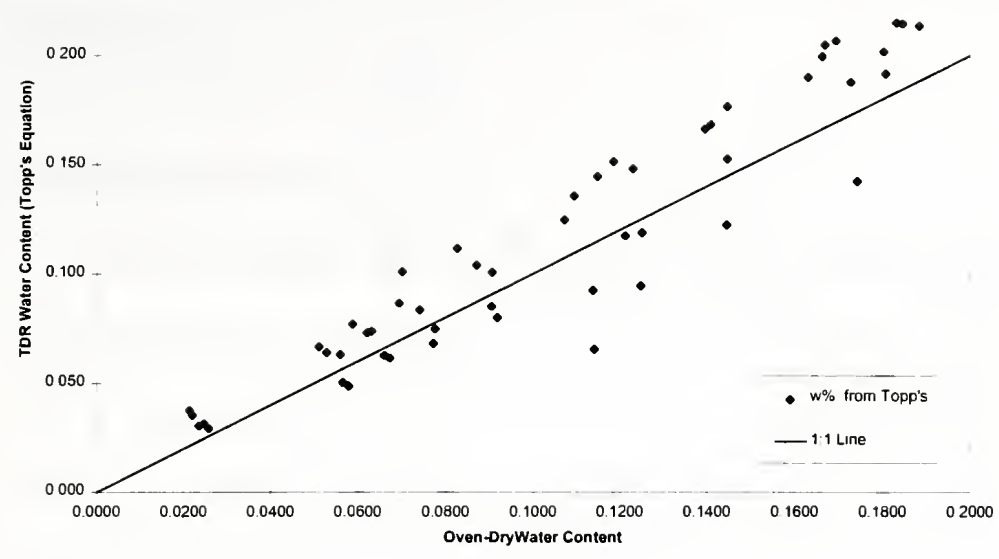

Figure 6.5 Comparison of the oven-dry water content and the TDR measured water content for Crosby Till using Topp's empirical equation.

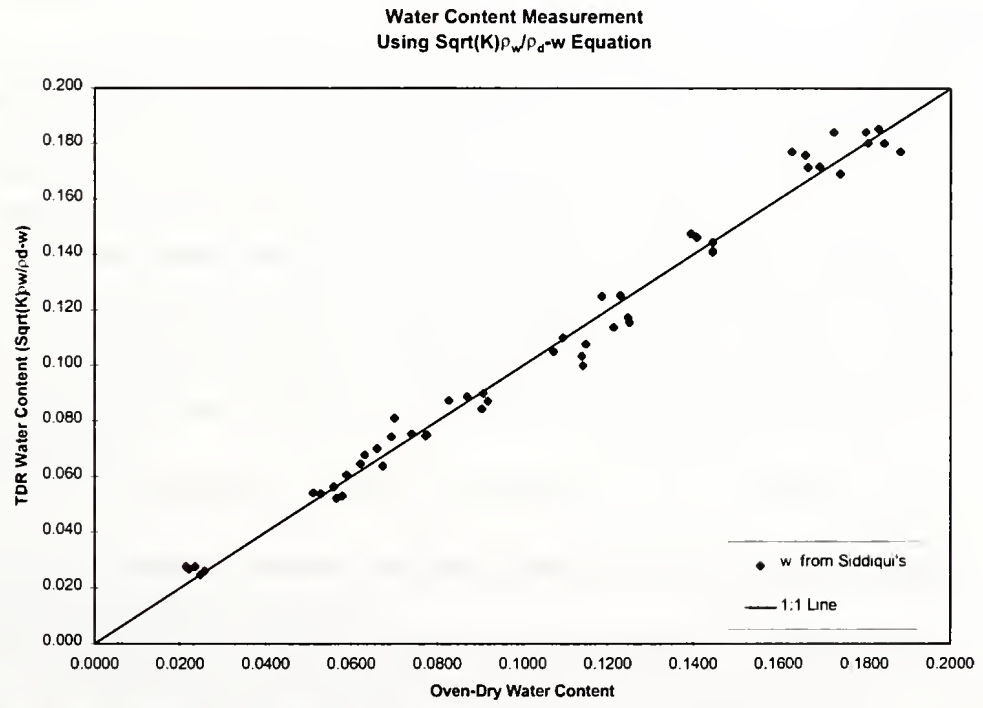

Figure 6.6 Comparison of the oven-dry water content and the TDR measured water content for Crosby Till using Density-compensating water content equation. 


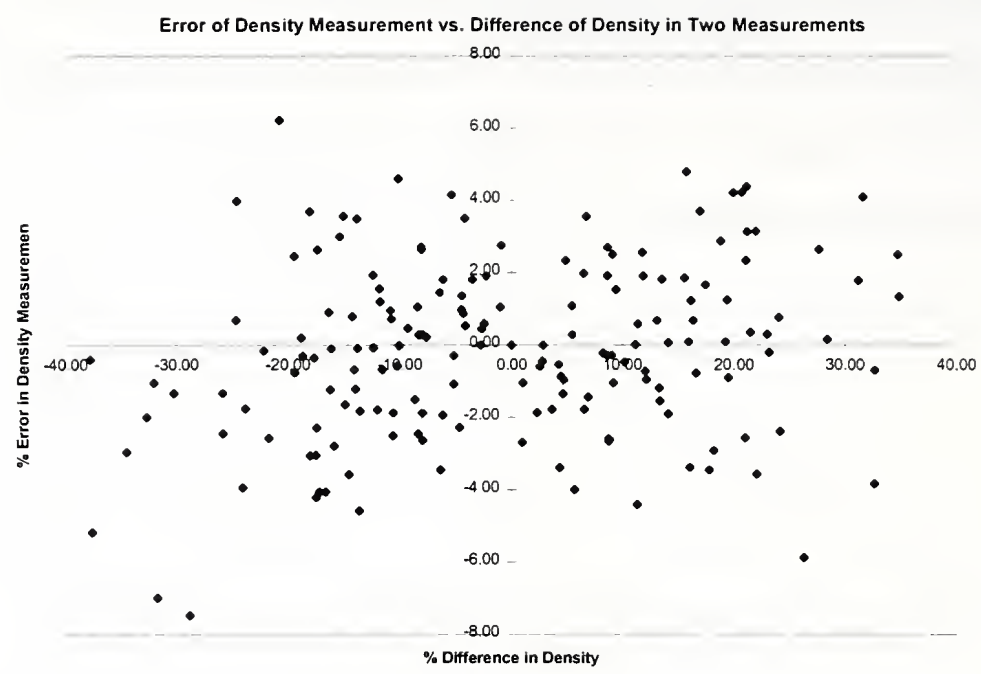

Figure 6.7 Variation of error in density measurement with the difference of density in two CC mold.

\subsection{Field Evaluation}

The developed prototype equipment was used at several construction sites to assess accuracy under field conditions. Quality control tests in the field require determination of water content and compacted density. The sand cone test and nuclear density test are the most common tests used by INDOT. When performing the sand cone test the water content is determined by oven drying so that actual dry density is not known until the following day. The nuclear density gauge can provide estimates of density and water content rapidly. However, the device requires frequent calibration and the errors in estimated water content and density can be substantial. Estimates of water content using the nuclear density gauge and the TDR method are compared to oven drying, and estimates of density are compared between sand cone, nuclear density, and TDR tests where available. Much greater scatter in 
the data can be expected under field conditions relative to laboratory tests because of the inherent spatial variability of soils, water contents, and densities that will result under field conditions.

\subsubsection{Experimental Method}

Forty-four quality control tests were performed at 11 construction sites. Some sites have only TDR and one of nuclear or sand cone tests, while some sites have all three tests. At each test location the TDR, nuclear and/or sand cone test were done as close as practical to each other. The TDR field test procedure was reviewed in Section 2.2. The soil excavated for compaction in the $\mathrm{CC}$ was taken from within the boundary formed by the MRP and uniformly from the entire depth of in-place measurement. The soils were placed directly in the CC to minimize moisture loss and compacted uniformly using either moderate hand compaction or standard compaction effort. The excavated soil samples from the TDR tests and sand cone tests were brought back to the lab to determine the oven-dry water content. The densitycompensating gravimetric water content equation (Eqn [6.3]) was used with average values of $a$ and $b$ generated using all the field test results to calculate water content and density using the TDR method. Average values were used because soil specific values of $a$ and $b$ were not determined.

\subsubsection{Results and Discussion}

A summary of the sites tested and soil characteristics are provided in Table 6.2. Eqn [6.3] is used to fit the data as shown in Figure 6.8 giving $a=0.8$ and $b=10$. This relationship was used to estimate water content and a comparison is made with oven dry water content and 
with nuclear density water content in Figure 6.9. Table 6.3 and 6.4 contain the results of TDR, nuclear and sand cone tests at all sites.

The water content measurements, obtained from the TDR and nuclear methods (if available) were compared with oven-dried values. As shown in Figure 6.9 and Table 6.3, the measurements indicate that the water contents obtained by the TDR method are more accurate than the nuclear density test. The standard error and maximum error for water content measured by TDR were $1.1 \%$ and $2.8 \%$ respectively, and were $1.8 \%$ and $4.4 \%$ for the nuclear method.

For a comparison of densities, twenty tests were performed with both the TDR and nuclear gage (direct transmission method with 6" depth). The results show significant variability in estimates obtained from the two methods. Thirteen tests with both TDR and sand cone measurements were made on two construction sites. These results show that there is also a significant variability between values obtained by TDR and sand cone tests. However, the accuracy of the sand cone tests on this site was limited by the fact that the compacted soil on this site consisted primarily of sand with gravel. Finally, at the Gas City site, eight measurements were done using all three methods on silty clay soil. The results indicate that the density obtained by the nuclear method compared more favorably to the sand cone test than did the TDR densities. When compared to the sand cone test, the standard error, and maximum error, of the difference in dry density measured by TDR was 0.097 $\mathrm{Mg} / \mathrm{m}^{3}(5.5 \%)$ and $0.140 \mathrm{Mg} / \mathrm{m}^{3}(7.7 \%)$ respectively, and $0.066 \mathrm{Mg} / \mathrm{m}^{3}(3.6 \%)$ and 0.138 $\mathrm{Mg} / \mathrm{m}^{3}(7.6 \%)$ for the nuclear gauge.

The difference in density that exists among the three methods is attributed partly to the spatial variability of soil, water content, and density at the construction sites. For example, the 
nuclear gauge showed a difference in density $0.04 \mathrm{Mg} / \mathrm{m}^{3}(2.2 \%)$ at a distance of only $20 \mathrm{~cm}$ (8 in) apart at the Knox site.

\subsection{Conclusions}

1) A reexamination of the calibration equations showed that the relationship proposed by Siddiqui (1995), Eqn [6.3], is superior to Topp's equation over the soil density range of interest in compaction quality control. Accordingly, this relationship should be used in the determination of both water content and density.

2) New and previous test results show that no appreciable benefit can be gained by restricting the difference in density between soils in the MRP and the CC mold.

3) The TDR method provided better estimates of water content than the nuclear method, but the nuclear method provided estimates of density more consistent with the sand cone test for the limited test results completed.

Table 6.2 Soil Characteristic for field tests.

\begin{tabular}{|c|c|c|c|c|c|c|c|}
\hline $\begin{array}{c}\text { Soil } \\
\text { Source }\end{array}$ & $\begin{array}{c}\text { Soil } \\
\text { Type }\end{array}$ & $\begin{array}{c}\text { P4 } \\
\%\end{array}$ & $\begin{array}{c}\text { P10 } \\
\%\end{array}$ & $\begin{array}{c}\text { P40 } \\
\%\end{array}$ & $\begin{array}{c}\text { P200 } \\
\%\end{array}$ & $\begin{array}{c}\text { Liquid } \\
\text { Limit }\end{array}$ & $\begin{array}{c}\text { Plasticity } \\
\text { Index }\end{array}$ \\
\hline Crawfordsville & SW & 64.9 & 44.2 & 15.9 & 0.3 & 22 & 9 \\
\hline Anderson I & SC & 98.3 & 88.6 & 51.6 & 18.3 & 29 & 12 \\
\hline Decatur & SW-SC & 93.6 & 72.1 & 29.1 & 5.8 & 39 & 20 \\
\hline Butler & SP-SC & 99.2 & 98.8 & 65.6 & 5.2 & 34 & 16 \\
\hline Mt. Vernon & SM & 90.5 & 87.1 & 74.1 & 39.8 & 27 & 4 \\
\hline Knox & SC & 99.9 & 92.1 & 49.5 & 21.6 & 30 & 11 \\
\hline Anderson II & SP-SC & 96.0 & 89.3 & 59.5 & 6.3 & 23 & 9 \\
\hline I-52 I & SW & 88.9 & 76.0 & 50.9 & 10.0 & -- & -- \\
\hline I-52 II & GW & 69.9 & 52.0 & 12.1 & 0.6 & -- & - \\
\hline I-52 III & SP & 96.9 & 85.8 & 61.9 & 10.4 & -- & -- \\
\hline Gas City & SC & 97.5 & 94.2 & 58.7 & 12.5 & 31 & 13 \\
\hline
\end{tabular}




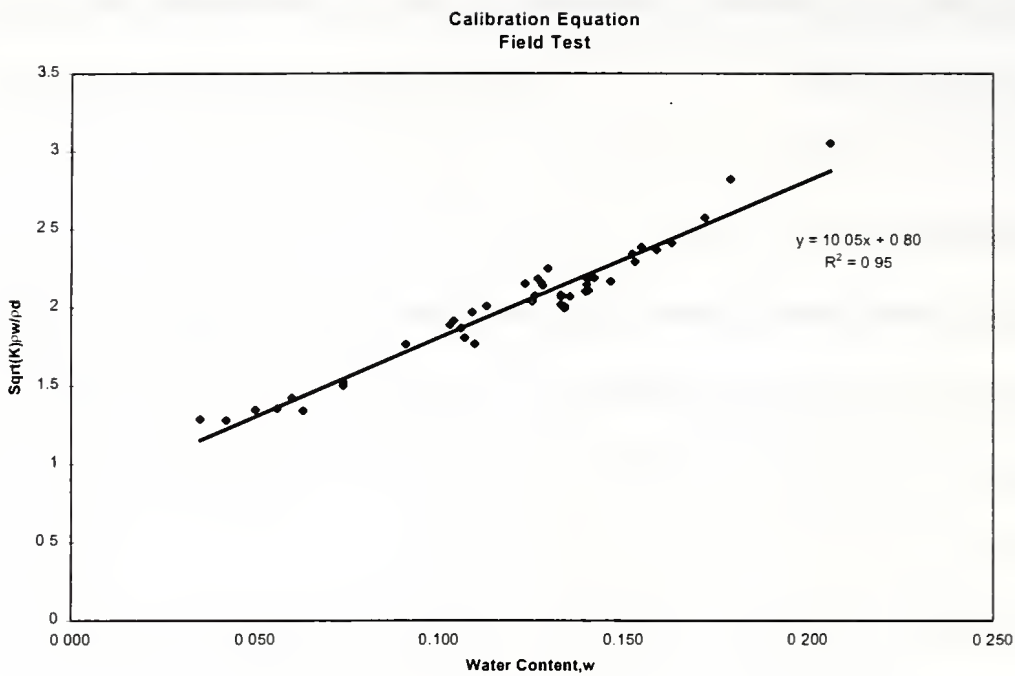

Figure 6.8 Density-compensating water content relationship for all soil types in field tests.

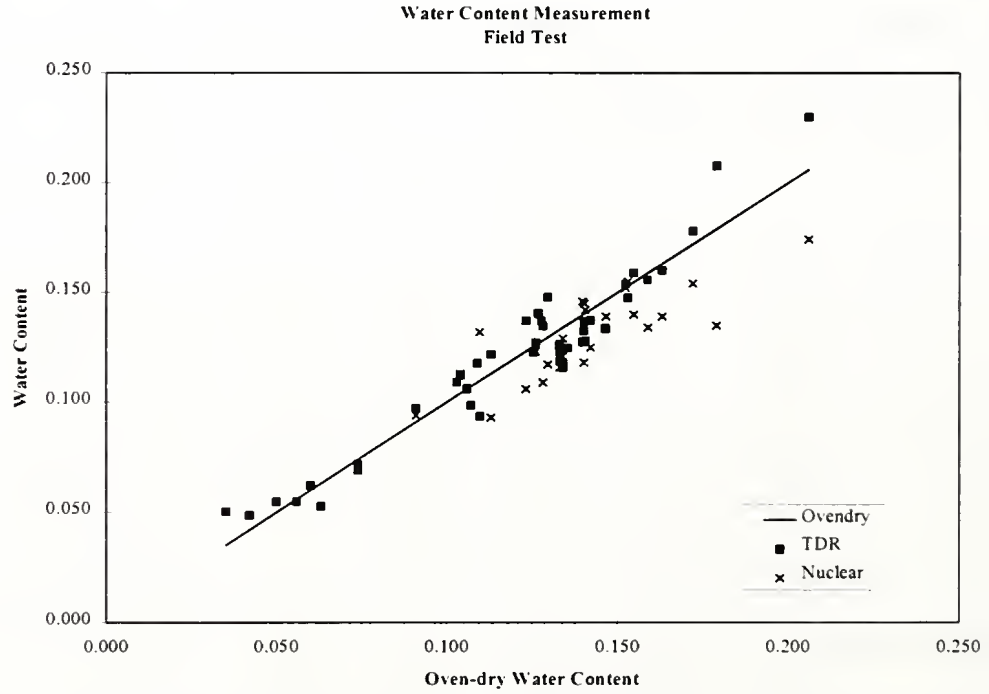

Figure 6.9 Comparison of the oven-dry water content with the TDR measured water content and Nuclear gauge measured water content in field tests. 
Table 6.3 The result of measurements of soil water content and density in field tests.

\begin{tabular}{|c|c|c|c|c|c|c|c|c|c|c|}
\hline \multirow[b]{2}{*}{ Site } & \multirow{2}{*}{ Test No. } & \multicolumn{3}{|c|}{$\% \mathrm{~W}$ Measurement $(\%)$} & \multicolumn{3}{|c|}{ Wet Density Measurement $\left(\mathrm{Mg} / \mathrm{m}^{3}\right)$} & \multicolumn{3}{|c|}{ Dry Density Measurement $\left(\mathrm{Mg} / \mathrm{m}^{3}\right)$} \\
\hline & & Oven dry & TDR & Nuclear & Sandcone & TDR & Nuclear & Sandcone & TDR & Nuclear \\
\hline Crawfordsville & $051496-1$ & 14.0 & 13.2 & 11.8 & N/A & 2.135 & 2.169 & N/A & 1.886 & 1.940 \\
\hline \multirow[t]{5}{*}{ Anderson I } & $070396-1$ & 13.3 & 12.6 & 12.0 & $\mathrm{~N} / \mathrm{A}$ & 2.143 & 1.953 & N/A & 1.903 & 1.744 \\
\hline & 070396-2 & 13.3 & 12.4 & 11.6 & N/A & 2.049 & 1.970 & N/A & 1.823 & 1.765 \\
\hline & 070396-3 & 13.4 & 11.6 & 12.1 & N/A & 2.301 & 2.008 & N/A & 2.062 & 1.791 \\
\hline & $070396-4$ & 14.2 & 13.7 & 12.5 & N/A & $\mathrm{t} .909$ & 1.908 & N/A & 1.679 & 1.696 \\
\hline & 070396-5 & 12.6 & 12.7 & 12.3 & N/A & 1.962 & 2.011 & N/A & 1.741 & 1.791 \\
\hline \multirow[t]{3}{*}{ Decatur } & 091996-1 & 17.9 & 20.8 & 13.5 & N/A & 1.637 & 2.040 & $\mathrm{~N} / \mathrm{A}$ & 1.356 & 1.797 \\
\hline & 091996-2 & 20.6 & 23.0 & 17.4 & N/A & 1.682 & 2.047 & $\mathrm{~N} / \mathrm{A}$ & 1.368 & 1.744 \\
\hline & $091996-3$ & 17.2 & 17.8 & 15.4 & N/A & 1.816 & 2.076 & $\mathrm{~N} / \mathrm{A}$ & 1.542 & 1.799 \\
\hline \multirow[t]{3}{*}{ Butler } & $092096-1$ & 10.4 & 11.2 & 11.3 & N/A & 2.295 & 2.038 & N/A & 2.064 & 1.831 \\
\hline & 092096-2 & 9.1 & 9.7 & 9.4 & N/A & 2.209 & 1.997 & N/A & 2.013 & 1.825 \\
\hline & 092096-3 & 11.3 & 12.2 & 9.3 & N/A & 2.244 & 2.045 & N/A & 2.001 & 1.871 \\
\hline \multirow[t]{4}{*}{ Mount Vernon } & $100496-1$ & 13.3 & 11.9 & 12.1 & $\mathrm{~N} / \mathrm{A}$ & 2.259 & 2.158 & N/A & 2.020 & 1.925 \\
\hline & $100496-2$ & 13.4 & 11.7 & 12.9 & N/A & 2.272 & 2.154 & N/A & 2.034 & 1.908 \\
\hline & $100496-3$ & 12.5 & 12.3 & 12.3 & N/A & 2.242 & 2.184 & $\mathrm{~N} / \mathrm{A}$ & 1.997 & 1.945 \\
\hline & $100496-4$ & 11.0 & 9.4 & 13.2 & N/A & 2.473 & 2.173 & $\mathrm{~N} / \mathrm{A}$ & 2.262 & 1.920 \\
\hline \multirow[t]{4}{*}{ Knox } & $100496-5$ & 14.7 & 13.4 & 13.9 & $\mathrm{~N} / \mathrm{A}$ & 2.148 & 2.125 & $\mathrm{~N} / \mathrm{A}$ & 1.895 & 1.866 \\
\hline & $100496-6$ & 14.1 & 12.8 & 14.2 & N/A & 2.235 & 2.134 & N/A & 1.982 & 1.869 \\
\hline & $100496-7$ & 14.0 & 13.7 & 14.5 & N/A & 2.161 & 2.126 & $\mathrm{~N} / \mathrm{A}$ & $1.90 \mathrm{t}$ & 1.857 \\
\hline & 100496-8 & 14.0 & 12.7 & 14.6 & $\mathrm{~N} / \mathrm{A}$ & 2.142 & 2.128 & N/A & 1.900 & 1.857 \\
\hline \multirow[t]{3}{*}{ Anderson II } & $102196-1$ & 12.8 & 13.7 & $\mathrm{~N} / \mathrm{A}$ & $\mathrm{N} / \mathrm{A}$ & $2.04 \mathrm{I}$ & N/A & N/A & 1.795 & N/A \\
\hline & $102196-2$ & 12.7 & 14.0 & N/A & N/A & 1.945 & $\mathrm{~N} / \mathrm{A}$ & N/A & 1.706 & $\mathrm{~N} / \mathrm{A}$ \\
\hline & 102196-3 & 13.5 & 12.4 & N/A & $\mathrm{N} / \mathrm{A}$ & 2.405 & $\mathrm{~N} / \mathrm{A}$ & N/A & 2.139 & N/A \\
\hline \multirow[t]{5}{*}{$1-521$} & $062997-1$ & 10.3 & 10.9 & N/A & 2.072 & 2.042 & $\mathrm{~N} / \mathrm{A}$ & 1.860 & 1.841 & N/A \\
\hline & $062997-2$ & 10.7 & 9.9 & N/A & 2.163 & 2.257 & $\mathrm{~N} / \mathrm{A}$ & 1.986 & 2.055 & N/A \\
\hline & $062997-3$ & 10.6 & 10.6 & $\mathrm{~N} / \mathrm{A}$ & 1.930 & 2.267 & $\mathrm{~N} / \mathrm{A}$ & 1.774 & 2.050 & N/A \\
\hline & $062997-4$ & 10.6 & 10.6 & $\mathrm{~N} / \mathrm{A}$ & 1.952 & 2.182 & $\mathrm{~N} / \mathrm{A}$ & 1.804 & 1.973 & $\mathrm{~N} / \mathrm{A}$ \\
\hline & 062997.5 & 10.9 & 11.8 & N/A & 2. 194 & 2.136 & $\mathrm{~N} / \mathrm{A}$ & 2.002 & 1.911 & N/A \\
\hline \multirow[t]{5}{*}{ I-52 II } & $071397-1$ & 7.4 & 6.9 & N/A & 2.226 & 1.944 & N/A & 2.059 & 1.819 & N/A \\
\hline & $071397-2$ & 4.2 & 4.9 & N/A & 2.252 & 2.079 & $\mathrm{~N} / \mathrm{A}$ & 2.123 & 1.982 & N/A \\
\hline & $071397-3$ & 7.4 & 7.2 & N/A & 2.082 & 2.404 & N/A & 1.979 & 2.243 & $\mathrm{~N} / \mathrm{A}$ \\
\hline & $071397-4$ & 6.3 & 5.3 & N/A & 2.064 & 2.072 & $\mathrm{~N} / \mathrm{A}$ & 1.968 & 1.969 & $\mathrm{~N} / \mathrm{A}$ \\
\hline & 071397-5 & 6.0 & 6.2 & $\mathrm{~N} / \mathrm{A}$ & 2.124 & 2.007 & N/A & 1.994 & 1.890 & N/A \\
\hline \multirow[t]{3}{*}{$1-52$ III } & $080397-1$ & 3.5 & 5.0 & $\mathrm{~N} / \mathrm{A}$ & 2.168 & 2.517 & $\mathrm{~N} / \mathrm{A}$ & 2.077 & 2.397 & $\mathrm{~N} / \mathrm{A}$ \\
\hline & 080397-2 & 5.6 & 5.5 & $\mathrm{~N} / \mathrm{A}$ & 2.076 & 2.355 & $\mathrm{~N} / \mathrm{A}$ & 2.017 & 2.233 & $\mathrm{~N} / \mathrm{A}$ \\
\hline & 080397-3 & 5.0 & 5.5 & $\mathrm{~N} / \mathrm{A}$ & 2.051 & 2.527 & N/A & 1.957 & 2.396 & $\mathrm{~N} / \mathrm{A}$ \\
\hline \multirow[t]{8}{*}{ Gas City } & $082897-1$ & 16.3 & 16.0 & 13.9 & 2.076 & 2.165 & 2.124 & 1.724 & 1.867 & 1.865 \\
\hline & 082897.2 & 15.9 & 15.5 & 13.4 & 2.111 & 2.137 & 2.065 & 1.845 & 1.850 & 1.821 \\
\hline & $082897-3$ & 15.2 & 15.4 & 15.2 & 2.108 & 2.214 & 2.098 & 1.815 & 1.919 & 1.821 \\
\hline & $082897-4$ & 15.3 & 14.8 & 15.5 & 2.149 & 2.208 & 2.102 & 1.860 & 1.924 & 1.820 \\
\hline & 082897.5 & 15.5 & 15.9 & 14.0 & 2.120 & 2.121 & 2.106 & 1.876 & 1.830 & 1.847 \\
\hline & $082897-6$ & 13.0 & 14.8 & 11.7 & 2.022 & 2.137 & 2.033 & 1.793 & 1.862 & 1.820 \\
\hline & $082897-7$ & 12.8 & 13.5 & 10.9 & 2.023 & 2.190 & 1.983 & 1.820 & 1.930 & 1.788 \\
\hline & 082897.8 & 12.3 & 13.7 & 10.6 & 2.012 & 1.950 & 2.032 & 1.792 & 1.715 & 1.837 \\
\hline
\end{tabular}


Table 6.4 The errors of measurements of soil water content and density in field tests.

\begin{tabular}{|c|c|c|c|c|c|c|c|c|c|c|}
\hline \multirow[b]{2}{*}{ Site } & \multirow[b]{2}{*}{ Test No. } & \multicolumn{2}{|c|}{$\begin{array}{c}\% W \text { error(\%) } \\
\text { Comparing to Ovendry }\end{array}$} & \multicolumn{2}{|c|}{$\begin{array}{c}\mathrm{pt} \text { error }\left(\mathrm{Mg} / \mathrm{m}^{3}\right) \\
\text { Comparing to Sandcone }\end{array}$} & \multicolumn{2}{|c|}{$\begin{array}{c}\text { d error }\left(\mathrm{Mg} / \mathrm{m}^{3}\right) \\
\text { Comparing to Sandcone }\end{array}$} & \multicolumn{3}{|c|}{ TDR/Nuclear } \\
\hline & & TDR & Nuclear & TDR & Nuclear & TDR & Nuclear & $w \%$ & $\rho t$ & $\overline{p d}$ \\
\hline rawfordsvill & $051496-1$ & -0.8 & -2.2 & $\mathrm{~N} / \mathrm{A}$ & $\mathrm{N} / \mathrm{A}$ & $\mathrm{N} / \mathrm{A}$ & N/A & 1.1 & 1.0 & 1.0 \\
\hline \multirow[t]{5}{*}{ Anderson I } & $070396-1$ & -0.7 & -1.3 & $\mathrm{~N} / \mathrm{A}$ & $\mathrm{N} / \mathrm{A}$ & $\mathrm{N} / \mathrm{A}$ & $\mathrm{N} / \mathrm{A}$ & 1.1 & 1.1 & 1.1 \\
\hline & 070396-2 & -0.9 & -1.7 & N/A & $\mathrm{N} / \mathrm{A}$ & N/A & $\mathrm{N} / \mathrm{A}$ & 1.1 & 1.0 & 1.0 \\
\hline & 070396-3 & -1.8 & -1.3 & N/A & $\mathrm{N} / \mathrm{A}$ & N/A & $\mathrm{N} / \mathrm{A}$ & 1.0 & 1.1 & 1.2 \\
\hline & $070396-4$ & -0.5 & -1.7 & N/A & $\mathrm{N} / \mathrm{A}$ & N/A & $\mathrm{N} / \mathrm{A}$ & 1.1 & 1.0 & 1.0 \\
\hline & 070396-5 & 0.1 & -0.3 & N/A & $\mathrm{N} / \mathrm{A}$ & $\mathrm{N} / \mathrm{A}$ & $\mathrm{N} / \mathrm{A}$ & 1.0 & 1.0 & 1.0 \\
\hline \multirow[t]{3}{*}{ Decatur } & 091996-1 & 2.9 & -4.4 & $\mathrm{~N} / \mathrm{A}$ & N/A & $\mathrm{N} / \mathrm{A}$ & $\mathrm{N} / \mathrm{A}$ & 1.5 & 0.8 & 0.8 \\
\hline & 091996-2 & 2.4 & -3.2 & N/A & $\mathrm{N} / \mathrm{A}$ & $\mathrm{N} / \mathrm{A}$ & $\mathrm{N} / \mathrm{A}$ & 1.3 & 0.8 & 0.8 \\
\hline & 091996-3 & 0.6 & -1.8 & N/A & $\mathrm{N} / \mathrm{A}$ & N/A & $\mathrm{N} / \mathrm{A}$ & 1.2 & 0.9 & 0.9 \\
\hline \multirow[t]{3}{*}{ Butler } & 092096-1 & 0.8 & 0.9 & N/A & $\mathrm{N} / \mathrm{A}$ & N/A & $\mathrm{N} / \mathrm{A}$ & 1.0 & 1.1 & 1.1 \\
\hline & 092096-2 & 0.6 & 0.3 & N/A & $\mathrm{N} / \mathrm{A}$ & N/A & $\mathrm{N} / \mathrm{A}$ & 1.0 & 1.1 & 1.1 \\
\hline & 092096-3 & 0.9 & -2.0 & N/A & $\mathrm{N} / \mathrm{A}$ & N/A & $\mathrm{N} / \mathrm{A}$ & 1.3 & 1.1 & 1.1 \\
\hline \multirow[t]{4}{*}{ ount Verno } & $100496-1$ & -1.4 & -1.2 & $\mathrm{~N} / \bar{A}$ & $\mathrm{~N} / \mathrm{A}$ & $\mathrm{N} / \mathrm{A}$ & $\mathrm{N} / \mathrm{A}$ & 1.0 & 1.0 & 1.0 \\
\hline & $100496-2$ & -1.7 & -0.5 & N/A & $\mathrm{N} / \mathrm{A}$ & N/A & $\mathrm{N} / \mathrm{A}$ & 0.9 & 1.1 & 1.1 \\
\hline & $100496-3$ & -0.3 & -0.2 & $\mathrm{~N} / \mathrm{A}$ & $\mathrm{N} / \mathrm{A}$ & $\mathrm{N} / \mathrm{A}$ & $\mathrm{N} / \mathrm{A}$ & 1.0 & 1.0 & 1.0 \\
\hline & $100496-4$ & -1.6 & 2.2 & N/A & $\mathrm{N} / \mathrm{A}$ & $\mathrm{N} / \mathrm{A}$ & $\mathrm{N} / \mathrm{A}$ & 0.7 & 1.1 & 1.2 \\
\hline \multirow[t]{4}{*}{ Knox } & $100496-5$ & -1.3 & -0.7 & $\mathrm{~N} / \mathrm{A}$ & $\mathrm{N} / \mathrm{A}$ & $\mathrm{N} / \mathrm{A}$ & $\mathrm{N} / \mathrm{A}$ & 1.0 & 1.0 & 1.0 \\
\hline & $100496-6$ & -1.3 & 0.1 & N/A & $\mathrm{N} / \mathrm{A}$ & N/A & $\mathrm{N} / \mathrm{A}$ & 0.9 & 1.0 & 1.1 \\
\hline & $100496-7$ & -0.4 & 0.5 & N/A & $\mathrm{N} / \mathrm{A}$ & $\mathrm{N} / \mathrm{A}$ & $\mathrm{N} / \mathrm{A}$ & 0.9 & 1.0 & 1.0 \\
\hline & 100496-8 & -1.2 & 0.6 & N/A & $\mathrm{N} / \mathrm{A}$ & N/A & $\mathrm{N} / \mathrm{A}$ & 0.9 & 1.0 & 1.0 \\
\hline \multirow[t]{3}{*}{ Anderson II } & $102196-1$ & 0.9 & N/A & N/A & $\mathrm{N} / \mathrm{A}$ & N/A & $\mathrm{N} / \mathrm{A}$ & $\mathrm{N} / \mathrm{A}$ & $\mathrm{N} / \mathrm{A}$ & $\mathrm{N} / \mathrm{A}$ \\
\hline & $102196-2$ & 1.3 & $\mathrm{~N} / \mathrm{A}$ & $\mathrm{N} / \mathrm{A}$ & $\mathrm{N} / \mathrm{A}$ & $\mathrm{N} / \mathrm{A}$ & $\mathrm{N} / \mathrm{A}$ & N/A & $\mathrm{N} / \mathrm{A}$ & $N / A$ \\
\hline & $102196-3$ & -1.1 & $\mathrm{~N} / \mathrm{A}$ & N/A & $\mathrm{N} / \mathrm{A}$ & $\mathrm{N} / \mathrm{A}$ & $\mathrm{N} / \mathrm{A}$ & N/A & N/A & N/A \\
\hline \multirow[t]{5}{*}{$1-52$ I } & $062997-1$ & 0.6 & $\mathrm{~N} / \mathrm{A}$ & -0.030 & $\mathrm{~N} / \mathrm{A}$ & -0.019 & $\mathrm{~N} / \mathrm{A}$ & $\mathrm{N} / \mathrm{A}$ & $\mathrm{N}^{\prime} \mathrm{A}$ & $\overline{\mathrm{N} / \mathrm{A}}$ \\
\hline & $062997-2$ & -0.8 & $\mathrm{~N} / \mathrm{A}$ & 0.094 & $\mathrm{~N} / \mathrm{A}$ & 0.069 & $\mathrm{~N} / \mathrm{A}$ & N/A & N/A & $\mathrm{N} / \mathrm{A}$ \\
\hline & $062997-3$ & 0.0 & $\mathrm{~N} / \mathrm{A}$ & 0.337 & $\mathrm{~N} / \mathrm{A}$ & 0.276 & $\mathrm{~N} / \mathrm{A}$ & $\mathrm{N} / \mathrm{A}$ & $\mathrm{N} / \mathrm{A}$ & $\mathrm{N} / \mathrm{A}$ \\
\hline & $062997-4$ & 0.0 & N/A & 0.230 & $\mathrm{~N} / \mathrm{A}$ & 0.168 & $\mathrm{~N} / \mathrm{A}$ & $\mathrm{N} / \mathrm{A}$ & N/A & $\mathrm{N} / \mathrm{A}$ \\
\hline & $062997-5$ & 0.9 & N/A & -0.058 & $\mathrm{~N} / \mathrm{A}$ & -0.091 & $\mathrm{~N} / \mathrm{A}$ & N/A & N/A & $\mathrm{N} / \mathrm{A}$ \\
\hline \multirow[t]{5}{*}{ I-52 II } & $071397-1$ & -0.5 & $\mathrm{~N} / \mathrm{A}$ & -0.282 & $\mathrm{~N} / \mathrm{A}$ & -0.241 & $\mathrm{~N} / \mathrm{A}$ & $\mathrm{N} / \mathrm{A}$ & $\mathrm{N} / \mathrm{A}$ & $\mathrm{N} / \mathrm{A}$ \\
\hline & $071397-2$ & 0.7 & $\mathrm{~N} / \mathrm{A}$ & -0.173 & $\mathrm{~N} / \mathrm{A}$ & -0.140 & $\mathrm{~N} / \mathrm{A}$ & $\mathrm{N} / \mathrm{A}$ & $\mathrm{N} / \mathrm{A}$ & $\mathrm{N} / \mathrm{A}$ \\
\hline & $07 \mid 397-3$ & -0.2 & N/A & 0.322 & $\mathrm{~N} / \mathrm{A}$ & 0.264 & $\mathrm{~N} / \mathrm{A}$ & $\mathrm{N} / \mathrm{A}$ & N/A & $\mathrm{N} / \mathrm{A}$ \\
\hline & $071397-4$ & -1.0 & $\mathrm{~N} / \mathrm{A}$ & 0.008 & $\mathrm{~N} / \mathrm{A}$ & 0.001 & $\mathrm{~N} / \mathrm{A}$ & $\mathrm{N} / \mathrm{A}$ & N/A & $\mathrm{N} / \mathrm{A}$ \\
\hline & $071397-5$ & 0.2 & $\mathrm{~N} / \mathrm{A}$ & -0.117 & $\mathrm{~N} / \mathrm{A}$ & -0.104 & $\mathrm{~N} / \mathrm{A}$ & $\mathrm{N} / \mathrm{A}$ & $\mathrm{N} / \mathrm{A}$ & $\mathrm{N} / \mathrm{A}$ \\
\hline \multirow[t]{3}{*}{ I-52 III } & $080397-1$ & 1.5 & N/A & 0.349 & N/A & 0.320 & N/A & $\mathrm{N} / \mathrm{A}$ & $\mathrm{N} / \mathrm{A}$ & $\mathrm{N} A$ \\
\hline & $080397-2$ & -0.1 & N/A & 0.279 & $\mathrm{~N} / \mathrm{A}$ & 0.215 & $\mathrm{~N} / \mathrm{A}$ & N/A & $\mathrm{N} / \mathrm{A}$ & $\mathrm{N} / \mathrm{A}$ \\
\hline & $080397-3$ & 0.5 & N/A & 0.476 & $\mathrm{~N} / \mathrm{A}$ & 0.439 & $\mathrm{~N} / \mathrm{A}$ & N/A & N/A & $\mathrm{N} / \mathrm{A}$ \\
\hline \multirow[t]{8}{*}{ Gas City } & $082897-1$ & -0.3 & -2.4 & 0.089 & 0.048 & 0.142 & 0.141 & 1.2 & 1.0 & 1.0 \\
\hline & $082897-2$ & -0.4 & -2.5 & 0.026 & -0.046 & 0.005 & -0.024 & 1.2 & 1.0 & 1.0 \\
\hline & $082897-3$ & 0.1 & 0.0 & 0.106 & -0.010 & 0.105 & 0.006 & 1.0 & 1.1 & 1.1 \\
\hline & $082897-4$ & -0.5 & 0.2 & 0.059 & -0.047 & 0.064 & -0.040 & 1.0 & 1.1 & 1.1 \\
\hline & $082897-5$ & 0.4 & -1.5 & 0.001 & -0.014 & -0.046 & -0.029 & 1.1 & 1.0 & 1.0 \\
\hline & $082897-6$ & 1.8 & -1.3 & 0.115 & 0.011 & 0.069 & 0.027 & 1.3 & 1.1 & 1.0 \\
\hline & $082897-7$ & 0.7 & -1.9 & 0.167 & -0.040 & 0.110 & -0.032 & 1.2 & 1.1 & 1.1 \\
\hline & $082897-8$ & 1.4 & -1.7 & -0.062 & 0.020 & -0.077 & 0.045 & 1.3 & 1.0 & 0.9 \\
\hline
\end{tabular}




\section{CHAPTER 7}

\section{STANDARDIZED PROCEDURE AND ASTM/AASHTO DRAFT STANDARDS}

\subsection{Introduction}

A standardized procedure for using TDR to measure the water content and density of compacted soil is introduced here to aid in obtaining consistent results. The recommended procedure differs slightly from the procedure outlined in the previous study. Draft standards have been prepared in the format of both ASTM and AASHTO.

\subsection{Modifications to the Testing Procedure}

Recommendations for implementing the developed technology were made in the final report of the previous study (FHWA/IN/JHRP-95/9). Two modifications to the previous work are recommended. One relates to the testing procedure and the other relates to the calculations.

\section{Procedure}

In the previous study a recommendation was made to compact the soil into the $\mathrm{CC}$ mold such that the density was within 10 percent of the in situ density. This restriction slows the testing process and requires repeating a test if the criterion is not met. New test data and a reevaluation of previous data indicate that the scatter in the measurements is not correlated to the difference in density between the two samples. Accordingly, to expedite the testing process, this restriction is no longer recommended. The only restriction on compaction in the $\mathrm{CC}$ mold is that the material be compacted as uniformly as possible without macro voids. 


\section{Calculation}

As discussed in Chapter 6, Topp's equation is no longer recommended for calculating water content due to the influence of soil density on accuracy. Eqn [6.3] should be used for this purpose with either soil specific, or general, coefficients $a$ and $b$. Recommended values for general coefficients are $a=0.8$ and $b=10$. The $a$ and $b$ values depend on the $b / a$ ratio and length of the coaxial line. The recommended values reported here differ from those of the previous study because modifications were made to the equipment geometry.

\subsection{Draft of Standards}

Drafts standards in the format of ASTM and ASSHTO are provided in Appendix I and II. 


\section{CHAPTER 8}

\section{SUMMARY, CONCULSIONS AND RECOMMENDATIONS}

\subsection{Summary and Conclusions}

Siddiqui and Drnevich (1995) developed a new method of measuring in-place density and water content of compacted soil. Equipment and a procedure were developed that uses time domain reflectometry (TDR) to make the measurements. The objectives of the present study were to evaluate the proposed approach under actual field conditions by developing prototype equipment, automating data interpretation, conducting tests on actual construction sites for comparison with other measurement methods, and preparing draft specifications.

The TDR technique is used to measure the apparent dielectric constant of the soil. The dielectric constant is correlated with the water content and density of the soil. The dielectric constant is obtained by measuring the velocity of an electromagnetic wave traveling through a coaxial line while soil is the insulating material. The velocity of a reflected electromagnetic wave is measured using a TDR apparatus and the coaxial line can either be a coaxial cylinder (CC) in which soil is compacted, or a multiple rod probe (MRP) that is inserted into the compacted soil. The dimensions of the CC and MRP have been optimized to obtain the best quality signal and to test a representative quantity of soil. Siddiqui and Drnevich (1995) presented a thorough investigation and description of both the spatial and electromagnetic variables.

Modifications were made to the equipment as part of the present study. The $\mathrm{CC}$ was modified so that the same head could be used for both the CC and MRP thus reducing the needed equipment. The data interpretation process was automated to eliminate operator 
dependence and expedite testing time. Data reduction was also automated and a database of test information developed.

Additional tests were conducted over a broader range in soil type and density and it was shown that the use of Topp's equation to define the relationship between volumetric water content and density did not have sufficient accuracy because it does not account for variations in soil density. Accordingly, the soil specific calibration equations of the form proposed by Siddiqui (1995) are used. When using these relationships the accuracy of results for tests over a greater density range were consistent with those of the previous study.

During field testing it is necessary to compact the tested soil into the CC mold. Although Siddiqui (1995) recommended that the density of the soil in the CC mold should be within 10 percent of the density in situ, additional testing showed that imposing this restriction did not appreciably improve density estimates. Accordingly, this criterion was relaxed and the only criterion for compaction of the soil in the $\mathrm{CC}$ mold is that the material be uniform and without macro voids.

The sand cone and nuclear density tests are the most common compaction control tests used in Indiana. Under field conditions it was shown that the TDR method is more accurate than the nuclear density gage in estimating water content when compared to oven drying, with standard errors of $1.1 \%$ and $1.8 \%$, respectively. Water content can not be estimated using the sand cone test. It is more difficult to assess the accuracy of these methods in the determination of dry density because the true dry density is not known because there are errors associated with all methods. Although not completely accurate, the sand cone test was conducted on several sites and is used here to compare the TDR and nuclear density test results. On sites where TDR, nuclear density, and sand cone tests were performed, the dry 
density estimated by the nuclear density gage was more consistent with the sand cone than was the TDR method, yielding standard errors of $3.6 \%$ and $5.5 \%$, respectively. It must be recognized that spatial variability with the compacted soil also played a role in the differences measured. The measured density differed by approximately $0.04 \mathrm{Mg} / \mathrm{m}^{3}(2.2 \%)$ for two nuclear density tests performed approximately $20 \mathrm{~cm}(8 \mathrm{in})$ apart. Under the laboratory condition, the standard error of the TDR method for density in compacted cylinders where the density is known accurately is $2.3 \%$.

The time require to perform the TDR test under field conditions is approximately 15 to 20 minutes. The sand cone test can also be performed in approximately 15 minutes while the nuclear density test can be performed in approximately 2 minutes. The time required to complete the TDR test relative to the nuclear density test is viewed as its greatest limitation.

In general, the nuclear gage: provides estimates of density and water content much more rapidly than the sand cone or TDR tests, is less accurate than the TDR test in estimating water content, and must be calibrated for a specific soil using sand cone tests. Moreover, the nuclear gage uses a hazardous source requiring operators to take safety training and leading to expenses associated with equipment maintenance and disposal. The sand cone test is time consuming, and can not provide estimates of water content. The TDR test is also time consuming, but does provide accurate estimates of water content. The errors associated with estimated dry density, when compared to the sand cone test, are larger than the nuclear density test which is calibrated using the sand cone test.

At the present stage of the research, the TDR test has not shown great advantage in the measurement of water content and density relative to the nuclear density test. However, progress is being made in the development of an approach to use other features of the 
reflected waveform, in addition to the apparent dielectric constant, within the interpretation process. The research has tremendous potential and is described briefly in the next section.

\subsection{Recommendations for Additional Research}

The present TDR test is based solely on the measurement of the apparent dielectric constant. The dielectric constant is a single parameter that is obtained from the reflected electro-magnetic waveform. During the completion of this study it became obvious when comparing curves of different soil type and at different densities that the reflected waveforms contained much more information than is currently being utilized. A new study has been initiated to use the entire waveform to estimate soil type and density. The primary objective is to increase the accuracy of the density estimate while eliminating the need to excavate and recompact the soil in the $\mathrm{CC}$ mold thereby reducing the test time substantially. Presently, a numerical model has been developed to simulate the coaxial system and reflected waveform. The input parameters to the model are soil properties and relative volumes of soil, air and water. The model captures even subtle features of the reflected waveform. The research is now directed toward solving the inverse problem of determining the soil parameters from the measured waveform. 


\section{REFERENCES}




\section{REFERENCES}

ASTM, D1556 (1997), "Standard Test Method for Density and Unit Weight of Soil in Place by the Sand-Cone Method," Annual Book of ASTM Standards, Vol. 04.08, 120-125.

ASTM, D1557 (1997), "Test Method for Laboratory Compaction Characteristics of Soil Using Modified Effort $\left(56,000 \mathrm{ft}-\mathrm{lbf} / \mathrm{ft}^{3}\left(2,700 \mathrm{kN}-\mathrm{m} / \mathrm{m}^{3}\right)\right)$," Annual Book of ASTM Standards, Vol. 04.08, 125-133.

ASTM, D698 (1997), "Test Method for Laboratory Compaction Characteristics of Soil Using Modified Effort $\left(12,400 \mathrm{ft}-\mathrm{lbf} / \mathrm{ft}^{3}\left(600 \mathrm{kN}-\mathrm{m} / \mathrm{m}^{3}\right)\right)$," Annual Book of ASTM Standards, Vol. 04.08, 77-84.

Baker, J. M. and Allmaras, R. R. (1990), "System for Automating and Multiplexing Soil Moisture Measurement by Time-Domain Reflectometry," Soil Sci. Soc. Am. J., Vol. 55, 1-6.

Birchak, J. R., Gardner, C. G., Hipp, J. E., and Victor, J. M. (1974), "High Dielectric Constant Microwave Probe for Sensing Soil Moisture," Proc. IEEE, Vol. 62 (1), 93-98.

Bohl, H. and Roth, K. (1994), "Evaluation of Dielectric Mixing Models to Describe the $\theta(\varepsilon)$ Relation," Proceedings of the Symposium and Workshop on Time Domain Reflectometry in Environmental, Infrastructure and Mining Applications, Evanston, IL., Spec. Publ. SP 19-94, 309-319.

de Loor, G. P. (1964), "Dielectric Properties of Heterogeneous Mixtures with a Polar Constituent," Appl. Sci. Res., Vol. 11, 310-320.

Dirksen, C. and Dasberg, S. (1993), "Improved Calibration of Time Domain Reflectometry Soil Water Content Measurements," Soil Sci. Soc. Am. J., Vol. 57, 660-667.

Fellner-Feldegg, H. (1969), "Measurement of Dielectrics in the Time Domain," Journal of Physical Chemistry, Vol. 73, 616-623.

Heimovaara, T. J. and Bouten, W. (1990), "A Computer-Controlled 36-Channel Time Domain Reflectometry System for Monitoring Soil Water Contents," Water Resources Research, Vol. 26, No. 10, 2311-2316.

Microsoft Corporation (Redmond, WA) (1993), "Visual Basic Programmer's Guide (for Visual Basic 3, Professional Version)."

Siddiqui, S. I. (1995), "A New Method of Measuring Density and Moisture Content of Soil Using the Technique of Time Domain Reflectometry,", Ph. D. Theses, Purdue University. 
Siddiqui, S. I. And Drnevich, V. P. (1995), "Use of Time Domain Reflectometry for the Determination of Water Content and Density of Soil," Joint Highway Research Project Report, FHWA/IN/JHRP-95/9, Purdue University.

Tektronix (Beaverton, OR) (1989), "SP232 Serial Extended Function Module for 1502B and 1503B MTDRs."

Timlin, D. J. and Pachepsky, Ya. A. (1996), "Comparison of Three Methods to Obtain the Apparent Dielectric Constant from Time Domain Reflectometry Wave Traces," Soil Sci. Soc. Am. J., Vol. 60, 970-977.

Topp, G. C., Davis, J. L. and Annan, A. P. (1980), "Electromagnetic Determination of Soil Water Content: Measurement in Coaxial Transmission Lines," Ware Resources Research, Vol. 16, 574-582.

Topp, G. C., Davis, J. L., and Annan, A. P. (1982), "Electromagnetic Determination of Soil Water Content Using TDR: II., Evaluation of Installation and Configuration of Parallel Transmission Lines," Soil Sci. Soc. Am. J., Vol. 46, 678-684.

Zegelin, S. J., White, I., and Jenskins, D. R. (1989) "Improved Field Probes for Soil Water Content and Electrical Conductivity Measurement Using Time Domain Reflectomety," Water Resources Research, Vol. 25, 2367-2376. 
APPENDIX 


\title{
Appendix I ASTM Standard Draft
}

\author{
Standard Test Method for \\ Determination of Water Content and Density of Soil in Place Using Time Domain \\ Reflectometry (TDR)
}

\section{Scope}

1.1 This test method may be used to determine the water content of soils and the in-place density and unit weight of soils using a TDR apparatus.

1.2 This test method is applicable for soils without an appreciable amount of rock or coarse materials in excess of 1.5 in. $(38 \mathrm{~mm})$ in diameter.

1.3 This test method is suitable for use as a means of acceptance for compacted fill or embankments.

1.4 This method may not be suitable for organic and highly plastic soils.

1.5 This standard does not purport to address the safety problems associated with its use. It is the responsibility of the user of this standard to establish appropriate safety and health practices and determine the applicability of regulatory limitations prior to use.

\section{Referenced Documents}

\subsection{ASTM Standards:}

D653 Terminology Relating to Soil, Rock, and Contained Fluids

D698 Test Methods for Moisture-Density Relations of Soils and Soil-Aggregate Mixtures, Using 5.5lb (2.49kg) Rammer and 12-in. (305-mm) Drop

D1556 Test Method for Moisture-Density of Soil In-Place by the Sand-Cone Method

D1557 Test Methods for Moisture-Density Relations of Soils and Soil-Aggregate Mixtures, Using $10 \mathrm{lb}$ (4.54kg) Rammer and 18-in. (457-mm) Drop

D2167 Test Method for Density of Soil ln-Place by the Rubber-Balloon Method

D2216 Method for Laboratory Determination of Water (Moisture) Content of Soil, Rock, and Soil-Aggregate Mixtures

D2922 Test Methods for Density of Soil and Soil Aggregate and Rock in Place by Nuclear Methods (Shallow Depth)

D2937 Test Method for Density of Soil In-Place by the Drive-Cylinder Method

D3017 Test Method for Water Content of Soil and Rock In-Place by Nuclear Methods (Shallow Depth)

D4643 Method for Determination of Water (Moisture) Content of Soil by the Microwave Oven Method

D4718 Practice for Correction of Unit Weight and Water Content for Soils Containing Oversize Particles

D4753 Specification for Evaluating, Selecting, and Specifying Balances and Scales for Use in Soil and Rock Testing

D4914 Test Method for Density and Unit Weight of Soil and Rock in Place by the Sand Replacement Method

D4944 Test Method for Field Determination of Water (Moisture) Content of Soil by the Calcium Carbide Gas Pressure Tester Method 
D4959 Test Method for Determination of Water (Moisture) Content of Soil by Direct Heating Method

D5030 Test Methods for Density and Unit Weight of Soil and Rock in Place by the Water Replacement Method

E380 Practice for Use of the International System of Units (SI) (the Modernized Metric System)

\section{Terminology}

3.1 Refer to Terminology D653 for standard definitions of terms.

3.2 Description of Terms Specific to This Standard:

3.2.2 Apparent length - The distance between two reflection points in the waveform measured by the TDR apparatus.

3.2.2 Apparent dielectric constant - The squared ratio of the velocity of light to the apparent velocity of electromagnetic wave propagation in the soil measured by TDR is named the apparent dielectric constant of the soil.

\section{Summary of Test Method}

4.1 The dielectric constant of the soil in-situ is determined using a multiple rod probe (MRP), a coaxial head (CH), and TDR apparatus. A small hole is excavated $\left(1650 \mathrm{~cm}^{3}\right)$ at the location of the in-situ measurement and the soil is compacted in a mold. The wet density is determined using a balance. The dielectric constant of the soil in the mold is measured. The moisture content and density of soil in-situ are determined using a correlation between the dielectric constant, moisture content and dry density.

\section{Significance and Use}

5.1 This test method can be used to determine the density and water content of compacted soils placed during the construction of earth embankments, road fill, and structural backfill.

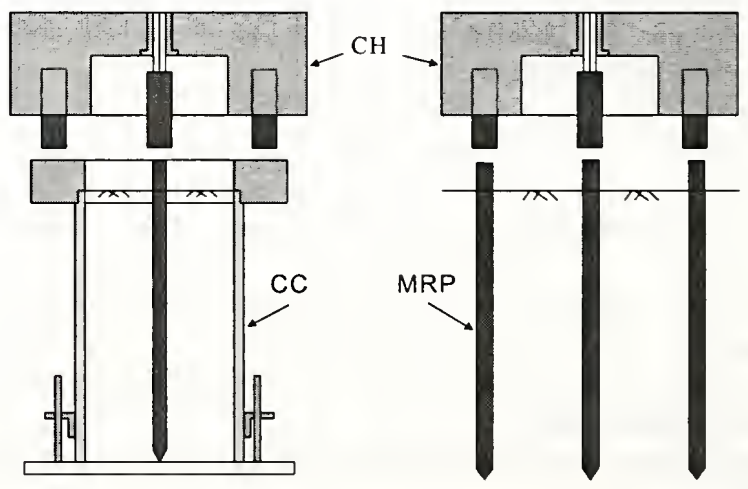

FIG. 1 Configuration of transmission lines. 


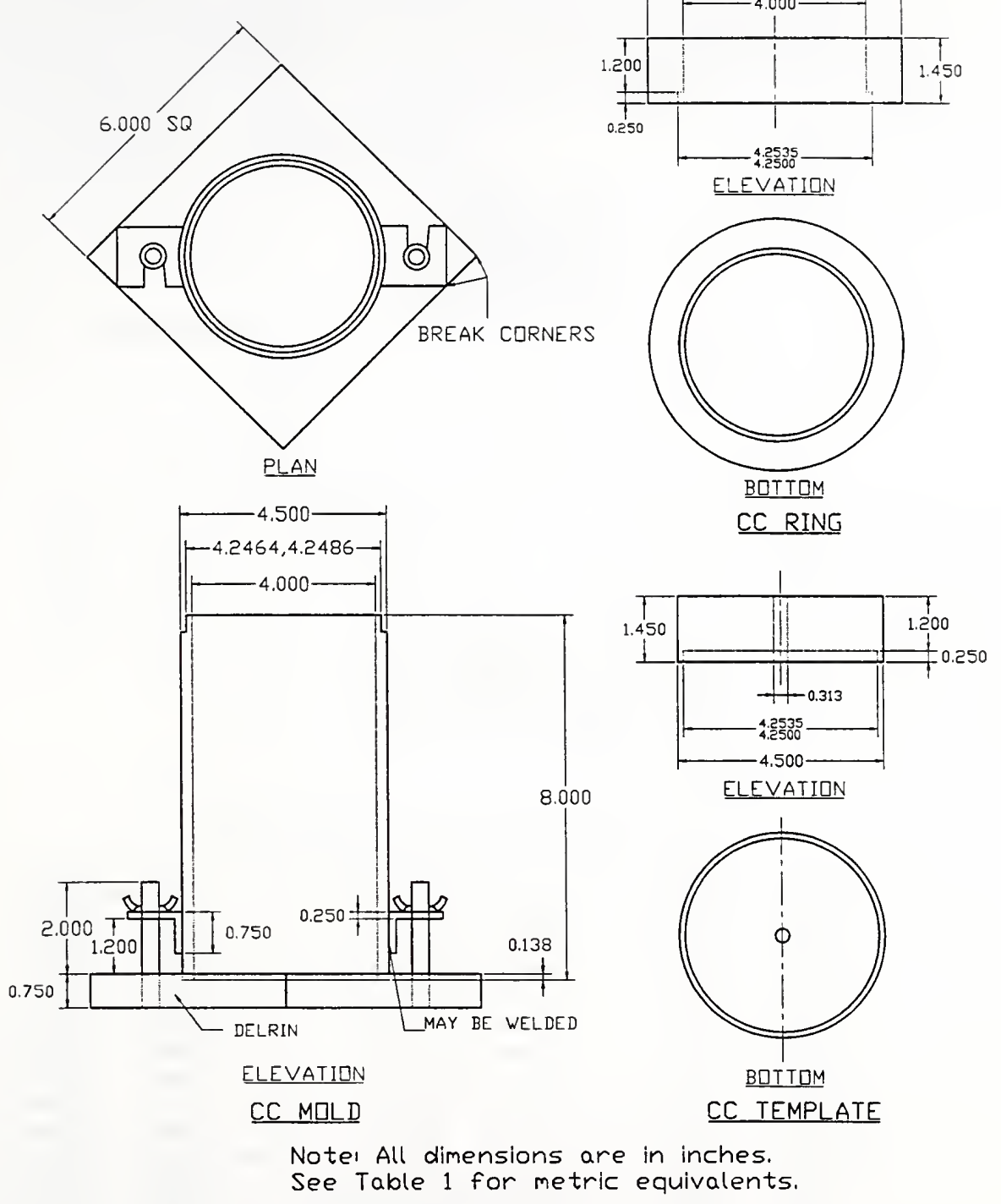

FIG. 2 CC mold, $\mathrm{CC}$ ring collar and $\mathrm{CC}$ guide template 

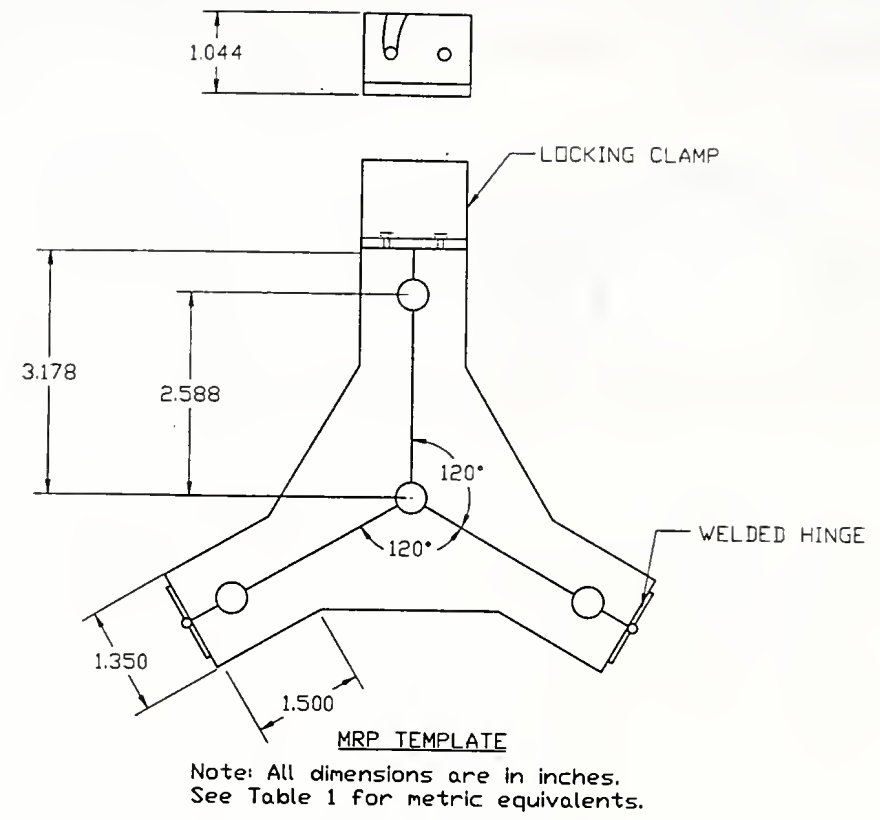

FIG. 3 MRP Guide templates

TABLE 1 Metric Equivalents for FIG. 2, 3 and 4

\begin{tabular}{rrrrrrr}
\hline in. & mm & in. & $\mathrm{mm}$ & in. & $\mathrm{mm}$ \\
\hline 0.050 & 1.27 & 0.750 & 19.05 & 3.3714 & 85.634 \\
0.100 & 2.54 & 0.800 & 20.32 & 3.3736 & 85.689 \\
0.138 & 3.51 & 0.825 & 20.96 & 3.3750 & 85.725 \\
0.185 & 4.70 & 1.000 & 25.40 & 3.3785 & 85.814 \\
0.188 & 4.78 & 1.044 & 26.52 & 3.9964 & 101.509 \\
0.250 & 6.35 & 1.188 & 30.18 & 3.9986 & 101.564 \\
0.288 & 7.32 & 1.200 & 30.48 & 4.0000 & 101.600 \\
0.313 & 7.95 & 1.350 & 34.29 & 4.0035 & 101.689 \\
0.325 & 8.26 & 1.450 & 36.83 & 4.2464 & 107.859 \\
0.375 & 9.53 & 1.500 & 38.10 & 4.2486 & 107.914 \\
0.388 & 9.86 & 1.844 & 46.84 & 4.2500 & 107.950 \\
0.413 & 10.49 & 2.000 & 50.80 & 4.2535 & 108.039 \\
0.500 & 12.70 & 2.188 & 55.58 & 4.500 & 114.300 \\
0.600 & 15.24 & 2.588 & 65.74 & 5.550 & 140.970 \\
0.612 & 15.54 & 3.000 & 76.20 & 6.000 & 152.400 \\
0.625 & 15.88 & 3.178 & 80.72 & 8.000 & 203.200 \\
\hline
\end{tabular}



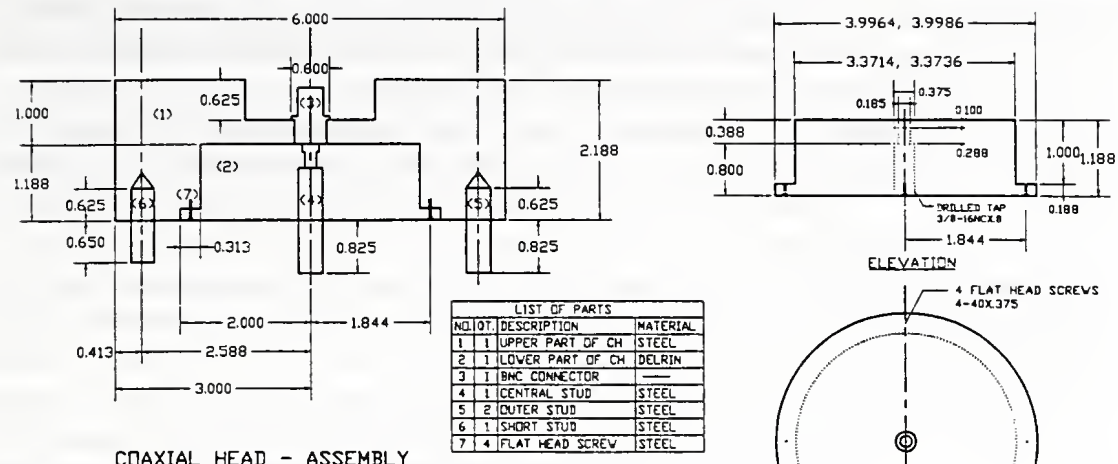

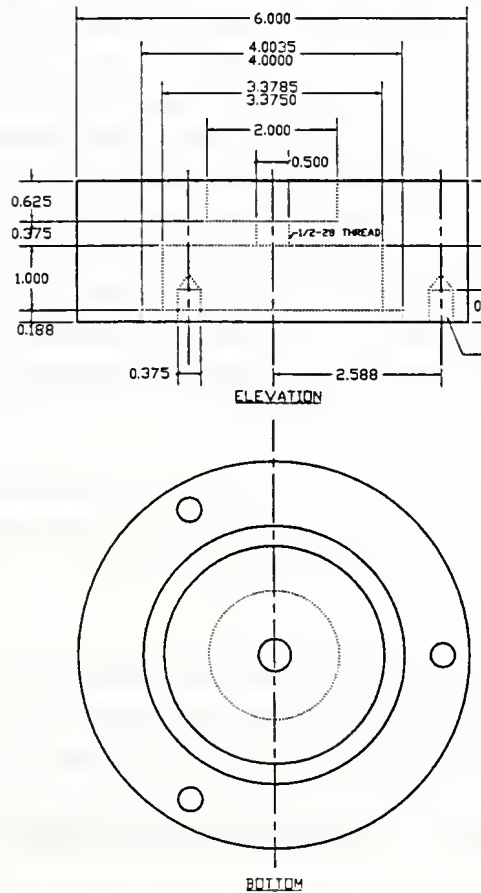

EART
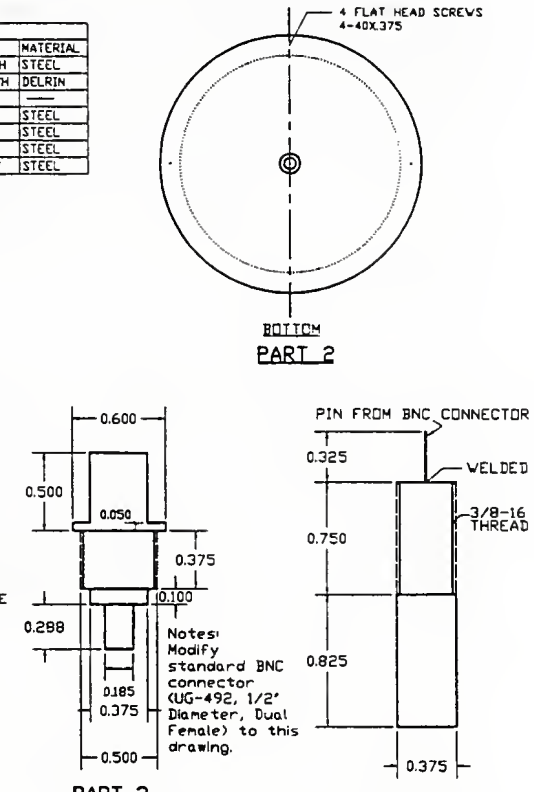

PART 3

PART 4
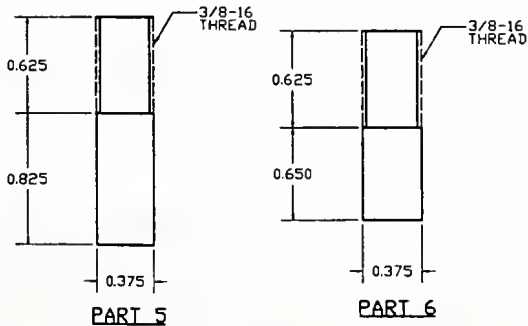

PARI 6

Noter All dlmenslons are in Inches.

See Table 1 for metric equlvalents.

FIG. 4 Coaxial Head (CH) 


\section{Apparatus}

6.1 TDR equipment: A Metallic Time Domain Reflectometer (e.g. Tektronix 1502B).

6.2 Transmission line apparatus: The configuration of the transmission lines is shown in FIG. 1, consisting of the following:

6.2.1 Coaxial Cylinder (CC) transmission line: The $\mathrm{CC}$ transmission line consists of a CC mold, a ring collar and a central rod. The details for CC mold and CC ring collar are shown in FIG. 2. The central rod is a stainless steel rod, $5 / 16$ in. $(79 \mathrm{~mm})$ in diameter and 9.2 in. $(23.4 \mathrm{~cm})$ in length.

6.2.2 Multiple Rod Probe (MRP) transmission line: The MRP transmission line consists of four common metal spikes 10 in. $(25.4 \mathrm{~cm})$ in length and uniform diameters of $3 / 8$ in. (3.8 mm).

6.2.3 Guide templates: One guide template is used with the $\mathrm{CC}$ mold to drive the central rod into the soil and one guide template is used with the MRP to drive the spikes into the soil. The details for the CC and MRP guide templates are shown in FIG. 2 and FIG. 3, respectively. After the rod/spikes are driven, the template is removed from the CC/MRP transmission line.

6.2.4 Coaxial Head $(\mathrm{CH})$ transmission line: The details for the $\mathrm{CH}$ are shown in FIG. 4. The $\mathrm{CH}$ has four metallic studs threaded into the metallic head. The central stud and two of the outer studs fixed and of equal length. The fourth stud is threaded of adjustable length. Coaxial cable connects the TDR equipment to the coaxial head $(\mathrm{CH})$. The $\mathrm{CH}$ is connected to MRP transmission line by placing it on the spikes so the central stud sits on top of the central spike and the two fixed outer studs sit on top of two outer spikes. The adjustable stud is tumed until contact is made with spikes. The $\mathrm{CH}$ is connected to $\mathrm{CC}$ transmission line by placing it on the ring collar so that the central stud sit on top of the central rod and the two fixed outer studs sit on top of the ring collar. The adjustable stud is turned until contact is made with the out ring.

6.3 Balances or scales: Meeting Specification ASTM D4753 to determine the mass of the soil in CC. A balance or scale having a minimum capacity of $10 \mathrm{~kg}$ and $5.0 \mathrm{~g}$ readability is suitable for determining the mass of the soil in $\mathrm{CC}$ when an apparatus with the dimension given in FIG. 2 is used.

6.4 Driving tools: One Brass Hammer for driving MRP spikes and CC central rod.

6.5 Miscellaneous tools: Small pick and shovel for digging holes and breaking up soils. A standard compaction hammer (ASTM 698) and straight edge for placing soils in CC.

\section{Procedure}

7.1 Determine the volume of the CC mold in accordance with Test Method D698 ANNEX A.1, Volume of Compaction Mold.

7.2 Determine and record the mass of the CC mold and base plate, length of CC central rod and length of MRP spikes.

7.3 Prepare the surface at the test location so that it is plane and level.

7.4 Seat the MRP guide template on the plane surface.

7.5 Drive the spikes through the guide holes so that the bottom surfaces of the spike heads touch the template. The outer rods should be driven first and then the central one to avoid creating an air gap around the central spike when driving the outer spikes. 
7.6 Remove the template. Check that all spikes are driven properly without any air gap around the spikes.

7.7 Connect the coaxial cable to the $\mathrm{CH}$ and the TDR device.

7.8 Wipe the top surfaces of the spike heads and ends of the studs on the $\mathrm{CH}$.

7.9 Place the $\mathrm{CH}$ on the spikes as described in section 6.2.4.

7.10 Determine and record the apparent length with the TDR equipment.

7.11 Remove the spikes.

7.12 Assemble and secure the CC mold and ring collar to the base plate.

7.13 Dig out a sufficient quantity of soil from the location of the in-place measurement and uniformly compact it in the CC. The soils are placed into CC mold in 4 lifts and applied 10 blows per lift using standard compaction hammer. Soil should be taken uniformly over the entire depth of in-place measurement. Remove the ring collar and strike the surface level after compaction.

7.14 Measure the mass of the soil and CC including the base plate.

7.15 Mount the $\mathrm{CC}$ guide template on to the $\mathrm{CC}$.

7.16 Drive the CC central rod through the guide hole into the soil until the top of rod is flush with the template using the brass hammer.

7.17 Remove the guide template from the $\mathrm{CC}$.

7.18 Determine and record the length of the central rod above the soil surface.

7.19 Place the ring collar on the CC.

7.20 Wipe the top surface of the ring collar and central rod and the ends of studs of the $\mathrm{CH}$.

7.21 Place the $\mathrm{CH}$ on the $\mathrm{CC}$ ring collar as described in Section 6.2.4.

7.22 Determine and record the apparent length with the TDR device.

7.23 Remove the soil from the CC.

\section{Calculation}

8.1 Calculate the apparent dielectric constant of the soil in place as follows:

$$
K_{\text {insitu }}=\left(\frac{l_{\text {insitu }}}{L_{\text {insitu }}}\right)^{2}
$$

where $1_{\text {insitu }}=$ measured apparent length insitu, $\mathrm{m}$, $\mathrm{L}_{\text {insitu }}=$ length of the spikes inserted into the soil, $\mathrm{m}$, $\mathrm{K}_{\text {insitu }}=$ apparent dielectric constant of the soil insitu.

8.2 Calculate the dielectric constant of the soil in the $\mathrm{CC}$ as follows:

$$
K_{C C}=\left(\frac{l_{c C}}{L_{c C}}\right)^{2}
$$

where

$\mathrm{l}_{\mathrm{CC}}=$ measured apparent length in the $\mathrm{CC}, \mathrm{m}$,

$\mathrm{L}_{\mathrm{CC}}=$ length of the rod inserted into the soil in the $\mathrm{CC}, \mathrm{m}$,

$\mathrm{K}_{\mathrm{CC}}=$ dielectric constant of soil in the CC. 
8.3 Calculate the wet density of the soil in $\mathrm{CC}$ as follows:

$\rho_{t, C C}=\frac{M_{1}-M_{2}}{V_{C C}}$

where

$\mathrm{M}_{1}=$ mass of the soil and $\mathrm{CC}, \mathrm{kg}$

$\mathrm{M}_{2}=$ mass of the $\mathrm{CC}, \mathrm{kg}$

$\mathrm{V}_{\mathrm{CC}}=$ volume of the $\mathrm{CC}, \mathrm{m}^{3}$,

$\rho_{\mathrm{t}, C \mathrm{C}}=$ wet density of the soil in the $\mathrm{CC}, \mathrm{kg} / \mathrm{m}^{3}$.

8.4 Calculate the water content of the soil in the $\mathrm{CC}$ and insitu as follows

$w_{\text {insitu }}=w_{C C}=\frac{\sqrt{K_{C C}}-a \rho_{t . C C} / \rho_{w^{\prime}}}{b \rho_{t, C C} / \rho_{w^{w}}-\sqrt{K_{C C}}} \times 100$

where

$\mathrm{K}_{\mathrm{CC}}=$ apparent dielectric constant of the soil in the $\mathrm{CC}$,

$\rho_{\mathrm{t}, C C}=$ wet density of the soil in the $\mathrm{CC}, \mathrm{kg} / \mathrm{m}^{3}$,

$\rho_{\mathrm{w}}=$ density of water $=1.0 \mathrm{~kg} / \mathrm{m}^{3}$,

$a=$ calibration constant, $\mathrm{a} \cong 0.8$ (See Annex)

$b=$ calibration constant, $\mathrm{b} \cong 10$ (See Annex)

$\omega_{\mathrm{CC}}=$ water content of the soil in the $\mathrm{CC}, \%$,

$\omega_{\text {insitu }}=$ water content of the soil insitu, $\%$.

8.6 Calculate the insitu dry density of the soil as follows:

$\rho_{t, \text { insitu }}=\frac{\sqrt{\boldsymbol{K}_{\text {insitu }}}}{\sqrt{\boldsymbol{K}_{C C}}} \times \frac{\rho_{t, C C}}{1+\omega_{C C} / 100}$

where

$\rho_{\mathrm{tCC}}=$ wet density of the soil in the $\mathrm{CC}, \mathrm{kg} / \mathrm{m}^{3}$,

$\mathrm{w}_{\mathrm{CC}}=$ gravimetric water content of the soil in the $\mathrm{CC}, \%$,

$\mathrm{K}_{\mathrm{CC}}=$ dielectric constant of soil in the CC,

$\mathrm{K}_{\text {nnsitu }}=$ dielectric constant of the soil insitu,

$\rho_{\mathrm{d} \text {.nnsitu }}=$ dry density of the soil insitu, $\mathrm{kg} / \mathrm{m}^{3}$.

\section{Report}

11.1 The report shall include the following:

9.1.1 Test site identification.

9.1.2 Name of the operator(s).

9.1.3 Make, model and serial number of the test instrument.

9.1.4 Visual description of material tested. 
9.1.5 Water content in percent of dry mass or dry unit weight.

9.1.6 Wet and dry densities in $\mathrm{kg} / \mathrm{m}^{3}$.

9.1.7 Calibration constants $a$ and $b$.

10. Precision and Bias

10.1 Precision:

10.1.1 Data are being evaluated to determine the precision of this test method.

10.2 Bias:

10.2.1 There is no accepted reference value for this test method, therefore, bias cannot be determined.

\section{Keywords}

11.1 water content, field density.

\section{Annex}

(Mandatory Information)

\section{A.1 Calibration Constants}

\section{A.1.1 Scope}

A.1.1.1 This annex describes the procedure to determine the calibration constants for use in Equation (4) to estimate soil water content.

\section{A.1.2 Apparatus}

A.1.2.1 TDR equipment, Tektronix 1502B.

A.1.2.2 Coaxial Cylinder (CC) transmission line.

A.1.2.3 CC Guide templates.

A.1.2.4 Brass Hammer.

A.1.2.5 Miscellaneous tools: Small picks and shovel for removing soils from the CC. A standard compaction hammer and straight edge for placing soils in CC.

\section{A.1.3 Procedure}

A.1.3.1 Air dry the soil sample.

A.1.3.2 Thoroughly break up the soil clumps in such a manner as to avoid breaking individual particles. Pass the material through a No. 4 sieve.

A.1.3.3 Prepare five specimens having water contents such that they bracket the estimated field water content and vary by about $2 \%$. Preparation procedure should be as specified in Section 10.2 or 10.3 of ASTM D 698

A.1.3.4 Determine the volume of the CC mold in accordance with Test Method D698 ANNEX A.1, Volume of Compaction Mold. 
A.1.3.5 Determine and record the mass of the CC mold and base plate, and the length of CC central rod.

A.1.3.6 Assemble and secure the CC mold and ring collar to the base plate.

A.1.3.7 The soils are compacted into CC mold in 4 lifts with 10 blows per lift using a standard compaction hammer.

A.1.3.8 Do procedure 7.14 to 7.22

A.1.3.9 Remove the soil from the CC mold. Obtain a portion of the sample for water content determination by slicing the compacted specimen axially through the center and removing at least $0.500 \mathrm{~kg}$ of soil from the cut faces. Obtain the water content in accordance with Test Method D2216.

A.1.3.10 Repeat A.1.3.6 to A.1.3.9 for each soil specimen.

\section{A.1.4 Calculation}

A.1.4.1 Calculate the dielectric constant of soil in the $\mathrm{CC}(\mathrm{K})$ as follows:

$$
K=\left(\frac{l}{L}\right)^{2}
$$

where

$1=$ measured apparent length in the $\mathrm{CC}, \mathrm{m}$,

$\mathrm{L}=$ length of the rod inserted into the soil in the $\mathrm{CC}, \mathrm{m}$,

$\mathrm{K}=$ dielectric constant of soil in the $\mathrm{CC}$.

A.1.4.2 Calculate water content in accordance with Test Method D2216.

A.1.4.3 Calculate the wet density of the soil in the $\mathrm{CC}$ as follows:

$\rho_{t}=\frac{\boldsymbol{M}_{\mathrm{1}}-\boldsymbol{M}_{2}}{\boldsymbol{V}}$

where

$M_{1}=$ mass of the soil and the $\mathrm{CC}, \mathrm{kg}$

$\mathrm{M}_{2}=$ mass of the $\mathrm{CC}, \mathrm{kg}$

$\mathrm{V}=$ volume of the $\mathrm{CC}, \mathrm{m}^{3}$,

$\rho_{\mathrm{t}}=$ wet density of the soil in the $\mathrm{CC}, \mathrm{kg} / \mathrm{m}^{3}$.

A.1.4.4 Calculate the dry density of the soil in the $\mathrm{CC}$ as follows:

$\rho_{d}=\frac{\rho_{t}}{1+w / 100}$

where

$\rho_{t}=$ wet density of the soil in the $\mathrm{CC}, \mathrm{kg} / \mathrm{m}^{3}$,

$w=$ water content, $\%$,

$\rho_{d}=$ dry density of the soil in the $\mathrm{CC}, \mathrm{kg} / \mathrm{m}^{3}$,

A.1.4.4 Calculate the calibration coefficients as follows: 
Plot $\sqrt{K} \rho_{w} / \rho_{\mathrm{d}}$ vs. $w$.

where

$K=$ dielectric constant of soil in the CC.

$\rho_{d}=$ dry density of the soil in the $\mathrm{CC}, \mathrm{kg} / \mathrm{m}^{3}$,

$\rho_{w}=$ density of water, $\mathrm{kg} / \mathrm{m}^{3}$,

$w=$ water content, $\%$.

Find the interception and slope of the best fit line.

$a=$ interception of the best fit line

$b=$ slope of the best fit line. 


\title{
Appendix II AASHTO Standard Draft
}

\author{
Standard Test Method \\ for \\ Determination of Moisture Content and Density of Soil in Place \\ Using Time Domain Reflectometry (TDR)
}

\section{SCOPE}

1.1 This test method describes a procedure to determine the moisture content and inplace density of soil using a TDR apparatus. The apparatus described in Section 6 is not suitable for soil with an appreciable amount of rock or coarse materials in excess of 1.5 in. $(38 \mathrm{~mm})$ in diameter. The method may not be suitable for organic and highly plastic soils.

1.2 The following applies to all specified limits in this standard: For the purposes of determining conformance with these specifications, an observed value or a calculated value shall be rounded off "to the nearest unit" in the last right-hand place of figures used in expressing the limiting value, in accordance with rounding-off method of AASHTO R 11, Recommended Practice for Indicating Which Places of Figures Are To Be Considered Significant In Specified Limiting Values.

\section{REFERENCED DOCUMENTS}

2.1 AASHTO Test Methods:

M231 Weights and Balances Used in the Testing of Highway Materials

T19 Unit Weight and Voids in Aggregate

T99 The Moisture-Density Relations of Soils Using a $5.5 \mathrm{lb}$. [2.5kg] Rammer and a 12 in. [305mm] Drop

T265 Laboratory Determination of Moisture Content of Soils

\section{DEFINITION OF APPARENT DIELECTRIC CONSTANT}

3.1 Apparent length - The distance between two reflection points in the waveform measured by the TDR apparatus.

3.2 Apparent dielectric constant - The squared ratio of the velocity of light to the apparent velocity of electromagnetic wave propagation in the soil measured by TDR is named the apparent dielectric constant of the soil.

\section{SUMMARY OF METHOD}

4.1 The dielectric constant of the soil in-situ is determined using a multiple rod probe (MRP), a coaxial head ( $\mathrm{CH})$, and TDR apparatus. A small hole is excavated $\left(1650 \mathrm{~cm}^{3}\right)$ at the location of the in-situ measurement and the soil is compacted in a mold. The wet density is determined using a balance. The dielectric constant of the soil in the mold is measured. The moisture content and density of soil in-situ are determined using a correlation between the dielectric constant, moisture content and dry density. 
4.2 The correlation involves constants, $a$ and $b$, which are the intercept and slope of the linear regression line for the squared root of dielectric constant divided by the ratio of dry density to density of water versus moisture content. The moisture content is calculated using this correlation with known calibrated constants and measured density in a mold. The ratio of unknown in-place density to the known density in the mold is equal to ratio of the squared root of dielectric constants in the two measurements. Hence, the density measurement does not depend on the calibration constants.

4.3 For all soil types, $a=0.8$ and $b=10$ are approximated values of the calibration constants to achieve an accuracy of $2 \%$ for moisture content if the apparatus described in Section 6 is used. One can increase the accuracy to be within $1 \%$ for moisture content by using constants specifically calibrated for the soil tested.

\section{SIGNIFICANCE}

5.1 This test method can be used to determine the density and moisture content of compacted soils placed during the construction of earth embankments, road fill, and structural backfill.

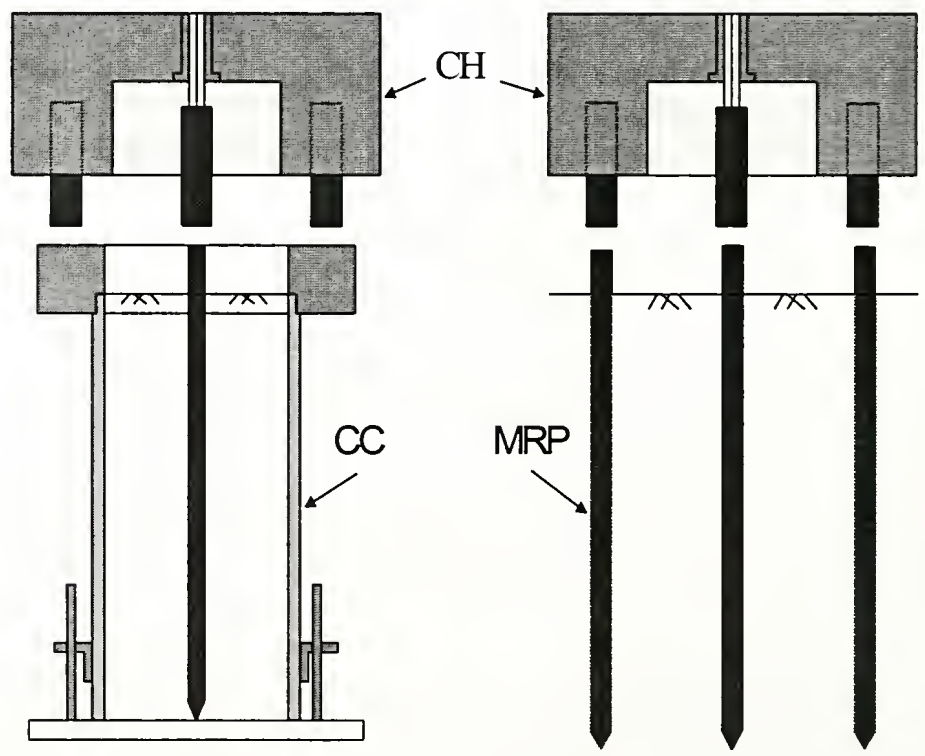

FIGURE. 1 Configuration of transmission lines. 

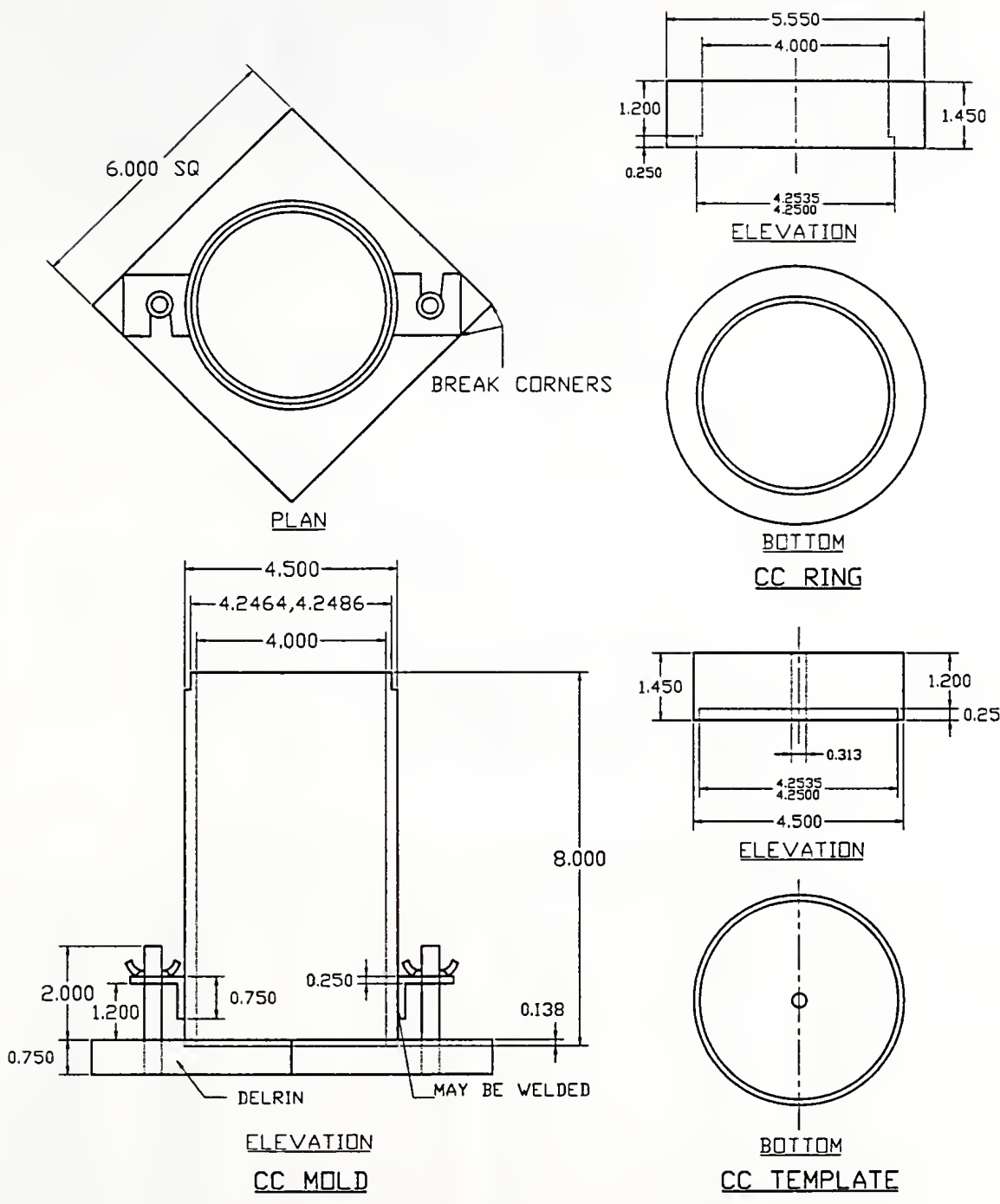

CC RING

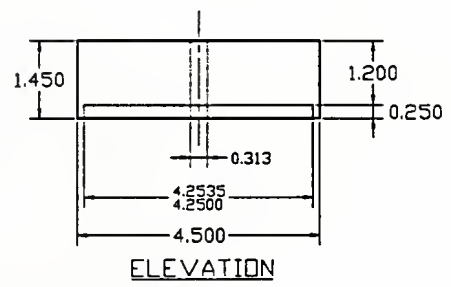

Notel All dimensions are in inches.

See Table 1 for metric equivalents.

FIGURE. 2 CC mold, $\mathrm{CC}$ ring collar and $\mathrm{CC}$ guide template 


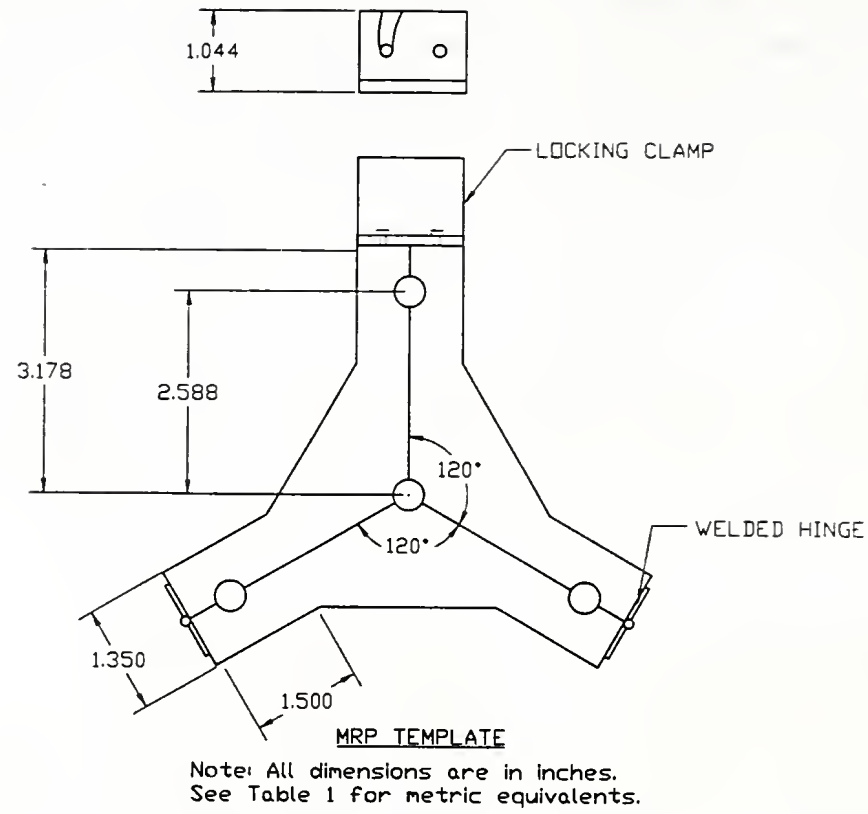

FIGURE. 3 MRP Guide templates

TABLE 1 Metric Equivalents for FIG. 2, 3 and 4

\begin{tabular}{rrrrrr}
\hline in. & $\mathrm{mm}$ & in. & $\mathrm{mm}$ & in. & $\mathrm{mm}$ \\
\hline 0.050 & 1.27 & 0.750 & 19.05 & 3.3714 & 85.634 \\
0.100 & 2.54 & 0.800 & 20.32 & 3.3736 & 85.689 \\
0.138 & 3.51 & 0.825 & 20.96 & 3.3750 & 85.725 \\
0.185 & 4.70 & 1.000 & 25.40 & 3.3785 & 85.814 \\
0.188 & 4.78 & 1.044 & 26.52 & 3.9964 & 101.509 \\
0.250 & 6.35 & 1.188 & 30.18 & 3.9986 & 101.564 \\
0.288 & 7.32 & 1.200 & 30.48 & 4.0000 & 101.600 \\
0.313 & 7.95 & 1.350 & 34.29 & 4.0035 & 101.689 \\
0.325 & 8.26 & 1.450 & 36.83 & 4.2464 & 107.859 \\
0.375 & 9.53 & 1.500 & 38.10 & 4.2486 & 107.914 \\
0.388 & 9.86 & 1.844 & 46.84 & 4.2500 & 107.950 \\
0.413 & 10.49 & 2.000 & 50.80 & 4.2535 & 108.039 \\
0.500 & 12.70 & 2.188 & 55.58 & 4.500 & 114.300 \\
0.600 & 15.24 & 2.588 & 65.74 & 5.550 & 140.970 \\
0.612 & 15.54 & 3.000 & 76.20 & 6.000 & 152.400 \\
0.625 & 15.88 & 3.178 & 80.72 & 8.000 & 203.200 \\
\hline
\end{tabular}



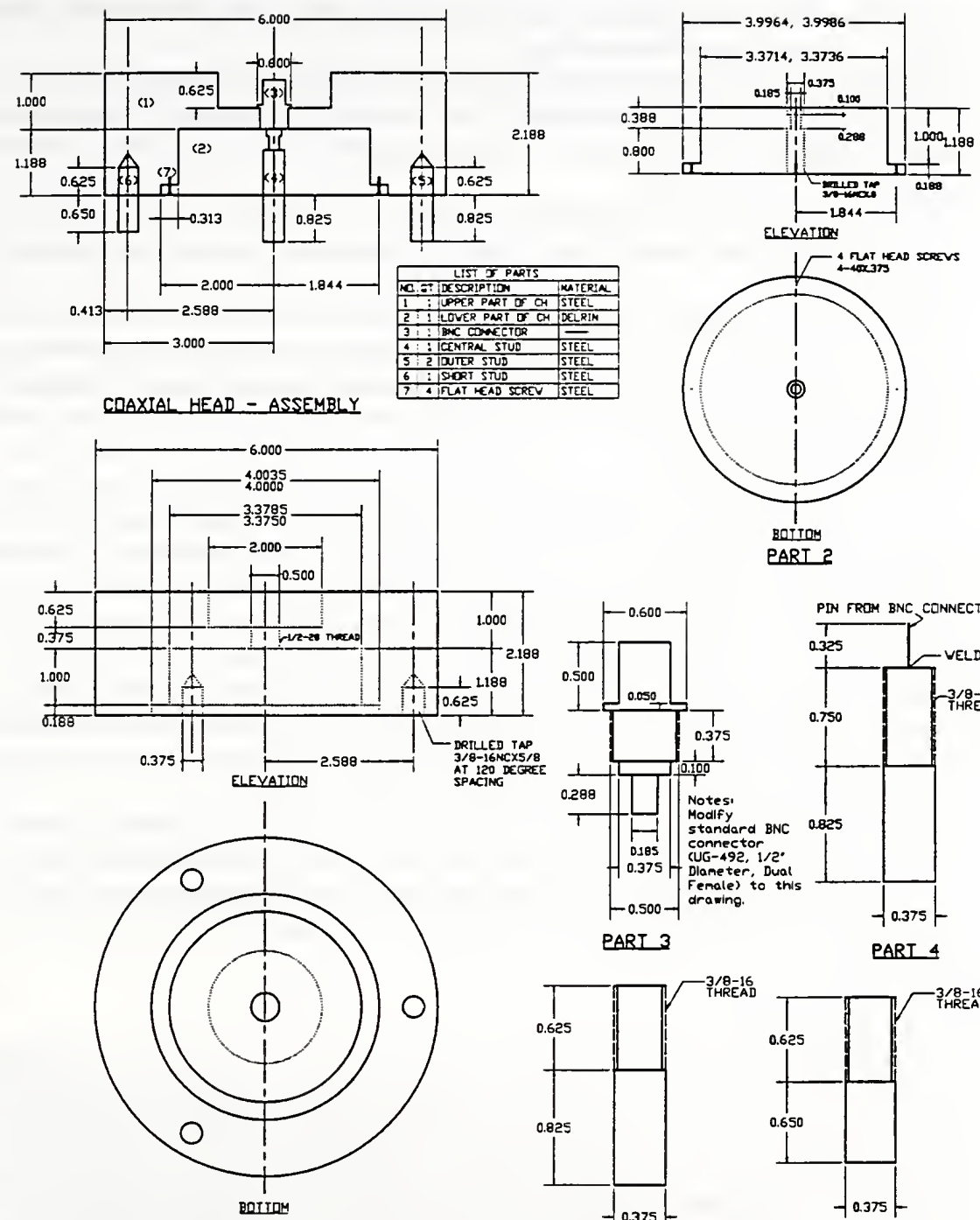

PARI L

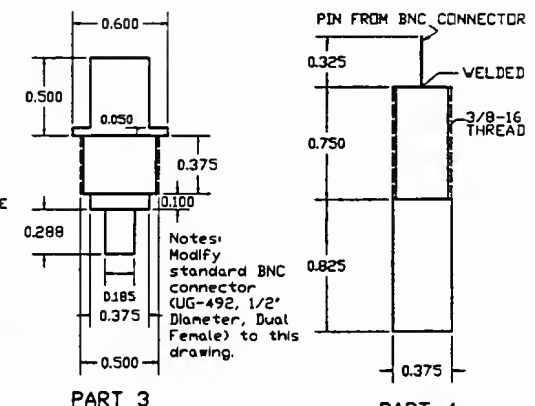

PART 3

PARI 4
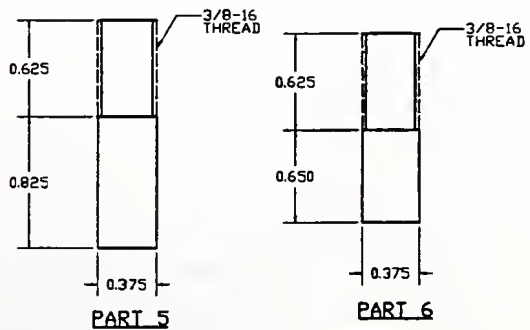

PARI 6

Notet All dimenslons are In Inches.

See Table 1 for metrlc equlvalents.

FIGURE. 4 Coaxial Head (CH) 


\section{APPARATUS}

6.1 TDR equipment: A Metallic Time Domain Reflectometer (e.g. Tektronix 1502B).

6.2 Transmission line apparatus: The configuration of the transmission lines is shown in Figure. 1, consisting of the following:

6.2.1 Coaxial Cylinder (CC) transmission line: The $C C$ transmission line consists of a $\mathrm{CC}$ mold, a ring collar and a central rod. The details for $\mathrm{CC}$ mold and $\mathrm{CC}$ ring collar are shown in Figure. 2. The central rod is a stainless steel rod, $5 / 16$ in. $(79 \mathrm{~mm})$ in diameter and 9.2 in. $(23.4 \mathrm{~cm})$ in length.

6.2.2 Multiple Rod Probe (MRP) transmission line: The MRP transmission line consists of four common metal spikes 10 in. $(25.4 \mathrm{~cm})$ in length and uniform diameters of $3 / 8$ in. $(3.8 \mathrm{~mm})$.

6.2.3 Guide templates: One guide template is used with the CC mold to drive the central rod into the soil and one guide template is used with the MRP to drive the spikes into the soil. The details for the CC and MRP guide templates are shown in Figure. 2 and Figure. 3, respectively. After the rod/spikes are driven, the template is removed from the $\mathrm{CC} / \mathrm{MRP}$ transmission line.

6.2.4 Coaxial Head $(\mathrm{CH})$ transmission line: The details for the $\mathrm{CH}$ are shown in Figure. 4. The $\mathrm{CH}$ has four metallic studs threaded into the metallic head. The central stud and two of the outer studs fixed and of equal length. The fourth stud is threaded of adjustable length. Coaxial cable connects the TDR equipment to the coaxial head $(\mathrm{CH})$. The $\mathrm{CH}$ is connected to MRP transmission line by placing it on the spikes so the central stud sits on top of the central spike and the two fixed outer studs sit on top of two outer spikes. The adjustable stud is turned until contact is made with spikes. The $\mathrm{CH}$ is connected to $\mathrm{CC}$ transmission line by placing it on the ring collar so that the central stud sit on top of the central rod and the two fixed outer studs sit on top of the ring collar. The adjustable stud is turned until contact is made with the out ring.

6.3 Balance: A balance conforming the requirements of AASHTO M231, Class G20.

6.4 Driving tools: One Brass Hammer for driving MRP spikes and CC central rod.

6.5 Miscellaneous tools: Small pick and shovel for digging holes and breaking up soils. A standard compaction hammer (AASHTO T99, Section 2.2.1) and straight edge for placing soils in $\mathrm{CC}$.

\section{CALIBRATION}

7.1 General coefficients of $a=0.8$ and $b=10$ could be used. Alternatively soil specific calibration of $a$ and $b$ can be completed. Calibration is established by determining the dielectric constants, moisture contents and densities of five soil specimens prepared such that they bracket the estimated field moisture content and vary by about $2 \%$, plotting the squared root of dielectric constant divided by the ratio of dry density to density of water versus moisture content, and placing a best fit straight line through the resulting points. The intercept and slope of the straight line are $a$ and $b$, respectively. Calibration can be established as follows:

7.1.1 Air dry the soil sample. Thoroughly break up the soil clumps in such a manner as to avoid breaking individual particles. Pass the material through a No. 4 sieve. 
7.1.2 Thoroughly mix the selected representative sample with sufficient water to prepare five specimens having moisture contents such that they bracket the estimated field moisture content and vary by about $2 \%$.

7.1.3 Determine the volume of the $\mathrm{CC}$ mold in accordance with par. 4 (Calibration of Measurement) of AASHTO T19.

7.1.4 Determine and record the mass of the $\mathrm{CC}$ mold and base plate, and the length of CC central rod.

7.1.5 Assemble and secure the $\mathrm{CC}$ mold and ring collar to the base plate.

7.1.6 The soils are compacted into CC mold in 4 lifts with 10 blows per lift using a standard compaction hammer (AASHTO T99, Section 2.2.1).

7.1.7 Measure the mass of the soil and CC including the base plate.

7.1.8 Mount the CC guide template on to the CC.

7.1.9 Drive the $\mathrm{CC}$ central rod through the guide hole into the soil until the top of rod is flush with the template using the brass hammer.

7.1.10 Remove the guide template from the CC.

7.1.11 Determine and record the length of the central rod above the soil surface.

7.1.12 Place the ring collar on the CC.

7.1.13 Wipe the top surface of the ring collar and central rod and the ends of studs of the $\mathrm{CH}$.

7.1.14 Place the $\mathrm{CH}$ on the $\mathrm{CC}$ ring collar as described in Section 6.2.4.

7.1.15 Determine and record the apparent length with the TDR device.

7.1.16 Remove the soil from the CC mold. Obtain a portion of the sample for moisture content determination by slicing the compacted specimen axially through the center and removing at least $0.500 \mathrm{~kg}$ of soil from the cut faces. Obtain the moisture content in accordance with AASHTO T265, Laboratory Determination of Moisture Contents of Soils.

7.1.17 Repeat 7.1.5 to 7.1.15 for each soil specimen.

7.1.18 Calculate the dielectric constant of the soil $(\mathrm{K})$ in the $\mathrm{CC}$ as follows:

$$
K=\left(\frac{l}{L}\right)^{2}
$$

where

$1=$ measured apparent length in the $\mathrm{CC}, \mathrm{m}$,

$\mathrm{L}=$ length of the rod inserted into the soil in the $\mathrm{CC}, \mathrm{m}$,

$\mathrm{K}=$ dielectric constant of soil in the $\mathrm{CC}$.

7.1.19 Calculate moisture content in accordance with AASHTO T265.

7.1.20 Calculate the wet density of the soil in the $\mathrm{CC}$ as follows:

$$
\rho_{t}=\frac{M_{1}-M_{2}}{V}
$$

where 
$\mathrm{M}_{1}=$ mass of the soil and the $\mathrm{CC}, \mathrm{kg}$

$\mathrm{M}_{2}=$ mass of the $\mathrm{CC}, \mathrm{kg}$

$\mathrm{V}=$ volume of the $\mathrm{CC}, \mathrm{m}^{3}$,

$\rho_{\mathrm{t}}=$ wet density of the soil in the $\mathrm{CC}, \mathrm{kg} / \mathrm{m}^{3}$.

7.1.21 Calculate the dry density of the soil in the $\mathrm{CC}$ as follows:

$\rho_{d}=\frac{\rho_{t}}{1+w / 100}$

where

$\rho_{t}=$ wet density of the soil in the $\mathrm{CC}, \mathrm{kg} / \mathrm{m}^{3}$,

$w=$ moisture content, $\%$,

$\rho_{d}=$ dry density of the soil in the $\mathrm{CC}, \mathrm{kg} / \mathrm{m}^{3}$,

7.1.22 Plot $\sqrt{K} \rho_{\mathrm{w}} / \rho_{\mathrm{d}}$ vs. $w$.

where

$K=$ dielectric constant of soil in the CC.

$\rho_{d}=$ dry density of the soil in the $\mathrm{CC}, \mathrm{kg} / \mathrm{m}^{3}$,

$\rho_{w}=$ density of water, $\mathrm{kg} / \mathrm{m}^{3}$,

$w=$ moisture content, $\%$.

7.1.23 Find the interception and slope of the best fit line.

$a=$ interception of the best fit line

$b=$ slope of the best fit line.

\section{PROCEDURE}

8.1 Determine the volume of the $\mathrm{CC}$ mold as described in 7.1.3

8.2 Determine and record: the mass of the $\mathrm{CC}$ mold and base plate, length of $\mathrm{CC}$ central rod and length of MRP spikes.

8.3 Prepare the surface at the test location so that it is plane and level.

8.4 Seat the MRP guide template on the plane surface.

8.5 Drive the spikes through the guide holes so that the bottom surfaces of the spike heads touch the template. The outer rods should be driven first and then the central one to avoid creating an air gap around the central spike when driving the outer spikes.

8.6 Remove the template. Check that all spikes are driven properly without any air gap around the spikes.

8.7 Connect the coaxial cable to the $\mathrm{CH}$ and the TDR device.

8.8 Wipe the top surfaces of the spike heads and ends of the studs on the $\mathrm{CH}$.

8.9 Place the $\mathrm{CH}$ on the spikes as described in section 6.2.4.

8.10 Determine and record the apparent length with the TDR equipment.

8.11 Remove the spikes.

8.12 Assemble and secure the $\mathrm{CC}$ mold and ring collar to the base plate. 
8.13 Dig out a sufficient quantity of soil from the location of the in-place measurement and uniformly compact it in the CC. The soils are placed into CC mold in 4 lifts and applied 10 blows per lift using standard compaction hammer. Soil should be taken uniformly over the entire depth of in-place measurement. Remove the ring collar and strike the surface level after compaction.

8.14 Measure the mass of the soil and CC including the base plate.

8.15 Determine and record the apparent length in $\mathrm{CC}$ by doing 7.1.8 to 7.1.14.

8.16 Remove the soil from the CC.

\section{Calculation}

9.1 Calculate the apparent dielectric constant of the soil in place as follows:

$$
K_{\text {insitu }}=\left(\frac{l_{\text {insitu }}}{L_{\text {insitu }}}\right)^{2}
$$

(1)

where $1_{\text {insitu }}=$ measured apparent length insitu, $\mathrm{m}$, $\mathrm{L}_{\text {insitu }}=$ length of the spikes inserted into the soil, $\mathrm{m}$,

$\mathrm{K}_{\text {insitu }}=$ apparent dielectric constant of the soil insitu.

9.2 Calculate the dielectric constant of the soil in the $\mathrm{CC}$ as follows:

$$
K_{C C}=\left(\frac{l_{C C}}{L_{C C}}\right)^{2}
$$

(2)

where

$1_{\mathrm{CC}}=$ measured apparent length in the $\mathrm{CC}, \mathrm{m}$,

$\mathrm{L}_{\mathrm{CC}}=$ length of the rod inserted into the soil in the $\mathrm{CC}, \mathrm{m}$,

$\mathrm{K}_{\mathrm{CC}}=$ dielectric constant of soil in the CC.

9.3 Calculate the wet density of the soil in $\mathrm{CC}$ as follows:

$$
\rho_{r, C C}=\frac{\boldsymbol{M}_{1}-\boldsymbol{M}_{2}}{\boldsymbol{V}_{c C}}
$$

where

$\mathrm{M}_{1}=$ mass of the soil and $\mathrm{CC}, \mathrm{kg}$

$\mathrm{M}_{2}=$ mass of the $\mathrm{CC}, \mathrm{kg}$

$\mathrm{V}_{\mathrm{CC}}=$ volume of the $\mathrm{CC}, \mathrm{m}^{3}$,

$\rho_{\mathrm{t}, \mathrm{CC}}=$ wet density of the soil in the $\mathrm{CC}, \mathrm{kg} / \mathrm{m}^{3}$.

9.4 Calculate the moisture content of the soil in the $\mathrm{CC}$ and insitu as follows 


$$
w_{\text {insitu }}=w_{C C}=\frac{\sqrt{K_{C C}}-a \rho_{t, c C} / \rho_{w}}{b \rho_{t, C C} / \rho_{w}-\sqrt{K_{C C}}} \times 100
$$

where

$\mathrm{K}_{\mathrm{CC}}=$ apparent dielectric constant of the soil in the CC,

$\rho_{\mathrm{LCC}}=$ wet density of the soil in the $\mathrm{CC}, \mathrm{kg} / \mathrm{m}^{3}$,

$\rho_{\mathrm{w}}=$ density of water $=1.0 \mathrm{~kg} / \mathrm{m}^{3}$,

$a=$ calibration constant (See Section 7)

$b=$ calibration constant (See Section 7)

$w_{\mathrm{CC}}=$ moisture content of the soil in the CC, \%,

$w_{\text {insitu }}=$ moisture content of the soil insitu, $\%$.

9.5 Calculate the insitu dry density of the soil as follows:

$\rho_{t, \text { insitu }}=\frac{\sqrt{\boldsymbol{K}_{\text {insitu }}}}{\sqrt{\boldsymbol{K}_{c c}}} \times \frac{\rho_{t, c c}}{1+\omega_{c c} / 100}$

where

$\rho_{\mathrm{tCC}}=$ wet density of the soil in the $\mathrm{CC}, \mathrm{kg} / \mathrm{m}^{3}$,

$\mathrm{w}_{\mathrm{CC}}=$ gravimetric moisture content of the soil in the $\mathrm{CC}, \%$,

$\mathrm{K}_{\mathrm{CC}}=$ dielectric constant of soil in the $\mathrm{CC}$,

$\mathrm{K}_{\text {insitu }}=$ dielectric constant of the soil insitu,

$\rho_{\text {d.insitu }}=$ dry density of the soil insitu, $\mathrm{kg} / \mathrm{m}^{3}$.

\section{Report}

10.1 The report shall include the following:

10.1.1 Test site identification.

10.1.2 Name of the operator(s).

10.1.3 Make, model and serial number of the test instrument.

10.1.4 Visual description of material tested.

10.1.5 Moisture content in percent of dry mass or dry unit weight.

10.1.6 Wet and dry densities in $\mathrm{kg} / \mathrm{m}^{3}$.

10.1.7 Calibration constants $a$ and $b$. 


\section{Appendix III GUIDELINES OF USING TDR++}

\section{System Requirements}

- A IBM compatible computer with a 486 or higher processor,

- Microsoft Windows $95^{\mathrm{TM}}$ or Windows $\mathrm{NT}^{\mathrm{TM}}$

- Available serial port,

- Mouse

- Microsoft Excel $^{\mathrm{TM}}$ is required for complete functional operation of TDR++.

\section{Setup}

Insert disk 1 into Drive A (3.5" Floppy Disk Drive). In Windows $95^{\mathrm{TM}}$, click on [Start], select [Run] in the menu list. Then in the "Run" dialog box, type "a:Isetup" and click on $[\mathrm{OK}]$.

A TDR setup form is displayed and a dialog box will prompt the user to enter the path (directory) where he or she would like to install the program. The default path is "C:IProgram Filesitdr++". The setup program will then install TDR++ and prompt the user to insert the second and third of the four disks. User then needs to create a directory "c:Itdr_l" and copy all the files on disk No. 4 (tool and data files) into that directory. The setup program will generate an icon named "TDR++" in the default or user-specified directory. The user may create a shortcut to "TDR++" for quick access. 


\section{Running TDR++}

In Windows $95^{\mathrm{TM}}$, click on "Start" and select "Programs" from the menu list. Locate the "tdr++" directory in the program list, and click on "tdr++". A loading form will be displayed informing you that the program is being loaded in the system.

The Main Form of TDR++ is displayed after a successful loading. The program will automatically check for a serial connection. Without the connection to Tektronix 1502B, TDR apparatus, the connection indicator will show "None". Many functions of TDR ++ will be disabled without this connection.

\section{Using TDR++ in a Non-Connected State}

The active functions that are possible without the connection to the Tektronix 1502B instrument include TDR data file manipulation, signal displaying, and note editing. These are described in section 5.2.2 and 5.2.3 of the report. A basic tutorial follows:

a. Open a waveform file:

Click on the [open] command from the command bar or the [file] menu. An "open" dialog box will pop up. Select the path to the default data file directory "c:ltdr_1". A list of files will show. User may select one of the files, for example chose "100496-4". A TDR waveform will be displayed in the picture box. The name of the opened waveform file is shown in the panel above the picture box. 
b. View properties of this file:

Click on [Properties] in the [File] menu list. The information associated with this waveform file will be displayed on a Properties Form. The form includes file name, path, the time when last modified, and the file size. Also, several attributes of the TDR waveform are given, including information on whether the test details, soil details, user input, and test results have been included in this file.

c. View information associated with the waveform

If the indicators in the File Properties box show that the file contains data, the user can view the file by giving different commands. By clicking the [Info] button on the command bar on the [Info] menu, the user can select a specific item for viewing. Clicking the [Result] button and selecting [Test Result] will display the results of the TDR test, including moisture content, wet density, and dry density.

d. View the text content of the waveform

With the opened waveform on the display click the [store!] button on the misc. bar and a colored box will appear. A small symbol will appear in this box when it is clicked with the left mouse key, a small symbol will show up. Drag and drop this symbol on to the text box and the waveform data will be displayed with the file name at the top.

\section{e. Comparing two waveforms}

With one or more waveforms stored in the waveform register (the black box), the user can open another file, then drag and drop a stored waveform to the picture box. Two 
or more waveforms can be displayed at the same time for comparison. Drag and drop the waveform into the "trash bin" on the bottom misc. bar when it is no longer desired in the picture box or the waveform register.

\section{f. View the TDR curve readings}

The user can perform the TDR curve readings by clicking on the [Result] button and selecting "Curve Reading". Selecting "Reading" will display the readings of Point 1 , Point 2, and the apparent length in the misc. bar. Selecting "Detail" will produce new tool bar. Clicking on the [Point 1] button, the user will see an indicator at the location of Point 1 on the TDR waveform. The [Point 2] button leads to the location of Point 2. The user can also view a smoothed curve by clicking [Smooth], and the first and second derivatives by click the corresponding buttons. Clicking on [Back] will recover the original waveform and the original tool bar.

\section{g. Print a waveform or a text file}

With a TDR waveform on the display, the user can get a hard copy of this waveform by clicking on the [Print] menu and selecting "waveform." For best results, user should set the page orientation to "Landscape" in the print setup. By clicking the [Print] menu and selecting "Text" when the text box is open will produce a hard copy of the text file. 


\section{h. Other}

TDR++ provides the user with several options such as selecting the color of the picture box and selecting the font in the text box. Also, waveform files can be saved in different formats. Moreover, test reports can be generated automatically in either long or short format. User can seek on-line help by clicking Help menu and select [Content].

\section{Remarks}

a. Report generating and database functioning will invoke Microsoft Excel ${ }^{\mathrm{TM}}$. Some difficulties may be encountered when Excel $^{\mathrm{TM}}$ was not appropriately installed.

b. To put a data file into the TDR database, TDR++ will prompt user to input a password, type "ddtdr" as the default password.

c. If user finds any problem when using $T D R++$, please report the problem to the address listed in "Technical Support". 
